\title{
Looking for an ounce of prevention: The potential for diagnostic assessment in academic acculturation
}

By

Melissa McLeod

A thesis submitted to the Faculty of Graduate and Postdoctoral Affairs in partial fulfilment of the requirement of the degree of Master of Arts in Applied Linguistics and Discourse Studies

School of Linguistics and Language Studies Carleton University, Ottawa, Ontario, Canada April 2012

C) Copyright 2012

Melissa McLeod 
Library and Archives

Canada

Published Heritage

Branch

395 Wellington Street

Ottawa ON K1A ON4

Canada
Bibliothèque et

Archives Canada

Direction du

Patrimoine de l'édition

395 , rue Wellington

Ottawa ON K1A ON4

Canada
Your file Votre référence

ISBN: 978-0-494-91604-9

Our file Notre référence

ISBN: $978-0-494-91604-9$
NOTICE:

The author has granted a nonexclusive license allowing Library and Archives Canada to reproduce, publish, archive, preserve, conserve, communicate to the public by telecommunication or on the Internet, loan, distrbute and sell theses worldwide, for commercial or noncommercial purposes, in microform, paper, electronic and/or any other formats.

The author retains copyright ownership and moral rights in this thesis. Neither the thesis nor substantial extracts from it may be printed or otherwise reproduced without the author's permission.
AVIS:

L'auteur a accordé une licence non exclusive permettant à la Bibliothèque et Archives Canada de reproduire, publier, archiver, sauvegarder, conserver, transmettre au public par télécommunication ou par l'Internet, prêter, distribuer et vendre des thèses partout dans le monde, à des fins commerciales ou autres, sur support microforme, papier, électronique et/ou autres formats.

L'auteur conserve la propriété du droit d'auteur et des droits moraux qui protege cette thèse. $\mathrm{Ni}$ la thèse ni des extraits substantiels de celle-ci ne doivent être imprimés ou autrement reproduits sans son autorisation.
In compliance with the Canadian Privacy Act some supporting forms may have been removed from this thesis.

While these forms may be included in the document page count, their removal does not represent any loss of content from the thesis.
Conformément à la loi canadienne sur la protection de la vie privée, quelques formulaires secondaires ont été enlevés de cette thèse.

Bien que ces formulaires aient inclus dans la pagination, il n'y aura aucun contenu manquant. 


\begin{abstract}
The growing diversity of the student population in post-secondary institutions and growing concern over student retention has generated a need for student support initiatives. The Diagnostic English Language Needs Assessment (DELNA) may be used to identify potentially linguistically at-risk students for individualized support. DELNA was modified for use with first-year engineering students at a large Canadian university. This case study investigates the role that such an assessment can play in a first-year student's academic acculturation into engineering. It examines the suitability of the diagnostic assessment and explores its contribution to the acculturation process. This study also discusses the effectiveness of the suggested student support services. The findings suggest that although the diagnostic assessment contributed greatly to one student's academic acculturation, linguistic ability is clearly not the only factor that determines academic success. Discipline-specific support initiatives and services are needed to ensure that students receive the help needed to succeed academically.
\end{abstract}

Keywords: diagnostic testing and assessment, DELNA, academic acculturation, first-year experience 


\section{Acknowledgements}

I am greatly indebted to my thesis advisor and professor, Dr. Janna Fox, and professors Dr. Devon Woods and Dr. Tim Pychyl for their knowledge and guidance. Their courses challenged my thinking and helped me develop as both a student and a teacher.

Grad school would not have been the same without the friendship and support of my fellow students in ALDS. Our weekly writing group got me through the more isolating stages of thesis writing. Our conversations in the grad lounge, at Mike's Place, and at Devon's parties contributed more to this thesis and to my grad school experience than they realize.

I would like to thank Anna for so willingly sharing her first-year experience with me. The memory of her persistence and work ethic will remain with me long after this study is complete. I am also grateful to my other participants for participating in my project and providing me with such valuable insight.

I am thankful for the support I received from my family throughout this journey. And finally to Libby, Penny, Elliott, and Oscar for sharing their college fund with me so that I could go back to school and for always being excited when I came to visit. 


\section{Table of Contents}

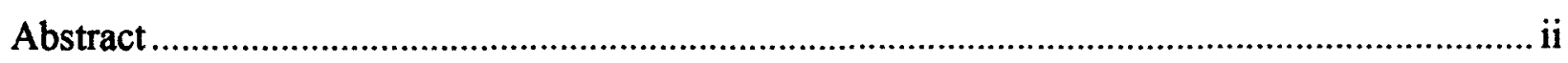

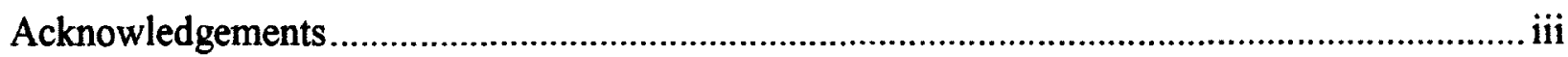

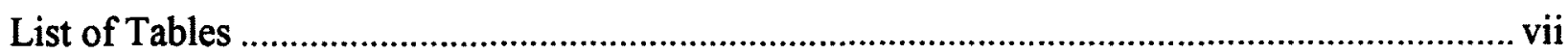

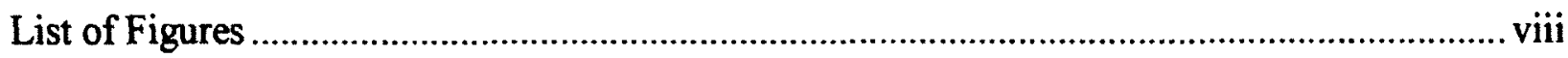

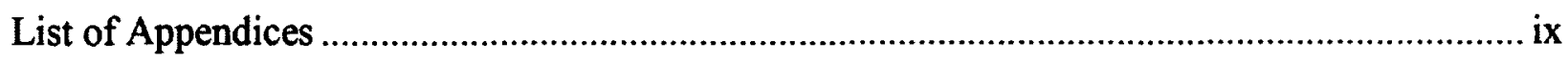

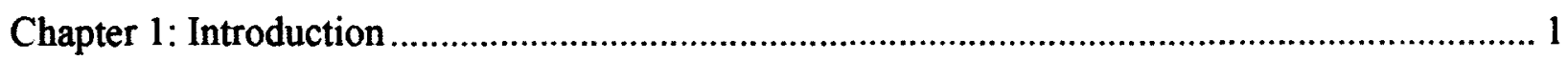

Motivation for the Study ........................................................................................................

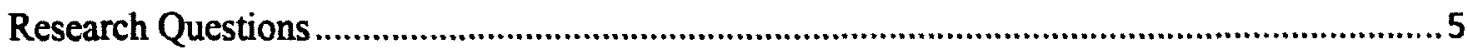

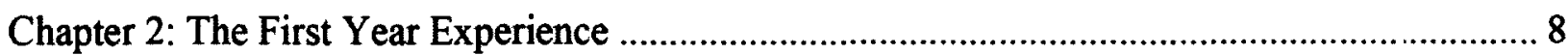

The Transition to Post-Secondary Culture.................................................................................. 10

The first year experience in engineering..................................................................................16

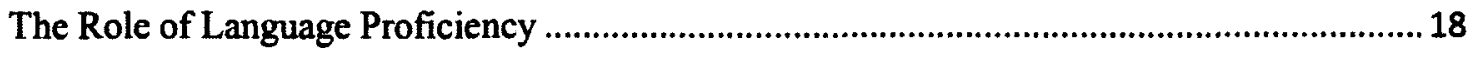

Successful Support Initiatives .............................................................................................. 23

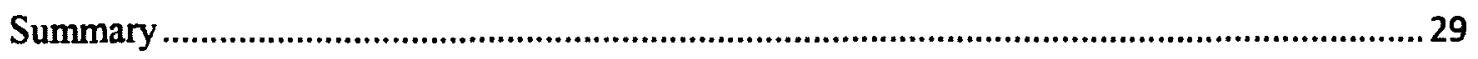

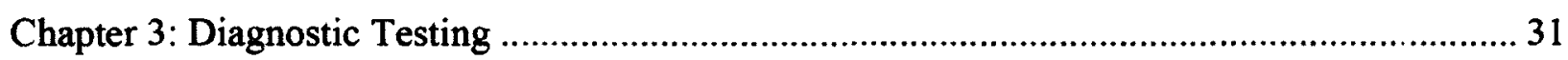

Towards a Definition of Diagnostic Testing ............................................................................31

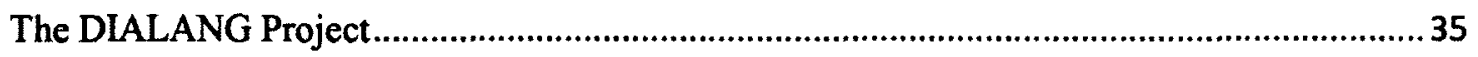

Diagnostic Testing and Assessment in the Context of Post-Secondary Education...................... 38

The classroom implications of diagnostic testing .................................................................38

The Diagnostic English Language Needs Assessment (DELNA). .......................................42

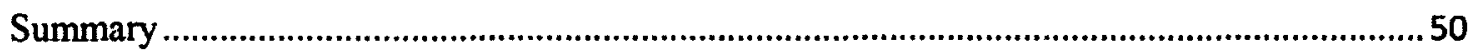

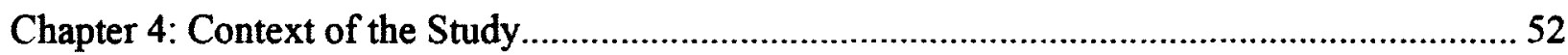

The DELNA Pilot Project in Engineering ……………………................................................. 53

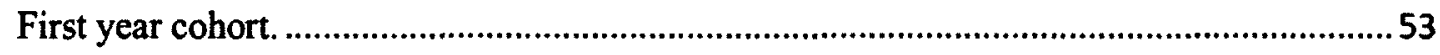


Marketing DELNA to first-year engineering students: self-assessment for engineering

(SAFE). 54

Campus-wide support services involvement.......................................................................5 56

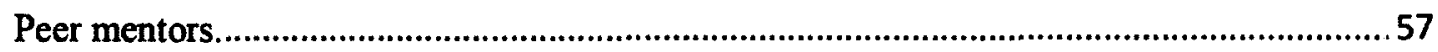

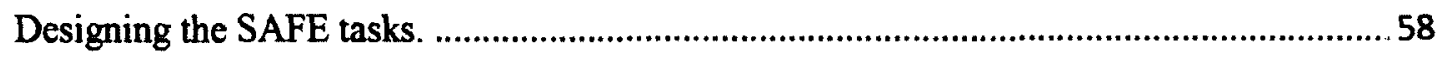

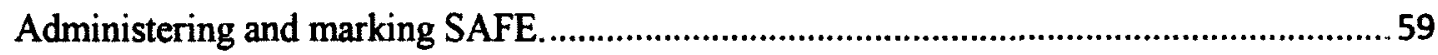

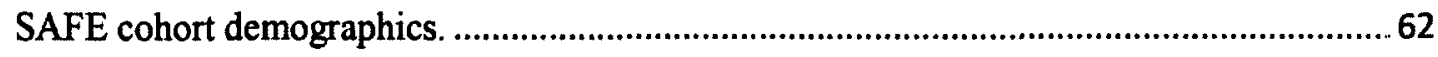

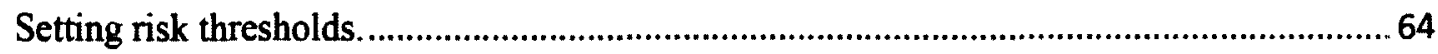

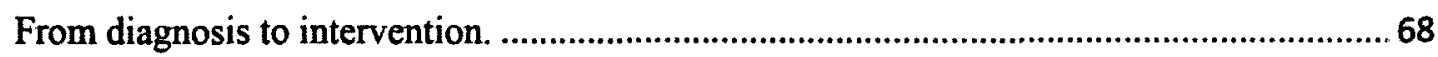

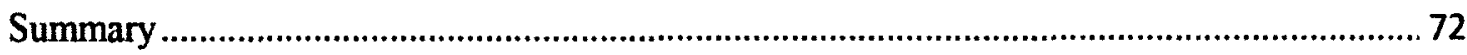

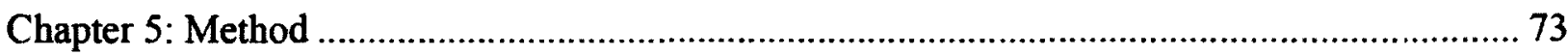

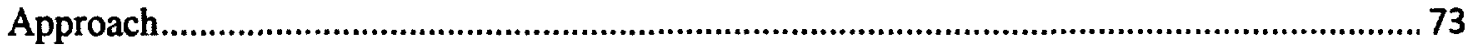

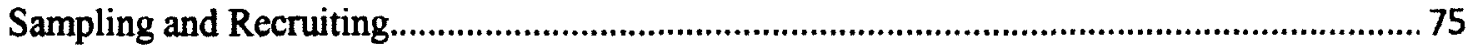

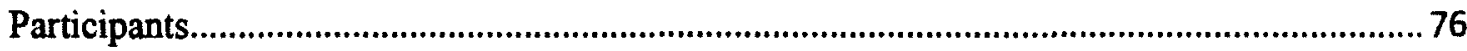

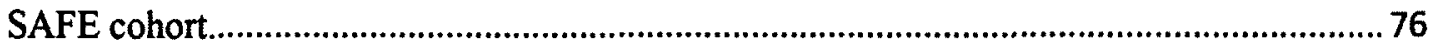

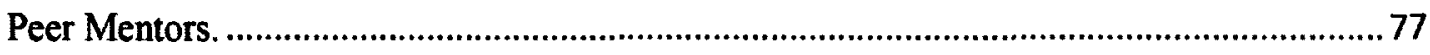

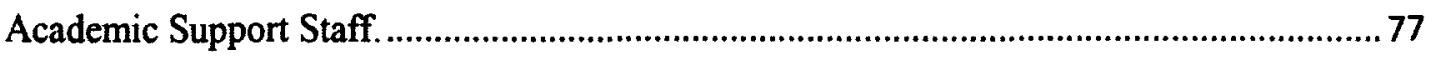

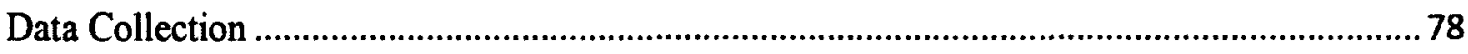

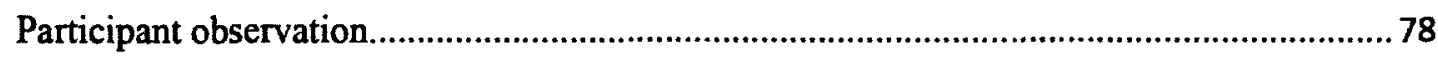

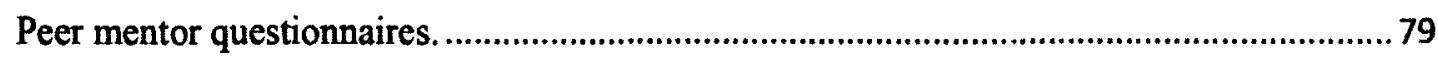

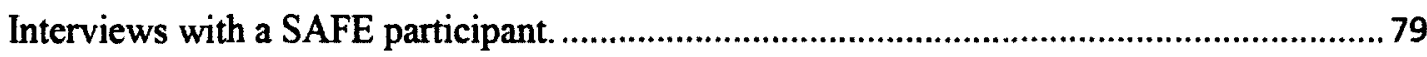

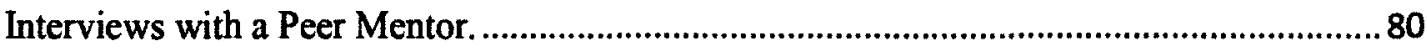

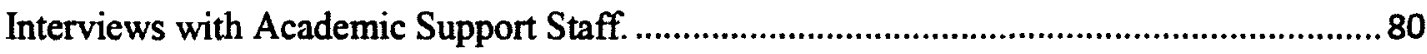

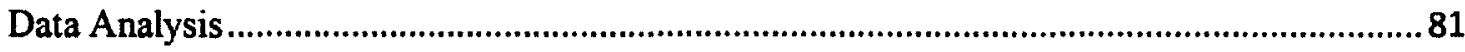

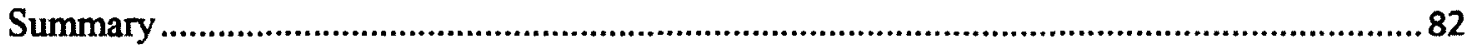

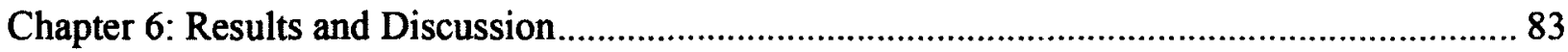




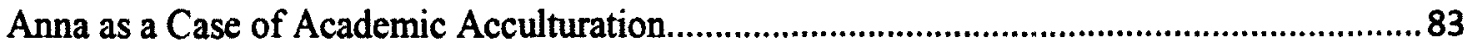

Q1. How well did the diagnostic tasks work for a first-year engineering student? ..................85

Q2. What role did the diagnostic assessment play in one student's academic acculturation into

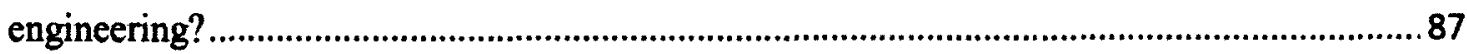

Q3. How well do the supports offered on campus address the diagnosed needs of a first-year

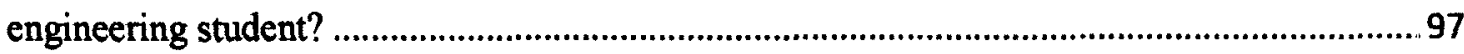

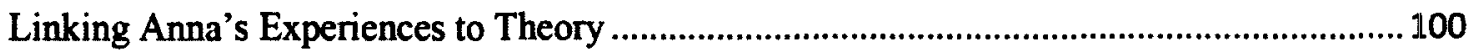

The accuracy of Anna's SAFE diagnosis, ........................................................................... 100

SAFE's contribution to Anna's academic acculturation.................................................. 104

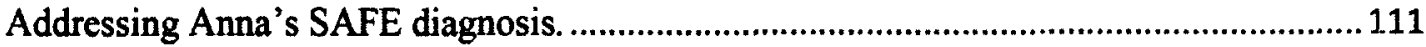

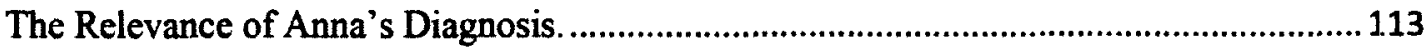

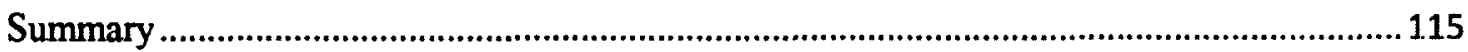

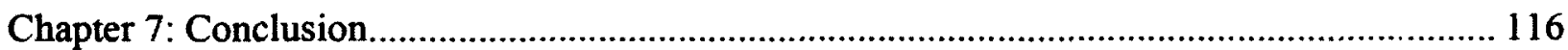

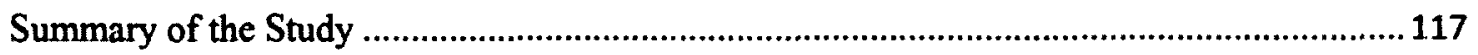

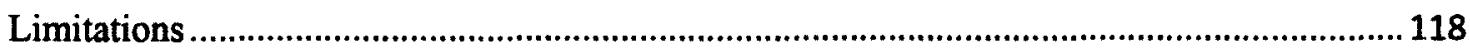

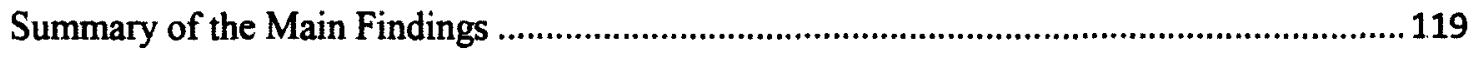

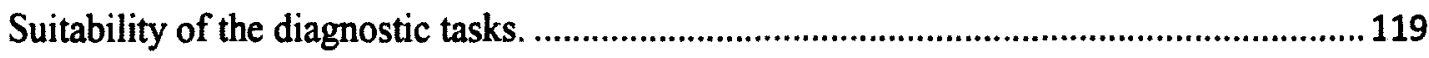

Contribution of diagnostic feedback to Anna's academic acculturation............................120

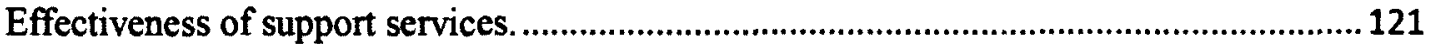

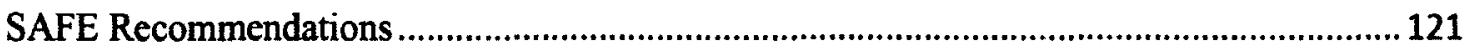

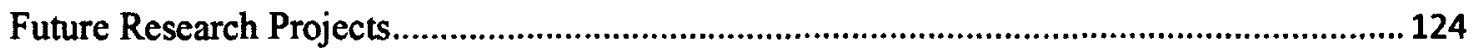

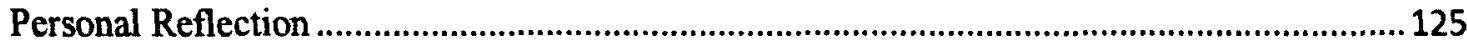

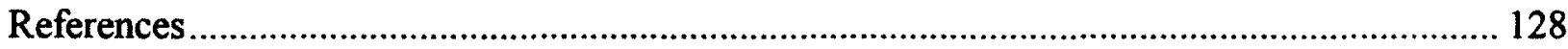

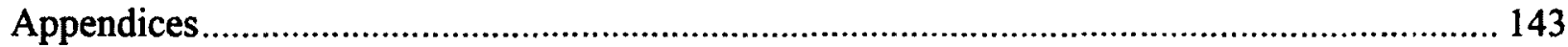




\section{List of Tables}

Table I Demographic information from SAFE participants (Fox, 2011) ........................63 Table 2 SAFE participants and other variables that contribute to academic success (Fox,

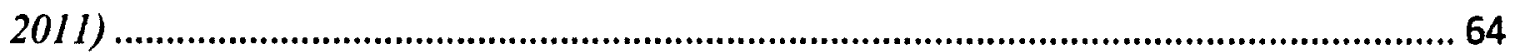

Table 3 Score for individual SAFE tasks from 489 cases (Fox, 2011) ........................... 65

Table 4 Risk thresholds for the 489 SAFE participants in each skill area (Fox, 2011) ... 66

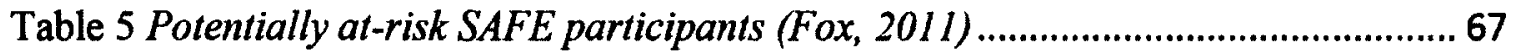

Table 6 Background on meeting language proficiency requirements for 24 SAFE

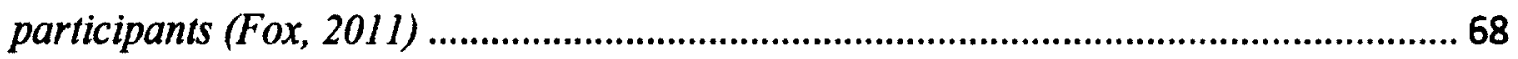

Table 7 Profiles of students who officially signed in at the SAFE Drop-In Centre ......... 70

Table 8 Anna's SAFE results compared with her cohort and the at-risk thresholds ........ 86 


\section{List of Figures}

Figure 1. Lawrence's (2005) Models of Student Success Practices ............................. 16

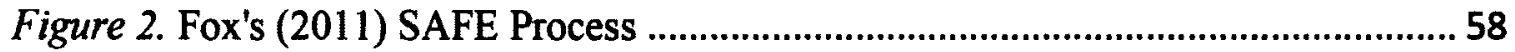

Figure 3. Situating the present case study within the larger phenomenon of first-year

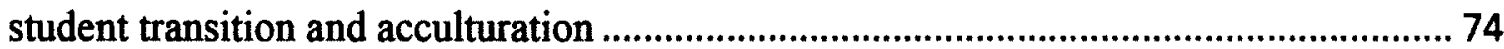

Figure 4. Elements contributing to and/or blocking Anna's learning potential during her

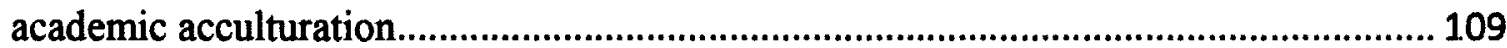




\section{List of Appendices}

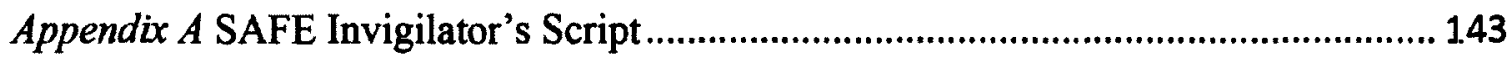

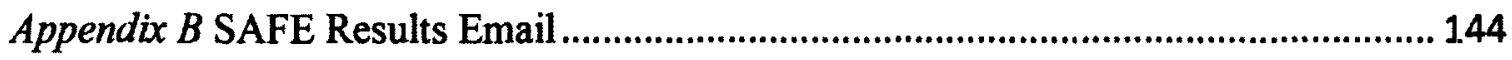

Appendix C Support Services Information Sheets .................................................................45

Appendix D SAFE Drop-In Centre Poster .................................................................... 1.47

Appendix E Ethics Clearance Form .............................................................................48

Appendix F Participant Recruitment Poster ................................................................. 149

Appendix $G$ Peer Mentor Questionnaire ......................................................................... 150

Appendix $H$ Line-by-Line Coding Sample .................................................................... 151 


\section{Chapter 1: Introduction}

Students are more likely to persist, learn, and graduate when they find themselves in settings that hold high expectations for their learning, provide needed academic and social support and frequent feedback about their learning, and actively involve them with other students and teachers in learning [...]. The key' concept is that of educational community and the capacity of institutions to establish educational communities in the first year that actively involve students with other members of the institution (Tinto, 2009, p. 5).

Tinto's (2009) concept of the importance of educational community in enabling students to persist in their studies reminds me of my own difficult first year experience. I struggled to understand what I needed to do to succeed at university and to manage my time so that I could cope with the increased work load. I was too intimidated to speak with my professors or teaching assistants. I changed majors twice. It was not until near the last year of my program that I began to seek out help when I needed it and take advantage of the support programs available on campus. I often wonder how different my undergraduate experience might have been if I had known in the first-year how to access the help I needed. If I could not seek out help on my own once I started having problems with my assignments and exams, who or what might have helped me?

Growing student enrollment and student diversity highlight the importance of the first-year experience in a Canadian post-secondary context particularly in view of retention statistics. At the large Canadian university in this study, the number of new 
first year students grew from 3839 in 2004 to 4578 by 2010 (Office of Institutional Research and Planning, 2012a). Enrollment in Architecture, Engineering, Computer Science, and Industrial Design also grew between 2004 and 2010 from 575 students to 952 students. During this period, the university continued to lose almost $40 \%$ of its first year students with $62.3 \%$ (2392) of students continuing to second year in 2004 and $63.8 \%$ (2920) of students in 2010. However, first year student retention in science and mathbased disciplines dropped slightly from $73.2 \%$ (421 students) to $72.6 \%$ (691 students) over the same time period (OIRP, 2012a). This means that by 2010 , roughly $36 \%$ of all students and $27.4 \%$ (261) of science students left their programs. While the reasons for their departure are unknown, this thesis will explore the complexities of the first-year experience and examine the potential contribution of diagnostic assessment in directing first-year engineering students to individualized support.

The diagnostic tool being examined in this thesis is the Diagnostic English Language Needs Assessment (DELNA). It has been used at a New Zealand university since 2000 to help ensure that linguistically at-risk students, regardless of their language background (i.e., English first language (L1) or second language (L2)), could be guided towards the appropriate support they needed to be successful in their post-secondary studies. There was growing international student enrollment and increasing numbers or "covert bilinguals" (Taffe \& Pringle, as cited in Fairbairn \& Fox, 2009, p.11), or students whose families had immigrated to New Zealand. Flexible admissions requirements meant that these groups of students, in addition to native speakers, may not have sufficiently developed the academic and/or language skills needed to succeed at university. 
The numbers of both international students and covert bilinguals are also growing in Canada. More than 180,000 international students were studying in Canadian secondary schools in 2008 , generating $\$ 6.5$ billion dollars (Long, 2012). By 2016, it is estimated that one fourth of the Canadian population will be youth either born in Canada to immigrant families or born outside the country (Rieti, 2012). There are also increasing numbers of international students at Canadian universities.

According to the Association of Universities and Colleges of Canada (2011), undergraduate enrolment at Canadian universities had grown to 755,000 full-time and 239,000 part-time students in 2010. This increase also includes growing international enrolment. In 1990, there were only 25,500 international students studying in Canada. By 2010, international enrolment had more than tripled to 90,000 full-time and 13,000 part-time international students. International students, studying both full- and part-time, now make up just over $10 \%$ of the undergraduate student body in Canada. In 2008, while only $8 \%$ of domestic students were studying in engineering and related programs, $16 \%$ of international students had chosen this discipline (AUCC, 2011). In the 2011-2012 academic year, the large Canadian university in this study reported 3,147 full-time undergraduate students whose native language was not English (OIRP, 2012b). With a total full-time undergraduate student body of $20,940^{1}$, non-native English speakers make up roughly $15 \%$ of the student body.

In the United States, only $43 \%$ of students who began in a college or university engineering program actually finished their programs and obtained their degrees (Astin as cited in Anson et al., 2003; see also Bernold, Spurlin, \& Anson, 2007). At a large

\footnotetext{
${ }^{1}$ There were 20,940 full-time undergraduate students for the 2010-2011 academic year. This figure was used as the data for the 2011-2012 academic year has not yet been released.
} 
Canadian university, $70 \%$ of first-year engineering students fail at least one course (D. Russell, personal communication, July 2011). Since students are admitted to engineering based on their high grades, it is unlikely that such a low completion rate or high failure rate is due purely to low academic ability. Engineering students have challenging course loads, in terms of both difficult content and number of concurrent courses. Thus, there is often little time for students to spend on seeking the support that they may need (Bernold et al., 2007).

In the last decade, researchers have begun to explore the potential of diagnostic assessment as a tool to help identify post-secondary students' potential strengths and weaknesses in academic literacy and to direct them to relevant support (see Read, 2008; Artemeva \& Fox, 2010; Elder, Bright, \& Bennet, 2007; Elder, Erlam, \& von Randow, n.d.; Elder \& von Randow, 2008; Fox, 2009; Fox \& Hartwick, 2011). In spite of this research and the growing potential of diagnostic assessment, there are still gaps in the knowledge of and agreement on its use (see Alderson, 2005). Alderson concludes that "the language testing literature offers very little guidance on how diagnosis might appropriately be conducted, what content diagnostic tests might have, what theoretical basis they might rest on, and how their use might be validated" (2005, p. 10). This thesis aims then to contribute to the growing body of literature on the role of diagnostic assessment and testing in the first-year experience in a Canadian post-secondary context. In my view, the first-year experience is best described as a process of acculturation characterized by intertwined and complex negotiations in which students manoeuvre to understand, accept, and adapt to their role as a university student (see also Cheng \& Fox, 2008). 


\section{Motivation for the Study}

Through my work teaching English to international students who wanted to pursue academic study in Canada, I frequently observed my students struggle to adjust to a new country, new academic expectations, and a new language. The majority of students I taught were unhappy they were required to take ESL classes - they intended on studying engineering or business and often commented that they did not need so much practice with reading and writing because they would only be studying math.

I first learned of Diagnostic English Language Needs Assessment (DELNA) at a teachers' conference and was immediately intrigued by the idea of an assessment that could help to identify potentially at-risk students and direct them towards programs that may give them the support they need to be successful at university. Through my curriculum and language testing course work in my MA program of Applied Linguistics and Discourse Studies (ALDS), I learned more about the potential of diagnostic assessment. As part of an initiative for program renewal, the Faculty of Engineering at a large Canadian university sought to identify not only potentially at-risk students, but also to gain perspective on what support their first-year cohort may need to be successful and persist in their studies. When I was offered the opportunity to participate in a DELNA pilot project in July 2011 , I accepted immediately. It was through the DELNA planning meetings and reading about diagnostic assessment that I arrived at my thesis topic.

\section{Research Questions}

The purpose of this thesis is to examine the first-year experience of an engineering student through the lens of diagnostic assessment. As such, the aim of this 
case study is to consider what contribution diagnostic assessment can make to the process of an engineering undergraduate student's first-year academic acculturation into postsecondary study. The research questions that guide this qualitative study are as follows:

1) How well did the diagnostic tasks work for a first-year engineering student?

2) What role did the diagnostic assessment play in one student's academic acculturation into engineering?

3) How well do the supports offered on campus address the diagnosed needs of a first-year engineering student?

Having introduced the focus of the study, Chapter 2 provides a discussion of the first-year experience by identifying elements which may contribute to academic acculturation and lead to academic success, both in university in general and more specifically in engineering. It considers language proficiency and the tendency of nonnative English speaking students to select math-based courses. It concludes with examples of discipline-specific first-year student support initiatives that have been successful in assisting students in their acculturation to post-secondary study. Chapter 3 introduces diagnostic testing and assessment by examining the conflicting literature on its definition and use. It provides an example of a large-scale diagnostic tool and several examples of diagnostic testing and assessment use in university classrooms. Finally, an institution-wide diagnostic assessment that aims to identify potentially linguistically atrisk students when they begin their post-secondary studies is outlined and discussed.

Chapter 4 explains the rationale behind piloting a discipline-specific diagnostic assessment and outlines its planning and implementation. It also includes the student 
cohort's demographics, diagnostic results, and participation in the feedback process. Chapter 5 provides a description of case study research and the methods used for this thesis. Information on sampling, participant demographics, data collection, and data analysis is included. Chapter 6 introduces my participant as a case of the role diagnostic assessment in academic acculturation. It then provides the results for each of the three research questions guiding this thesis and discusses them in relation to the first year experience and diagnostic testing literature from Chapters 2 and 3. Chapter 8 concludes with a consideration of key findings, the limitations of the research design, potential future research directions, and a reflection on my learning from this research.

In Chapter 2, which follows, the first-year experience is discussed drawing on the research literature. 


\section{Chapter 2: The First Year Experience}

The first year of university study is arguably the most crucial time for engaging students in their learning community and equipping them with the requisite skills, not only to persist, but to be successful and independent in their new learning throughout their undergraduate years and for a lifetime of professional practice in which they will be continually required to learn and to engage with new ideas that go beyond the content of their university course (Queensland University of Technology, 2009, p.l).

Tinto $(1975,2002 a \& 2002 b)$ has made considerable contributions to the large body of literature dedicated to student retention and the first year transition (see also Astin \& Lee, 2003; Astin 1975; 1993a; Wintre, Bowers, Gordner, \& Lange, 2006; Scanlon, Rowling, \& Weber, 2007; Wilson \& Lizzio, 2008). Many studies have also sought to identify factors which may predict student retention, such as parents' education level, financial concerns, and participation in campus activities (see Fike \& Fike, 2008; Mayo, Helms \& Codjoe, 2004; Allen, Robbins, Casillas, \& Oh, 2008; Astin \& Lee, 2003; Braxton, Vesper, \& Hossler, 1995; Chapman, \& Pascarella, 1983). Even though much of the literature on the first year experience uses the term transition, the term acculturation is more appropriate for this study because it encompasses the complex adaptation that students experience rather than a linear trajectory as they move from one learning context to another (which the term transition suggests). Whereas transition has been defined as a move from one state to another (Hussey \& Smith, 2010), Cheng and Fox (2008) define 
academic acculturation as "the dynamic adaptation processes of linguistically and culturally diverse students engaging with the academic study cultures of $[\ldots]$ Englishmedium universities" (p. 309). The term acculturation may, however, be contentious for some if it were simply viewed as requiring students to conform to postsecondary/disciplinary culture. However, if acculturation is viewed as a process, it takes into account how students view "what is happening and what it means, what they perceive, what they choose to appropriate [or reject], and how they interpret their expectations of and experiences in university classrooms" (Cheng \& Fox, 2008, p. 309) in relation to their own beliefs and culture. Consequently, instead of focusing on transition and identifying retention predictors as is common in quantitative studies, the present case study aims to examine how diagnostic assessment may assist an increasingly diversified first-year student population as they begin to acculturate into engineering.

This chapter provides an overview of the first-year experience in post-secondary study. It outlines the struggle many students may face if their background knowledge is insufficient or unsuitable to assist them in their new learning environments and discusses several components that may be key to a successful acculturation. The role that language proficiency plays in academic acculturation and academic success is considered with some discussion of post-secondary institution language entry requirements and mathbased courses. Finally, this chapter includes a discussion of successful university-wide and engineering-specific support initiatives for acculturating students. 


\section{The Transition to Post-Secondary Culture}

All first year students, regardless of their ethnicity, age, educational history, family background, linguistic profile, etc..., need to make the transition to university life in varying degrees (Lawrence, 2005). Hussey and Smith define these transitions as "a significant change in a student's life, self-concept, and learning: a shift from one state of understanding, development and maturity to another" $(2010$, p. 156). They put forth that how a student makes these transitions is of the utmost importance. A successful transition includes adapting their learning style, building and feeling a connection to their discipline, and viewing themselves through a new lens. Krause describes this transition as a battle comprised of "a conflict of values, a challenge to one's identity, and a threat to the familiar ways of knowing and doing" $(2006$, p. 1).

Bourdieu (1977) defines cultural capital as "cultural heritage" (1977, p. 488), or explicit knowledge and implicit understandings that are passed down to an individual. This knowledge includes, for example, the home learning environment which is influenced by the level of education a parent has achieved, how much value is placed on schooling, learning, reading, etc..., or how asking for assistance is perceived. Different societies or classes will thus possess and transmit different cultural capital. An educational institution typically diffuses the dominant culture of the society and yet often offers little in the way of explicit explanation of this culture's expectations (Bourdieu, 1977). Therefore, Bourdieu (1990) argues that a student whose cultural capital is similar to that of their chosen post-secondary institution may use their capital as a form of currency to make their transition. Habitus is a "sense of one's place" (Bourdieu, 1990, p. 131) within their surrounding milieu. One's social conditions, and thus their cultural 
capital, bring about an individual's sense of self. A student's habitus may therefore contribute greatly to their acculturation if they feel they belong at their institution.

Kairos, a classical Greek concept of the qualitative value of time, can be defined as "the right or opportune time to do something, or right measure in doing something" (Kinneavy, 2002, p. 58). This concept may also play a role in a student's acculturation. Students may create, seize, or miss a kairotic moment to "interact with a particular audience in a particular way within particular circumstances" (Yates \& Orlikowski as cited by Artemeva, 2005, p. 394). For example, kairotic moments could come in the form of taking advantage of situations to engage with peers, ask professors or teaching assistants questions about specific needs, or shape the focus of an assigned topic in relation to individual interests.

Tinto (2009) identifies four conditions that must be in place for students to succeed. First, in terms of student achievement, universities need to set clear and high expectations and hold students to them. The second condition is feedback: prompt and frequent feedback can guide students in their learning. In their study on how students' perceive the feedback they receive in university, Poulos and Mahony (2007) put forth that feedback for first-year students is not just about helping them obtain good grades: "effective feedback for these students is that which provides emotional support and facilitates integration into university" (p. 152).

Third, students need both academic and social support services. Further, the academic support that is offered to students cannot be generic. It must have a solid link with what students are facing in their classes so that students can apply their support strategies in their personal learning contexts (see also Tinto, 2002a\&b; Fike \& Fike, 
2008; Chapman \& Pascarella, 1983; Peach, 2005). If students cannot make the connection between the academic support offered and the classroom, students will not be able to implement the support they receive. The link between their support and their courses is created when all parties at the university align their plans. Lastly, students need to be engaged because "the more students are academically and socially involved, the more likely they are to persist and graduate" (Tinto, 2009, p. 4; see also Tinto, 2002b; Nora 2004; Thomas, 2002). Indeed a number or researchers have identified persistence as a quality that is characteristic of students who complete their studies (see Fox, 2008). Student engagement can be defined as "the quality of effort students themselves devote to educationally purposeful activities that contribute directly to desired outcomes" (Hu \& Kuh as cited in Krause \& Coates, 2008, p. 493). Mayo, Helms, and Codjoe (2004) argue that a student's engagement in their academic institution through interaction with both their peers and their professors contributes to their success. This interaction, though, should not only be initiated by instructors: students themselves must make an effort to engage with others if they expect to succeed academically. This places the final responsibility for learning on the students even though universities must take the responsibility for fostering an environment that promotes student engagement. A longitudinal Canadian study on university leavers found $29 \%$ of the students reported that their university felt impersonal and that they were not always able to build connections with their professors and/or classmates. Moreover, of the 49 students who withdrew or failed, $44.9 \%$ of them did not discuss their decision with anyone prior to leaving university. One student who failed commented that more support may have enabled them to continue with their studies (Wintre et al., 2006; see also Nora, 2004). 
Building the new academic and social connections described by Tinto (2009) is challenging when students from diverse backgrounds need to construct a new student identity. Scanlon et al. (2007) reported that students often found their transition difficult because they relied on the knowledge gained from their past learning experiences, i.e. high school, in their approach to university study. The students found that this previous knowledge often did not match with the new expectations they had to meet in a university learning context. Large class sizes and thus limited contact with professors made it difficult for students to understand how to meet these expectations. Professors have the knowledge, or cultural capital (see Bourdieu, 1977), that can assist students in building their new student identities, and yet the students reported feeling the professors were distant. Although students took this as a cue to become more independent learners, they felt anonymous and disconnected, and they struggled to meet what they felt were unclear expectations. Students did, however, begin to make friends and construct social networks that helped them transition into their new learner identity by providing the support they needed (Scanlon et al., 2007).

Woods (1996) points out that one's beliefs, assumptions and knowledge, or BAK, greatly influence the decision making process. Although his work focused mainly on teachers' BAK, Woods (2006) discusses that learners also come to the classroom with their own BAK. Their BAK influences their decisions about their learning and classroom practices. Consequently, learners thus reflect on the events that take place and then "evaluate them (in the context of all other life decisions being made) and these interpretations and evaluations feed into subsequent decisions" (Woods, 2006, p. 94). Students' expectations about their college experience influence their academic and social 
integration. Braxton et al. (1995) found the more closely students' expectations about college match with their experiences, the more students will integrate both academically and socially (see also Thomas, 2002; Walker et al., 2009). In addition, as students integrated more, their level of commitment to their institutions increased (Braxton et al., 1995).

In order to succeed in university, it is vital that students be able to self-assess, or "distinguish what they know from what they do not know" (Pressley, Synder, Levin, Murray, \& Ghatala as cited in Nist, Holschuh, \& Sharman, 1995, p. 3; see also Taras, 2001; Cassidy, 2007; Lew, Alwis, \& Schmidt, 2010). This self-assessment must also come as students cope with an increased workload and less time to spend with friends and family. For example, undergraduate students may often procrastinate when they have to prepare for assignments and exams. Pychyl, Morin, and Salmon (2000) found that even though students who procrastinate could predict how much time they would actually spend studying, they started studying later and spent less time studying.

Students must also develop into autonomous learners so that they can make their own decisions about their learning. Their decisions will be based on their awareness of their learning habits and their knowledge gaps (Hussey \& Smith, 2010). Assessment can also be designed to assist new university students in raising the awareness they need to monitor their own progress (Taylor, 2008). Autonomy is not, however, intuitive and students usually need guidance and practice to develop as independent learners (Railton $\&$ Watson, 2005). Students must also learn to synthesize information. They cannot simply memorize facts - they must begin to piece information together and see how each piece fits a more complex process (Nist et al., 1995; see also Hussey \& Smith, 2010). 
This "deep learning" (Hussey \& Smith, 2010, p. 158) will enable them to explain the material they are learning and apply the knowledge gained to other topics of study. A student employs "strategic learning" (Hussey \& Smith, 2010, p. 158) when they have a specific objective that they are trying to meet, such as passing a test, and simply memorizing the material will enable them to answer the questions. (See also Thompson, Pilgrim, \& Oliver, 2005 for a brief discussion on surface, deep, and strategic learning in higher education.)

First semester courses will be the first time the students will need to "engage, master, and demonstrate the subject's discourses and cultural practices" (Lawrence, 2005, p. 20). Students need to do this while also building new social relationships, balancing school with paid work and/or family, and time management. Lawrence's (2005) Model of Student Success Practices (see Figure 1 on page 16) highlights critical, reflective, and socio-cultural competencies as the three key, dynamic elements that may guide a student to success in university.

Reflective competency is a student's ability to notice and take in the cultural practices occurring around them at the university. Through observation and reflection, a student can readjust and refine their approach to their work. Critical competency is a student's sense of self and the institution's processes through critical self-awareness and being cognizant of the power relationships at work on campus. Socio-cultural competencies "facilitate the development of study groups, writing groups and learning circles, newsgroups, mentors, friendship networks [...] and develops more resources/sources of help" (Smith as cited by Lawrence, 2005, p. 26; see also Thomas, 2002). These support networks play a vital role in student retention by both empowering 
students to adapt to their new learning environment and learning needs and assisting with time and stress management.

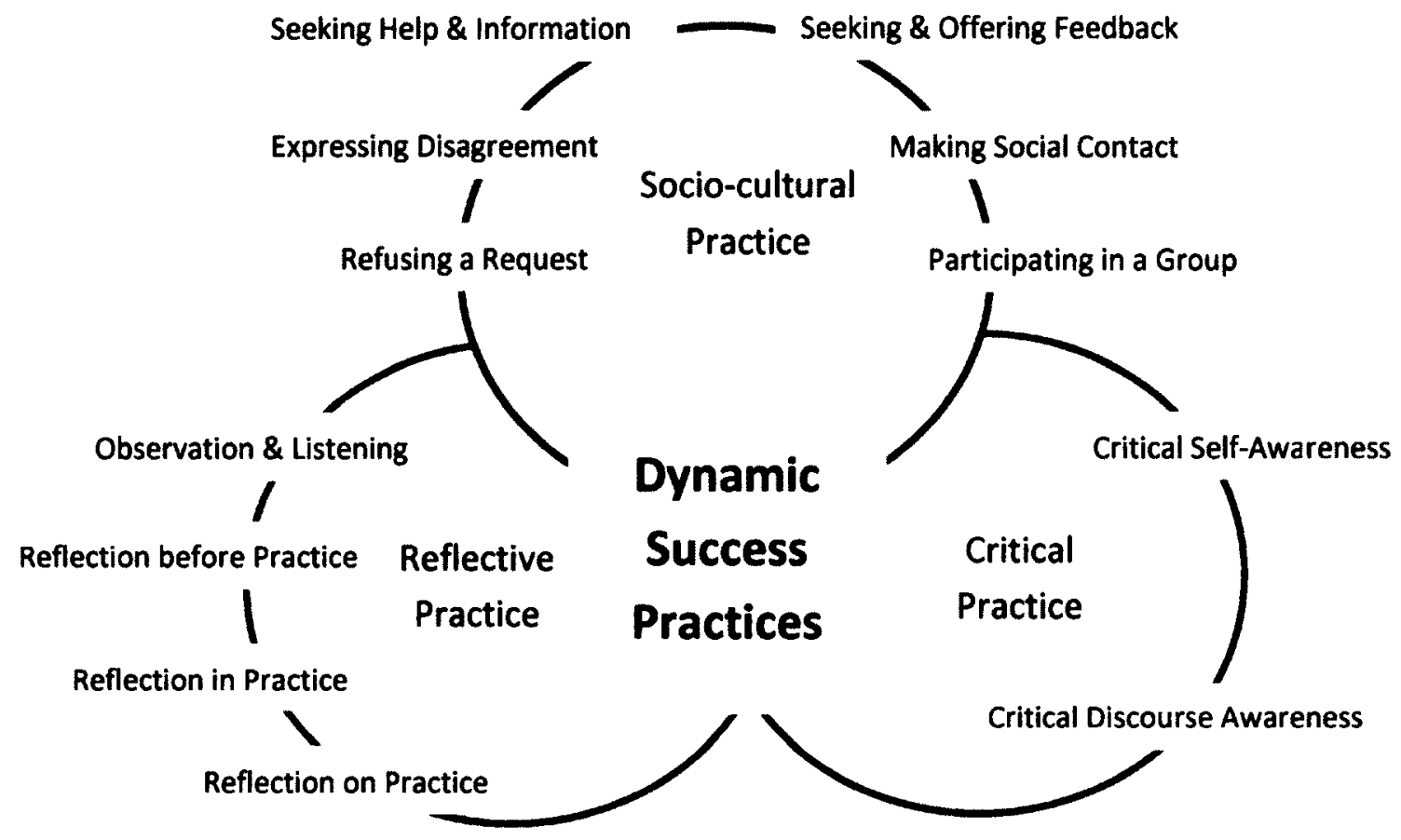

Figure 1. Lawrence's (2005) Models of Student Success Practices

The first year experience in engineering. Students who persist in engineering have been identified as those who have had at least minimal exposure to the engineering profession, either through family members or friends or through engineering-related summer camps or competitions (Pierakkos, Beam, Constantz, Johri, \& Anderson, 2009; see also Astin, 1993b; Artemeva, 2005). These connections helped them to begin to feel as though they identified at least slightly with the engineering community even though they did not yet feel they were engineers themselves. These students are, thus, more intrinsically motivated to pursue engineering studies instead of simply following the recommendations of high school teachers or guidance counsellors. Pierakkos et al. 
(2009) also found that compared to students who transferred out of engineering, students who persisted were more inclined to engage and participate in activities related to engineering and to build an engineering social network.

Foor, Walden, and Trytten (2007) provide engineering-specific examples of Bourdieu's (1977) notion of knowledge as a form of wealth. Having a family member or close family friend who is an engineer is an example of social capital. Knowing how to study in engineering or how to prepare for a job interview are examples of cultural capital while participating in an engineering co-op program is a type of symbolic capital. Lacking these types of capital makes it difficult for some engineering students to compete in their highly competitive programs. Moreover, having limited capital resources at the beginning of a program makes it all the more difficult for a student to acquire new capital throughout their programs (Foor et al., 2007; see also Artemeva, 2005).

Artemeva (2005) found that having family members who are engineers can provide students with real world examples of the content they will learn in their programs. The novice engineer in her study, Sami, was able to build a bank of discipline appropriate communication strategies based on knowledge passed to him from his family and his course work. Sami accredited the business and professional decisions he made directly to his father and that he had a much deeper knowledge of the engineering workplace and the hierarchy that exists in an engineering firm. An undergraduate course in professional engineering communication also afforded him the opportunity to produce oral presentations and written communications that were sensitive to the needs of an engineering audience (Artemeva, 2005). 
Artemeva (2005) uses the theory of kairos (Kinneavy, 2002) to illustrate how Sami's experiences demonstrating his expertise with engineering communications in the workplace led to his creation of a kairotic moment. This concept could also be extended to an engineering classroom if students have and/or create the opportunities to choose their projects' topics to suit their own needs. However, Artemeva (2005) cautions that few students actually create their own kairotic opportunities - instructors typically do this themselves through assigning topics and setting deadlines. Unfortunately, this may do little to assist students who lack sufficient engineering-related cultural capital.

\section{The Role of Language Proficiency}

Research into proficiency in English and academic success has not determined a clearly defined relationship. Graham (1987) provided an overview of 20 studies of which some found that English proficiency was not linked with academic success, some that found it was, and still others who reached a mixed conclusion. What Graham's overview does offer is potential reasons for why a student's academic achievements may not be based on their linguistic abilities. English proficiency is often measured by standardized tests like the TOEFL. While these high-stakes test are highly researched, their validity is sometimes debated and these tests only assess if a student can function in the English skills covered on the test and not their academic abilities. O'Loughlin (2011) found that little is done to ensure that the decisions universities make using language proficiency test entrance scores are working - there is little tracking of students admitted under such requirements. Just as Elder et al., (2007), Krause and Coates (2008), and Dooey (2010) confirmed, Graham (1987) concluded that the wide range of results indicates that many 
factors, not only English proficiency, contribute to academic achievement. Graham (1987) goes on to posit that it is likely that there is a minimum English proficiency level that a student must attain before other factors, such as motivation or math ability, can play a more influential role in determining a student's academic success. (For a discussion on TOEFL scores and international student success in engineering, see Wait \& Gressel, 2009).

For students whose first language is not English, the two most common ways to gain university acceptance are either to complete a number of years of secondary school in an English-medium school or to pass a standardized language proficiency test (such as TOEFL or IELTS). This growing cohort of university students is admitted to Canadian universities without further linguistic assessment. However, since they satisfied the university's admissions requirements, even if they find they could benefit from additional linguistic support, they typically do not qualify for any further language programs. Fox (2005) set out to examine "language residency" (p. 86), defined as the number of years spent in an English-medium secondary school, and its potential link with academic performance at university. In their first year, the 265 students admitted to a large Canadian university on the basis of language residency achieved an average GPA of Cwhile the average GPA of all first-year students was B-. 72 of the students received an unsatisfactory evaluation from the registrar's office. In their second year, only 39 of the 265 students had successfully completed their credit requirements and achieved an average GPA of C+ compared to the average second-year student GPA of B-. 29 of the students had withdrawn completely from the university (Fox, 2005). 
di Gennaro (2009) compared the writing abilities of international students with those of language residency students and found that, in terms of cohesion, grammar, and sociolinguistic control, language residency students' writing did not differ significantly from that of international students. Moreover, while the language residency students typically produced longer essays, their essays often lacked appropriate and/or sufficient content. What di Gennaro's study also highlights is the need to gather as much background information as possible about incoming students. Since it was impossible for the university to identify "covert bilinguals" (Taffe \& Pringle, as cited in Fairbairn \& Fox, 2009, p.11) who had met the language residency entrance requirements, all incoming students had to complete a background questionnaire when they took their composition course placement exam. Raters used this information along with the writing samples to more accurately place students in the appropriate courses (di Gennaro, 2009).

Although ESL students often enrol in mathematics courses because they perceive them to be less demanding linguistically, they do not realize that a lower English proficiency could potentially cause them great difficulty (Neville-Barton \& Barton, 2005). In five studies of students enrolled in secondary and post-secondary mathematics courses, Neville-Barton and Barton (2005) confirmed a $12-15 \%$ difference in achievement on math tests between the native and non-native speakers. Further, the majority of the ESL students were not able to self-identify that they were at a disadvantage linguistically in their mathematics courses.

Barton and Neville-Barton (2004; see also Neville-Barton \& Barton, 2005) claim that although math courses are perceived as being lighter in terms of language, they are actually just as challenging as language-rich courses. Dale and Cuevas (as cited by 
Barton \& Neville-Barton, 2004) provide several examples that outline the complexity of vocabulary used in mathematics:

- technical vocabulary, e.g. quadrilateral, algorithm, factorial;

- everyday vocabulary that takes on different meanings, e.g. rational, range, product, integrate;

- complex phrases combining more than one concept, e.g. least common multiple;

- several words signalling the same mathematical concept, e.g. add, sum, and, increase, plus;

- general English vocabulary;

- symbols (which can be both conventional and free, depending on the context) e.g. $+,=, \pi, x, y$. (p. 3$)$

Fox (2005) found that language-residency students who were struggling academically were more likely to register in math-based courses. This suggests that these students may have had more confidence in their abilities to "read formulas and solve problems more effectively than $[\ldots]$ read extended texts and write lab reports or academic papers" (Fox, 2005, p. 101). The move towards math-based courses was in contrast to other groups of students on campus. For example, students who do not meet the language residency entry requirement and thus take English for Academic Purposes (EAP) classes during their first year at university tend to begin with more math-based courses. Then, as they acculturate to university study, they progress to more linguistically demanding courses in subsequent years

A large number of students in Fox's (2005) study were enrolled in Engineering (27.4\%). Interviews with Engineering professors revealed that they noticed that as 
language-residency engineering students encountered academic difficulties, the students became increasingly frustrated with both their ineligibility for English-language support classes and the lack of support available on campus. Moreover, the Engineering professors interviewed explained that they did not have extra time to offer to their potentially linguistically at-risk students (Fox, 2005).

Regardless of how students meet the language requirements to begin university study, they will have to acculturate to their post-secondary institution. Cheng and Fox (2008) found that many of the L2 students in their study reported consciously using strategies to reach their academic goals. The students focused on time management to complete assignments early so they could seek feedback and they prepared for lectures before attending them. They also formed study groups, skimmed their long readings, and chose classes that they felt they could succeed in. Even though Canadian university students are encouraged to ask their professors and teaching assistants questions, many of the students Cheng and Fox interviewed explained that they felt apprehensive of approaching them. "Acculturation does not (and cannot) evolve as a one-way transmission from a community of specialists to novices" (Cheng \& Fox, 2008, p. 327). Students also recognized how important acculturating socially was to their academic success. By making an effort to expose themselves to English outside of class, they could build the confidence, language skills, and networking skills they needed to participate effectively in group work. However, building social connections was challenging for the L2 students as they did not know how to meet or interact successfully with their Canadian classmates (Cheng \& Fox, 2008). 
Evans and Morrison (2011) identified motivation, social connections, hard work, effective study routines, and self-developed learning strategies as key components of an L2's academic success in an English-medium university. Tracking 28 Chinese native speakers as they progressed through their programs at an English-medium university in Hong Kong revealed that often their greatest roadblock was not language proficiency, but adapting to their new student life. The drive to continue practicing their skills and to build up peer support networks was found to contribute the most effectively to their academic acculturation (Evans \& Morrison, 2011).

\section{Successful Support Initiatives}

While post-secondary institutions are increasingly recognizing the need to offer specialized support for first-year students, Kift argues that students' first year experience is "everyone's business" $(2008$, p. 3$)$. The benefits of this support are two-fold: if students can receive the support they need to succeed, they perform better academically, make more social connections, and stay enrolled in their programs. Staying enrolled lowers an institution's attrition rate which is likely to assist them with funding, accountability, and student recruitment. However, the purpose of retaining students is not only to keep students enrolled. Tinto points out that learning is still the primary goal of a university and that "retention and graduation are its by-products" $(2009$, p. 5$)$.

Nist et al. (1995) warn that interventions tailored to students' needs are "neither a short-lived or simplistic solution" $(1995$, p. 6). Student support interventions need to become embedded in an institution's practices and not just "sit at the margins of institutional life" (Tinto, 2009, p. 1; see also Hussey \& Smith, 2010; Read, 2008). 
"Creating an environment of assistance on campus is as crucial as providing assistance; it is what encourages students to not only seek out services, but to feel as though they are receiving support from the campus as well" (Stern, 2001, p.3). "Timely access to support" (Kift, 2008, p. 4) ensures that students get the help they need when they need it the most - at the beginning of their acculturation experience (see also Wilson \& Lizzio, 2008). It becomes increasingly more difficult to make a difference in a student's life as the semester passes. Universities need to implement "early warning systems" (Tinto, 2009, p. 4) to identify students that may need assistance early in the school year.

Just as much of the research on the first-year experience has been done in Australasia, so has much of the research on institution-wide support programs (see Chapter 3 for an explanation of the DELNA initiative). However, there are no one-sizefits-all student retention programs - individual institutions need to design, implement, and evaluate programs to ensure that they are meeting the needs of their institution/departments and their student body (Fike \& Fike, 2008; see also Chapman \& Pascarella, 1983; Peach, 2005; Bernold et al., 2007).

The Student Success Program (SSP) at a large Australian university began as a pilot project in one faculty (see Nelson, Duncan, \& Clarke, 2009) and is now an institution-wide support program for at-risk, transitioning students. Nelson, Quinn, Marrington, and Clarke put forth that all staff, whether they are administrators, instructors, or support staff, "have an obligation to provide the necessary milieu to support students to engage academically, socially, and personally with their institution" (2012, p. 84; see also Tinto, 2009). By collecting extensive student information, such as attendance, assignment submissions and grades, course participation (both in-class and 
online), and demographic profiles, SSP proactively identifies students who may need help completing their semester successfully.

In spite of the fact that SSP is an institution-wide program, it does not offer generic academic support (see also Tinto, 2002a; 2002b; Fike \& Fike, 2008; Chapman \& Pascarella, 1983; Peach, 2005). The Student Success Advisors (SSAs) who contact the first-year students are all upper-year students who can provide discipline-specific support. The SSAs also receive training on the other support services on campus, such as the library or counselling services, so that they can direct students on if needed. Partnerships were built between any university staff members involved in social, administrative, personal, and/or academic services for students which likely greatly contributed to the SSP becoming "embedded institution-wide" (Nelson et al., 2012, p. 94; see also Tinto, 2009).

These partnerships also enabled the SSP to offer four stages of proactive support to students. In Stage 1, students who wait to accept their admission offer or have problems registering are provided with information on services related to the decision to enrol, such as financial assistance. Stage 2 in the first month of the semester involves contacting all students who skipped orientation sessions or come from a demographic that may benefit from transition support (see Fike \& Fike, 2008). The third and fourth stages involve the SSAs calling students whose profiles indicate they may be in need of help. Stage 3 calls go out during the semester with the intention of creating a plan that students can put into action to improve their learning. Whether the SSAs are able to speak to the student or not, they follow up on all phone calls with an email. The email either outlines the action plan the SSA and student discussed, or includes study tips for any student the 
SSAs were unable to reach by phone. Stage 4 calls go out at the end of the semester to students who may end up on academic probation. SSAs ensure these students know who on campus they should talk to about their options (Nelson et al., 2012).

Nelson et al. (2012) report that students have indicated they appreciated the advice they received when they spoke with an SSA in the first, second, or third stages of the program. Of the 242 students contacted during Stage 1 in the fall of 2008, 186 (76.9\%) were still enrolled one year later. They also found that students who were contacted in Stage 4 were twice as likely to being taken off academic probation and more likely to still be enrolled the following semester as those who did not speak with an SSA. Overall, the attrition rate for first-year students at this Australian university had dropped from $18.1 \%$ to $15.8 \%$ within two years of implementing the Student Success Program. Department-specific support programs are emerging - engineering programs across the United States have begun to focus their efforts on helping their students' transition into the discipline and build the social connection they need to help them succeed in their studies. Watson, Pierrakos, and Newbold (2010) highlight the importance of knowledge of the engineering profession to enhancing first-year student engagement with their program and building an "engineering identity" (p. 1). While not geared solely at first-year retention per se, the curricula changes they report on contributed to raising students awareness of engineering as a profession and thus enabling "them to develop an understanding of how the foundational coursework correlates to, and is integrated into, engineering practices (Watson et al, 2010, p. 2). This will, Watson et al. (2010) argue, let students make more informed decisions about whether to change from or persist in their engineering program. 
Voluntary, online self-assessments were developed for first-year engineering students at a large American university to help them learn to apply empirical functions, computer programing, and ethics to real-life engineering problems (Kemppainen \& Hein, 2008). The instructors of a first-year core engineering course recognized that although many of the students had no prior knowledge of these areas and needed more support, they could not spend extra class time on the material. Instead, the department turned to self-assessment as a way of meeting student needs. The self-assessments were designed so that students receive immediate feedback on their mastery of the course content. Students can complete the assessments as many times as they wish. Students who completed the assessments reported feeling they had increased their knowledge base by $9 \%-13 \%$. Although the students still slightly doubted the benefit of any contribution from the self-assessments to their overall grade, they indicated that they had improved understanding of the specific topics covered in the assessments and thus scored higher on assignment/exam questions based on that material. Results after the first semester of use demonstrated that completing the self-assessments may have contributed to overall course grades as students who chose to use them scored on average $6 \%$ higher than those who did not. Based on the apparent success of this initiative, self-assessments were developed for two other core engineering courses and offered to all course sections (Kemppainen \& Hein, 2008).

Learning communities, or student cohorts, were implemented by another large American engineering program in order to ensure that students received the extra math support that they required to be successful in an engineering program. Scott (2009) reports that students in the program who needed further math instruction were required to 
register in a specific cohort. Making cohort participation mandatory improved retention rates for the students who entered the program with insufficient mathematical knowledge. These cohorts of students were enrolled in all of their classes together (see Tinto, 2009 for the benefits of learning communities). Cohort students learned more about engineering because these students were offered targeted symposiums and professional talks. Their English course was also geared specifically towards engineering communications and writing.

With only about $60 \%$ of first-year engineering students continuing into the second year of their program, Tsang, Halderson, and Kallen (2007) explain the potential of learning communities in improving student retention rates at a large American university (see also Tinto, 2009 for the benefits of learning communities). First-time, first-year students were grouped either by their major or their first semester math level. These groups of students were clustered into the same 3 or 4 course sections and an anchor class taught by an engineering faculty mentor. Tsang et al. (2007) found that this cohort of students had a statistically significant higher successful course completion rate and approximately $5 \%$ more students from this cohort continued into the second semester of their program than first-year students who were not in the learning communities. Moreover, after the first year of implementing the clustered courses, the retention rate from first to second year increased between $8 \%$ and $17 \%$. While the pilot only had four learning communities, the second year of the project increased to twelve. This project was not, however, only for first year students. The need for faculty involvement in the first year transition was highlighted as the authors state that a learning community for the 
faculty was also created and that "caring faculty members are invited to serve as faculty mentors" (Tsang et al., 2007, p. 1; see also Tinto, 2009).

Further to the implementation of learning communities, the same university also launched the Engineering House (EH) program as part of their First-Year Engineering Experience (FYEE) program (Tsang, Darrah, Engelmann, Halderson, \& Butt, 2009). The department recognized that EH would enable students, who spend the majority of their time outside of the classroom, to "develop the life skills, academic habits, and connections that will help them persevere and become successful in engineering and applied sciences" (Tsang et al., 2009). In its first year, the EH had 41 residents, but by its third year it had grown to 178 residents. In an FYEE survey, the EH students scored significantly higher on items relating to having friends in their cohort and knowing how to use various academic supports available on campus. Through this initiative, Tsang et al. (2009) again highlighted the need for collaboration between student support services and faculty members as these groups worked together to plan and implement various events for the EH students to encourage their integration into the program and the university (see also Tinto, 2009; Nelson et al., 2012).

\section{Summary}

This chapter has discussed how concepts such as Bourdieu's cultural capital (1975) and habitus (1990) and the importance of building new academic and social connections (Tinto, 2009; 2002a; 2002b; Scanlon et al., 2007) apply to the first year experience. The challenges for students admitted to post-secondary study with a lower language proficiency were highlighted (see Fox, 2005; Cheng \& Fox, 2008; Evans \& 
Morrison, 2011 ) as well as potential language issues with writing (di Gennaro, 2009) and mathematics (Fox, 2005; see also Neville-Barton \& Barton, 2004; 2005). The chapter concluded by presenting successful support initiatives that are embedded in the university and offer discipline-specific support to potentially at-risk students (Tinto, 2009; Nelson et al., 2012; Watson et al., 2010; Kemppainen \& Hein, 2008; Scott, 2009; Tsang et al., 2007; 2009).

The following chapter examines research on diagnostic testing and assessment. After an introduction to conflicting definitions and uses of diagnostic tests, the chapter focuses on the importance of diagnostic feedback in an international suite of diagnostic tests and in post-secondary coursework. Finally, a university-wide first year support initiative that uses diagnostic assessment is discussed. 


\section{Chapter 3: Diagnostic Testing}

The previous chapter discussed the theoretical framework which informs this study of first-year academic acculturation and the relevant research literature. This chapter introduces diagnostic testing and its potential role in assisting with that acculturation. The chapter begins with a discussion of the conflicting definitions of and challenges with diagnostic testing. Alderson's $(2005 ; 2007)$ tentative definitions are highlighted as is his work with an international diagnostic testing project, the DIALANG. Next, several examples of how diagnostic feedback has already been used in postsecondary classrooms are presented. The chapter concludes with a detailed discussion of DELNA, a diagnostic assessment and support initiative for incoming university students that is both institution wide and embedded in the university's culture.

\section{Towards a Definition of Diagnostic Testing}

In Testing for Language Teachers, Hughes (1989) defined diagnostic tests as those "used to identify students' strengths and weaknesses. They are intended primarily to ascertain what further teaching is necessary" (p. 13). Despite this seemingly straightforward definition, Hughes points out that diagnostic tests for language learning contexts are incredibly challenging to develop and, as a result, very few diagnostic tests actually exist. Little had changed by the time Hughes published the second edition of his book in 2003 - there were only two additions to his discussion on diagnostic testing. The first addition being the suggestion that since learners tend to have problems with lower level listening skills, a diagnostic test could be useful. However, with his second 
addition, Hughes raises doubts about the possibility of diagnosing vocabulary knowledge in terms of usefulness and feasibility.

Contrary to Hughes' doubts about the potential of diagnostic test development, Bachman (1990) posits that "virtually any language test has some potential for providing diagnostic information" (p. 60) and that consequently, placement and readiness tests can generate diagnostic information by examining student responses. Bachman then defines a diagnostic test as one that "has been designed and developed specifically to provide detailed information about the specific content domains that are covered in a given program or that are part of a general theory of language proficiency" $(1990$, p. 60). Bachman and Palmer (1996) offer a brief description of diagnostic testing that is similar to that put forth by Hughes. They, however, suggest that the information about a learner's strengths and weaknesses provided by a diagnostic test could be used to "assign students to specific courses or learning activities" (1996, p. 98). They also provide an example of a diagnostic achievement test in an ESP program which determines if learners are able to effectively use the material covered in an ESP course. Although this appears to be an achievement test, Bachman and Palmer (1996) explain that learners who are not able to effectively use the course concepts receive diagnostic feedback that can be used to guide future instruction.

Brown (1996) devotes considerable discussion to diagnostic testing in his language testing course book and defines a diagnostic test as one "designed to determine the degree to which the specific instructional objectives of the course have been accomplished" (p. 15). The only distinction he makes between a diagnostic test and an achievement test is that a diagnostic test is best administered at the beginning and middle 
of a course to make diagnostic decisions which are "aimed at fostering achievement by promoting strengths and eliminating the weaknesses of individual students" (Brown, 1996, p. 14). Brown also suggests that the same test could be used 3 times throughout a course: at the beginning and mid-point for diagnosis and at the end for achievement. Despite the lack of distinction between diagnostic and achievement tests, Brown does provide an overview of how diagnostic assessment is used in a university language institute. However, the diagnostic procedures that he outlines do not seem diagnostic. In the second week of classes, teachers administer a diagnostic test of the skills taught in their class to see if any students have been misplaced, not to highlight a student's strengths and weaknesses.

Alderson's work $(2005 ; 2007)$ makes clear that the field of language testing needs more research on diagnostic testing so that we can more clearly define what a diagnostic test is and exactly what it is that we are diagnosing. He argues that theories in second language acquisition are not yet sufficiently defined or detailed to allow for diagnostic tests that might truly inform a learner of their learning progress (Alderson 2005; 2007). The fact that few purely diagnostic tests exist seems to support the vastly different views on the matter: diagnostic tests are difficult to develop (Hughes, 1989; 2003; Alderson \& Huhta, 2005), any test can offer diagnostic information (Bachman, 1990), and diagnostic tests would likely be program specific (Bachman \& Palmer, 1996). Alderson (2005) concludes that "the language testing literature offers very little guidance on how diagnosis might appropriately be conducted, what content diagnostic tests might have, what theoretical basis they might rest on, and how their use might be validated" (p. 10). 
Alderson (2005) was only able to put forth a tentative list of the characteristics of diagnostic testing after taking into consideration both the lack of literature concerning diagnostic testing and the confusion that reigns over differentiating a diagnostic test from other forms of language testing, i.e. proficiency, placement, or achievement tests. Of the nineteen characteristics that Alderson suggests, several are contradictory supporting his notion that not enough is known about diagnostic testing and assessment. Many of the characteristics highlight areas that require further research and analysis to determine their importance in diagnostic testing. The nine characteristics that apply most directly to this thesis are that diagnostic tests:

- are designed to identify strengths and weaknesses in a learner's knowledge and use of language;

- are more likely to focus on weaknesses than on strengths;

- should lead to remediation in further instruction;

- should enable a detailed analysis and report of responses to items or tasks;

- give detailed feedback which can be acted upon;

- provide immediate results, or results as little delayed as possible after testtaking;

- are typically low-stakes or no-stakes; and are thus

- expected to involve little anxiety or other affective barriers to optimum performance; 
- of language skills like speaking, listening, reading, and writing are (said to be) easier to construct than tests of language knowledge and use. Therefore, the results of such tests may be interpretable for remediation or instruction. (p. $11)^{2}$

\section{The DIALANG Project}

In response to the lack of literature on diagnostic testing, Alderson (2005, 2007; see also Alderson \& Huhta, 2005) provides a detailed explanation of the DLALANG project. DIALANG was developed to provide language learners with information on their writing, reading, listening, vocabulary, and grammar skills in the 14 European languages of the Common European Framework of Reference for Languages: Teaching, Learning, and Assessment (CEFR). Every stage of this test is voluntary. Learners can decide if and when they want to take the test, whether they wish to self-assess or not, in which skill(s) they wish to be tested, and finally which results they receive. They also have the option of stopping the test at any stage. Easy, medium, and difficult are the three levels of the test that are currently available. According to Alderson and Huhta (2005), the reading, writing and listening sections each have eighteen corresponding selfassessment 'I can' statements that relate to the CEFR scale. The vocabulary section was then introduced as another way to determine which level of the test would be

\footnotetext{
${ }^{2}$ See Language Assessment Quarterly 2009, 6(3) for an entire issue on cognitive diagnostic testing (informing the development of tests and the interpretation of test scores with an understanding of test taker psychology). A subsequent issue in $\mathbf{2 0 1 0}$ contains several commentaries and responses. See also Koizumi et al., 2011 for an additional example that diagnostic tests are resource-intensive to develop and that second language acquisition theories are not yet developed enough to make clear what is being diagnosed.
} 
administered based on concerns with using only the self-assessment statements to make this determination. If the learners opt to complete the initial vocabulary and selfassessment sections, the results from those sections will be combined to determine which version of the DIALANG learners will complete. Should a learner choose to complete neither the vocabulary test nor the self-assessment, they will be presented with the medium level DIALANG (Alderson, 2005).

After they complete the tests, learners can choose between several types of results and feedback. Feedback on the vocabulary placement test offers learners a brief description of their vocabulary size. Learners can get their CEFR level, as determined by the tests they have completed, and the results of each of the skills separately with a breakdown of items based on their sub-skill group, i.e. making inferences, identifying main ideas, etc. "Advisory feedback" (Alderson, 2005, p. 30) details how a learner may improve their language proficiency so that they may, in turn, improve their CEFR level. DIALANG also provides a comparison of learners' self-assessments of their reading, writing, and listening to their actual test results in these skill areas. This comparison allows learners to reflect on why there may be differences between their own evaluation of their language skills and their skills as assessed by DIALANG. If there is a mismatch between the self-assessment and the DIALANG results, possible reasons for this discrepancy are also listed for learners to read. The test's developers hope that this information will enable learners to self-diagnose and raise their language learning awareness. Alderson (2005) described self-assessment as:

the heart of the DIALANG philosophy that an ability to assess one's language proficiency accurately will not only reveal, or lead to, greater self-awareness, it is 
also believed to contribute to the setting of more realistic goals for (further) language learning. This in turn will contribute to the development of learner autonomy. (p. 118)

Alderson and Huhta (2005) put forth that the range of its feedback is one of the DIALANG's most innovative aspects. Alderson (2007) contends that diagnostic testing is intended to be low-stakes and posits that the DIALANG is, in fact, no stakes since interested learners can take the DIALANG online for free at any time they wish. Furthermore, the feedback they receive is for their personal use only. It does not determine access to either education or employment.

As Alderson (2005) points out with his list of diagnostic test characteristics, the detailed diagnostic feedback learners receive must be such that it can inform future instruction. DIALANG meets this goal through its connection with CEFR. This European-based framework lays out the abilities required for communication, the skills and knowledge a learner needs to develop those abilities, and the different situations in which that communication occurs. The CEFR document "facilitates a clear definition of teaching and learning objectives and methods and provides the necessary tools for assessment of proficiency" (Council of Europe, n.d.). The implications of CEFR with DIALANG are that since CEFR is linked with learning, teaching, and assessment materials, and DIALANG is linked with CEFR, then DIALANG results could potentially link directly to language learning and teaching (Alderson, 2005).

Despite his immense contributions to the field of diagnostic testing, Alderson (2007) questions how test developers should decide which strengths and weaknesses need to be identified for a learner through a diagnosis. This is especially true when diagnosing 
language proficiency since there is still debate on how language proficiency develops. Since there is no clear picture of which abilities play a role in language development, choosing which abilities to test for weaknesses is problematic. In terms of feedback, generating usable feedback from the test is a key factor in diagnostic testing (Alderson, 2007). Any diagnostic test must therefore be designed to generate detailed feedback which can be used to inform teaching and learning.

\section{Diagnostic Testing and Assessment in the Context of Post-Secondary Education}

The classroom implications of diagnostic testing. Alderson (2005) posits that both a learner's strengths and weaknesses will be highlighted by a diagnostic test. By highlighting the areas where a learner may need improvement or refinement and providing a detailed feedback report, learners and teachers become aware of where future instruction may focus. This feedback should be given to the learner as soon as possible after the test is completed and be in a format that enables the learner to put the feedback. into action. As part of a two year study on the impact of a new admission policy, these characteristics were applied to a classroom diagnostic assessment that Fox (2009) used to "provide on-going, systematic, and comprehensive information to both groups [teachers and policy makers] about the learning progress of students admitted on the basis of the new policy" (Fox, 2009, p. 28). As some the diagnostic testing literature suggests that a placement or achievement test could also be used for diagnostic purposes (see Bachman, 1990; Bachman \& Palmer, 1996), Fox modified a researched and validated placement test, the Canadian Academic English Language Assessment (CAEL), into a diagnostic tool. Surveying the literature on academic language development allowed Fox (2009) to 
identify diagnostic indicators of the sub-component skills. Then, the CAEL test specifications were analyzed and placed into the corresponding sub-component categories. This retrofitting process helped to ensure the diagnostic strength and interpretability of the newly designed diagnostic tool. The diagnostic CAEL was administered at the beginning of the session and was used to generate a learning profile for each student (Fox, 2009).

Teachers had freedom in how to use the diagnoses and profiles. Some teachers created more student-friendly profiles so that students could know their diagnostic score in each skill tested, suggested focus areas, and teacher comments. Many teachers had face-to-face meetings with each student to go over their diagnosis. Slowly teachers began to adapt their classroom practices to address areas identified in their students' diagnoses and focused more on addressing the needs of individual students. There was also evidence of increased student motivation. One teacher reported on how incorporating the diagnoses more into the students' work led to increased class participation and improved results overall. Another used her teaching assistant to address specific student needs through optional work groups which had high participation (Fox, 2009).

Linking the diagnoses to the students' own assessment of their skills, setting goals with the TA, and then meeting at regular intervals to discuss progress was incredibly motivating for many students. Setting their own goals means that students "assume ownership of a goal" and as a result they are more likely to work to reach it (Sadler, 1989, p. 129). Moreover, the profiles and on-going assessment provided policy makers 
with more information on program effectiveness and learning over time and highlighted the need for continued academic language support.

In year two, Fox and Hartwick (2011) used the re-engineered CAEL to refocus ESL learner portfolio work. In the past, the portfolios were used to focus students on their learning process, but the students were often skeptical about or uninterested in developing their portfolios. Students completed both a self-assessment of their academic skills and the diagnostic CAEL at the beginning of the term and then received a personal learning profile. Teachers provided in-class reflection time so that students could read their profiles and ask questions about them. Raising students' awareness of their own strengths and weaknesses was a key part of the entire process. Reflective tasks were continually used through the semester to promote this and support self-evaluation.

In focus groups, students received further diagnostic tests and activities to determine the sub skills on which they needed to focus. Students then had to create portfolios of all of their tasks to be handed in for grading at the end of the term. The shift in portfolio use led to increased motivation and initiative among the students. "They recognized the purpose, could articulate what they were doing, why they were doing it, and its potential benefits" (Fox \& Hartwick, 2011, p. 55). Students felt that the on-going diagnostic assessment prompted them to practice and focus more on their identified weaknesses. The low-stakes, continual assessment increased student participation and learning (Fox \& Hartwick, 2011).

Using a diagnostic assessment of genre knowledge enabled instructors to make informed pedagogical decisions about an introductory communications course for engineering students (Artemeva \& Fox, 2010). To meet the requirements of the 
Canadian Engineering Accreditation Board, an engineering communications course was added to the curriculum at a large Canadian university (see Artemeva, 2005 for an example of the potential benefit of such a course for novice engineer graduates). However, many of the students required to take the course requested an entrance exam so that they could show they already had the communications skills required for engineering and could thus be exempted from the course. Instructors soon realized that they could mould the course to the students' needs if they had a diagnostic assessment at the beginning of the course. The no-stakes diagnostic assessment was comprised of five passages from different genres discussing the same engineering-related topic. Students were required to identify the genre of each passage and then select the pertinent information from the passages in order to write a technical report. Not only did this provide instructors with diagnostic information, it provided students "with an opportunity to see for themselves whether they were proficient users of the technical report genre" (Artemeva \& Fox, 2010, p. 486). Students were then also given the opportunity to reflect and self-assess their performance before receiving their diagnostic feedback.

The majority of the engineering students were able to correctly identify the technical report genre among the five reading passages and 7 out of 62 students were able to write an appropriate technical report of their own. The instructors, who did not expect any students to have this genre knowledge at the start of the course, used this information to place students in peer feedback groups with a variety of roles and to adjust assignments accordingly. When given the opportunity to reflect on their diagnostic assessment again at the end of the course, students could recognize their "ability to focus and reflect on the central role of audience awareness in writing and its effects on 
rhetorical and linguistic features of engineering texts" (Artemeva \& Fox, 2010, p. 496; see also Artemeva, 2005). The students may not have fine-tuned their engineering writing abilities without the safety of the no-stakes diagnostic assessment to show them what they already knew and where they still needed practice.

The Diagnostic English Language Needs Assessment (DELNA). The Diagnostic English Language Needs Assessment (DELNA) was introduced at a New Zealand university in 2000 as a way of ensuring that linguistically at-risk students could get the support they needed to respond to academic requirements (Read, 2008). International student enrollment in New Zealand had reached 14,026 for primary and secondary schools and 13,373 for tertiary institutions by 2002 (Elder et al., 2007). According to Elder et al., (n.d.), DELNA has four purposes:

1) to diagnose the English language needs of university entrants;

2) to raise consciousness of students' language among university staff;

3) to guide those found to be in need towards suitable sources of language support \& to counsel them about optimal academic pathways; and

4) to enhance the chances of success among the student population. (p. 1)

Screening and diagnosis are the two parts of the DELNA. The 30-minute, computer-based screening section is comprised of both a vocabulary and reading test. The 27 -item vocabulary test requires students to match academic vocabulary with a oneword definition. The two parallel versions of the vocabulary test are based on words from the University Word List (see Xue \& Nation, 1984) and were first developed and validated by Beglar and Hunt (1999). Elder and von Randow regard this task as "a quick 
and simple way of measuring the size of a learner's vocabulary" (2008, p. 177). In the three parallel speed reading tasks, students have 10 minutes to complete a 73 -item clozeelide exercise. That is, they have to identify the redundant word in each line of an academic text. Although this is not an academic reading skill, the ability to skim and scan through large amounts of academic text is. This speed reading task was also judged to better distinguish between native and non-native English speakers because of the assumption that a native speaker will be better able to cope with the rapid processing required (Elder \& von Randow, 2008).

Elder and von Randow (2008) found that the vocabulary and speed reading tasks had reliabilities of 0.87 and 0.86 respectively. Moreover, the two tests demonstrated a significant difference in mean scores between the native and non-native English speaking test takers. The greatest difference was on the speed reading task which separated the two groups by more than 20 points. In terms of sensitivity, scoring 70 or lower on the screening identified $93 \%$ of the students who did not perform well on the subsequent diagnosis. False negatives, or students who needlessly took the diagnosis, were $13 \%$ (Elder \& von Randow, 2008). However, setting a cut-off score of 70 exempts very few students from the subsequent diagnosis, making it somewhat impractical for a university setting in which several thousand students may be required to complete the 2-hour diagnosis. Setting the cut-off score for diagnosis at 60 exempts more students, but reduced the number of false negatives to only $1 \%$ of test takers (Read, 2008).

Participating students and their departments receive email notifications of their screening results. Email notifications from the screening process provide a student's category: good, satisfactory, or recommended for diagnosis. Good means that a student 
does not need linguistic support while students placed in the satisfactory category are recommended to seek support at one of the campus's two learning support centres (Read, 2008).

The screening section is designed to filter through the majority of students and to flag students who are likely to struggle with academic literacy. Once flagged, students are suggested to take the two hour paper-based diagnosis which includes listening, reading, and writing sections that model typical academic literacy demands. The 30minute listening component requires students to listen to a mini-lecture on a general academic topic. They have to use the information from the lecture to complete multiple choice, information transfer, and short answer items. The 45-minute reading test requires students to complete a variety of item types using the information from one or two general academic texts totalling approximately 1200 words. The 30 -minute writing task requires students to interpret a simple graph or table of a social trend and write approximately 200 words commenting on the trend shown (Read, 2008).

The diagnostic section is designed so that students know in which of the three areas tested they need support, thus providing students with a very clear idea of where they need to focus. The following 6-point band scale is used for the students who participate in the diagnosis:

- Bands 8 \& 9: Proficient or highly proficient user. No support required. Unlikely to experience any difficulties with academic English.

- Band 7: Independent user. English is satisfactory and no support is required. The student may, nevertheless benefit from further practice in one or other skill area. 
- Band 6: Adequate user. English is mainly satisfactory but would be advised to seek concurrent support in one or more skill areas.

- Band 5: Limited user. May be at risk with academic study due to limited English skills. Needs intensive English language support.

- Band 4: Very limited user. Is likely to be at severe risk of academic failure due to inadequate English. Needs intensive English language support. (University of Auckland, 2011)

Email notifications report a letter grade. An average of A or B across listening, reading, and writing indicates that a student has placed in the same good or satisfactory categories as the screening section. Those students receive an email notifying them of their results and no further action is taken. A grade of $\mathrm{C}$ or $\mathrm{D}$ on the diagnosis indicates that a student is greatly in need of academic linguistic support. Those students are sent an email inviting them to a face-to-face meeting with a DELNA language advisor in order to receive and discuss their results (Read, 2008).

In their case study for test validation, Davies and Elder (2005) propose eight hypotheses about DELNA:

H.1 Students performing above a specified threshold will perform satisfactorily on all of the second tier diagnostic components.

H.2 All test components will function uniformly for the different populations of test-takers.

H.3 Essays rated high will contain a higher incidence of linguistic and discoursal features, which have been found to be characteristic of academic prose in various disciplinary areas. 
H.4 Academics from different disciplines will accept the writing tasks as representative of the language demands placed on students in their discipline. H.5 The standards they use to judge the adequacy of samples of academic writing will conform with those applied by the language experts who have been trained to rate the scripts.

H.6 Students, language instructors, and faculty administrators will be able to interpret and make use of the test results for relevant test purposes.

H.7 Academic language proficiency (as measured by DELNA) will be significantly related to performance in the academic domain (as measured by GPA).

H.8 The student population will benefit from the information that the test provides. (p. 805)

With regard to interpreting and using the test results, students and instructors receive a more detailed report of strengths and weaknesses, while program administrators typically receive only the overall band scores of the students with support suggestions. Administrators can then use these suggestions to determine what resources and supports to make available. Davies and Elder (2005) recognize that validating DELNA's effectiveness is both challenging and complicated. First, it is important to consider how you interpret benefit in the hypothesis as this could refer to multiple benefits such as uptake of relevant supports, improved linguistic abilities of those using the supports, and/or higher GPAs or few course failures. A diagnostic profile may not be the only factor that contributes to a student's use of a support service. A student who is highly motivated to succeed may seek out support regardless their DELNA results. On the other 
hand, a student may be limited in how much time they have to attend support sessions or how much money they may need to spend if using a support service may result in extending their academic study period.

Read (2008) explains that face-to-face meetings were not always part of the diagnosis. However, when studying the effectiveness of the DELNA, it was discovered that many students who received $C$ or $D$ were not seeking out the support opportunities offered. The students interviewed mentioned that meeting with someone instead of only receiving an impersonal email would have been more beneficial (Bright \& von Randow, as cited in Read, 2008). Students now receive a personal discussion of their DELNA diagnosis and they also receive information about the different language support programs available to them. The university offers credit writing classes and has learning support centres on campus. The courses and support centres are specific to either ESL students or native English speakers. The support centres offer one-on-one advising, noncredit courses, and workshops. Some disciplines offer language tutorials which are linked with content courses in the discipline. Continued monitoring of the students is also conducted. Moreover, some departments now also follow up with students (Read, 2008). Elder and von Randow (2008) report that some departments will use the linguistic profiles of the students who participate in DELNA to design language tutorials that are specific to their discipline.

Taking the DELNA is a free, "low-stakes" testing situation (Read, 2008, p. 182) because it is taken after acceptance to the university has been granted. Read (2008) devotes considerable discussion to how the DELNA is presented to both students and staff. He argues that test presentation is an important part of this initiative because how 
the test is presented will play a significant role in the impact of the test on all of the stakeholders. The use of the DELNA has been accepted by the faculty members as many of them had voiced concerns about the increasing need for academic language support for their students. However, as its use expanded, there was a need for increased communication across the university on how to use the DELNA results and how to offer support to the students identified by the assessment. Printed materials are provided to faculty and face-to-face meetings are set to ensure that the assessment has the desired impact on the study body (Read, 2008).

The university offers DELNA and the academic supports as optional, but puts a strong positive spin on participating in the assessment and the subsequently recommended support programs. The university recognized that they needed to present DELNA in a way that emphasized its benefits to students. Promotional literature used the slogan "Increases your chance of success" (Read, 2008, p. 185) and in the early years of the program, the university sent positively-worded letters to applicants inviting them to take part in the DELNA. DELNA was presented as a post-entry assessment with some personal choice for the students and shared responsibility with the university for meeting academic language needs. By $2005,40 \%$ of those invited were participating in the DELNA (Read, 2008). By 2007, most of the departments had changed their policies to require all incoming students go through the DELNA screening process. Information about the DELNA is now available on the university's website and in the program literature of each department. Students can access the DELNA handbook and sample versions of the assessment online and they can take the assessment on the day they prefer (Read, 2008). 
5,427 students took the screening section of the test in 2007 and it was suggested that 1,208 students should return to complete the diagnostic section. Of those who received the suggestion, $42 \%$ returned. The lower participation in the diagnostic section could be because students worried that poor results on the diagnosis would affect their admission even though DELNA is offered post-entry. Rather than measuring students' abilities, Read (2008) insists that the focus needs to remain on helping students meet their academic language needs so that they can achieve their academic goals. In 2002 , when DELNA administration began, there were concerns that the support services that students may need either did not exist or were not sufficiently developed to cope with an increase in clientele. However, as the students' linguistic profiles indicated the areas upon which students needed to focus, the number of support services available to students at the University of Auckland has increased (Elder \& von Randow, 2008).

High first-year grades are unlikely for students whose average skill score places them in Band 6 or lower and students testing into Band 5 or lower in more than one skill are at risk of failing at least one class (Elder \& von Randow, 2008). Elder et al. (2007) administered the DELNA to 3042 entering undergraduate students. They found that the majority of the non-native English speakers and just under half of the native English speakers scored a band level 7 or lower meaning that they were likely to need at least some linguistic support throughout their academic study. $12 \%$ of all the students tested scored below band 6 indicating that they were at high risk for academic failure. The majority of students scoring below band 6 were non-native English speakers. After the first semester of study, the students who scored a band 4 or 5 had a much higher failure rate, $23.5 \%$, than those who scored a 6 or higher. 
When studying two successive university intakes, Elder et al. (2007) found a significant, albeit weak, relationship between academic performance and DELNAmeasured language proficiency. Although the relationship was stronger for reading and listening than for writing, less than $10 \%$ of the variance in the students' GPA could be attributed to their language proficiency as measured by DELNA. This suggests that language proficiency is not the only factor that contributes to academic success (Elder et al, 2007; see also Krause \& Coates, 2008; Dooey, 2010; Graham, 1987). According to Fox (2004), if being proficient in English were the only requirement for tertiary academic success, all native English speakers would succeed in their studies, regardless of their motivation or background. That is, however, not the case. Even though DELNA is still a relatively new diagnostic testing initiative that requires further study, it seems to offer the possibility for making "assessment, learning, and teaching more technologically sophisticated, more critical and empowering, more collaborative and reflective, than they have ever been" (Hargreaves, Earl, \& Schmidt as cited in Fox, 2008, p. 103). Despite the thus far positive implications of DELNA, Elder et al. (n.d.) warn that without wellestablished support programs in place, a diagnostic assessment alone will not be able to help the students identified as at-risk.

\section{Summary}

This chapter introduced diagnostic testing and assessment by discussing the conflicting definitions and uses available in the language testing literature (Alderson 2005; 2007; Hughes 1989; 2003; Bachman, 1990; Bachman \& Palmer, 1996; Brown, 1996; Alderson \& Huhta, 2005). DIALANG, perhaps the world's most prominent suite 
of diagnostic tests, was introduced to exemplify Alderson's (2005; see also Alderson \& Huhta, 2005) argument that diagnostic testing is low-stakes and provides detailed feedback. Finally, examples of diagnostic testing and assessment in a post-secondary context were presented with DELNA particularly relevant to the first-year transition experience.

In an effort to gain awareness of the diversity and needs of their first-year students, the Engineering Faculty at a large Canadian university opted to modify DELNA to suit the specific needs of engineering and offer individualized support to their incoming students. Chapter 4, which follows, provides a description of the diagnostic assessment pilot project that constitutes the larger context of the present case study. 


\section{Chapter 4: Context of the Study}

We need to help disadvantaged students effectively utilize their meager capital resources to locate and acquire the additional social, cultural, and symbolic capital resources needed to excel in engineering programs and pursue academic careers (Foor et al., 2007, p. 113).

Students entering into engineering have typically achieved high academic results in high school. From 2003-2011, the mean admission average to the Faculty of Engineering at a large Canadian university was $83.95 \%^{3}$ (OIRP, 2012c). Despite this past high level of academic success of incoming students, $70 \%$ of first-year engineering students fail at least one course (D. Russell, personal communication, July 2011). Of the $883^{4}$ students who registered in first year engineering in the Fall of 2011, 220 were international students (OIRP, 2012d; 2012e). High course failure rates and growing international enrollment in the faculty raised concerns that there were possibly increasing numbers of students who may potentially be unprepared to meet the demands of their studies. Given the success of DELNA in New Zealand and Australia, the ease of administering the screening section, and its suitability to discipline-specific modifications, DELNA was chosen for a faculty-wide, first-year support initiative. In case study research, the case, or bounded system, is inseparable from its context. Describing the context of the case is done for the purpose of "situating the case

\footnotetext{
${ }^{3}$ This mean only represents students applying directly from Canadian high schools and does not include: the grades of international applicants.

${ }^{4}$ Interestingly, 2,378 students were approved to enter engineering and yet only $883(37 \%)$ actually registered.
} 
within its setting" (Creswell, 1998, p. 61). Chapter 4 offers a detailed description of the context of the present study so that the case being studied may be situated within the larger context. This rich and thick description is drawn from two sources. My role as a participant observer began two months before the diagnostic assessment was piloted. I attended planning meetings, assisting in writing a background questionnaire, administered and marked the assessment, and worked shifts in the support centre until its closure in mid-October. In mid-November, the SAFE Report for Engineering (Fox, 2011) was written for the Faculty of Engineering. The data in the report are based on data analysis of the first year cohort's diagnostic assessment results and their background information. The report aimed to highlight for the faculty the diversity of their incoming students, their diagnosed strengths and weaknesses, and the students who may potentially be at the most risk both linguistically and mathematically.

This chapter begins by explaining the timing and marketing of the DELNA pilot project and providing a brief overview of the support services involved. Second, the modifications of the original DELNA tasks and the design of engineering-specific tasks are outlined. Then, after explaining the administration and marking of the diagnostic assessment, demographic and assessment result information for the entire cohort is provided. Lastly, the subsequent support and student participation in the feedback process is discussed.

\section{The DELNA Pilot Project in Engineering}

First year cohort. Approximately 850 students entered the faculty of Engineering in September 2011. As in all disciplines, class time is extremely valuable. 
Finding class time when all 850 students could complete a diagnostic assessment proved impossible. Consequently, the department decided to pilot the assessment during the first-year orientation session the day before the beginning of the fall session. EngFrosh is a week-long event with activities like white-water rafting, a movie night, and boat building. While open to all first-year students, EngFrosh is typically attended by certain demographics of students and skipped by others (D. Russell, personal communication, July 2011). It was estimated that 400 students would attend EngFrosh and thus complete the diagnostic tasks. As part of the scheduled 'academic orientation' during EngFrosh, students were divided into groups based on their major and the groups rotated through a faculty welcome session, a departmental orientation, and the diagnostic assessment. Students who did not attend EngFrosh but still wished to take the assessment would be offered the possibility to do so during the second week of regular classes on their own time.

\section{Marketing DELNA to first-year engineering students: self-assessment for} engineering (SAFE). Alderson (see 2005; 2007) contends that diagnostic assessment is low- or even no-stakes. On the contrary, Fox argues that if an intervention takes place based on test scores, the test cannot be low stakes: "If the intervention is useful, it may reduce the stakes, if it is not, it may increase the stakes and the likelihood that the learner will not progress in the ways he/she could" (J. D. Fox, personal communication, October 13, 2011; see also Read, 2008). The worry that students would perceive the assessment as high stakes and Read's (2008) emphasis on positive marketing strategies informed Engineering's decisions on how to present and administer the assessment. 
The engineering department recognized the need to positively present DELNA to the first-year students and offer the support in a non-punitive manner. Moreover, it was recognized that the math tasks likely needed to be highlighted. Galloway argues that "the number one 'soft skill' that has almost certainly kept many engineers from holding leadership and political positions is their unwillingness or inability to communicate effectively" (2008, p. 25) and that engineers are often unclear about the mechanics, i.e. grammar, etc..., that more formal written communication entails (see also Artemeva, 2005 for an example of how written communications may be perceived in an engineering firm). Even though written reports are required for all first-year labs, the associate dean suspected that the students would strongly disagree with any suggestion that they will have substantial writing in the program. There was also the concern that using the name DELNA (Diagnostic English Language Needs Assessment) would result in the students viewing the assessment as a test of their academic English reading and writing skills. Self-Assessment for Engineering (SAFE) did not use the terms 'test' or 'English" and gave the impression of student self-responsibility.

Research has identified upper year engineering students as a valuable resource for first-year students (see Nelson et al., 2012; Meyers, Silliman, Gedde, \& Ohland, 2010). To further emphasize SAFE as a student-driven assessment rather than a test from professors, only peer mentors were present in the lab during administration. They introduced themselves as upper year students, introduced SAFE, and fielded any questions during the administration. Peer mentors also operated the SAFE Drop-In Centre which again kept the focus of SAFE as students helping students rather than as a 
top-down initiative. (For a script of what peer mentors said to welcome students and introduce SAFE, see Appendix A.)

Campus-wide support services involvement. The objective for SAFE in September 2011 was identified as "mobilizing support for students at risk across already existing support services" (J. Fox, personal communication, August 12, 2011). In July 2011, two professors from Applied Linguistics and Discourse Studies (ALDS), an Associate Dean in Engineering, instructors for Engineering communications and English as a Second Language Academic (ESLA) courses, the coordinator for the Writing Tutorial Service (WTS), two librarians and three ALDS graduate students met to discuss the SAFE pilot project. (Meetings with the Math Tutorial Centre (MTC) and Learning Support Services (LSS) took place at a later date - both centres declined to participate in the project beyond the services that they already offer to students.)

The ESLA instructor suggested that engineering-specific reading workshops could be developed and delivered by ALDS teaching assistants. In terms of writing support, the Engineering communications instructors admitted to advising students to avoid seeking support at the campus writing centre. The WTS is currently staffed almost entirely by TAs from ALDS and although the WTS can meet so many writing needs, it can be challenging when both the novice writer and the TA are unfamiliar with the genre. A former WTS TA explained that "a TA can be much more helpful and efficient when they have that discourse savvy, thus giving more informed assistance" (M. FriesenStowe, personal communication, December 3, 2011). At the July planning meeting, the WTS coordinator pointed out that it would be beneficial for students needing writing 
support if some engineering TAs could be assigned to the WTS for at least part of their weekly hours. The associate dean and communications instructors acknowledged that they could possibly find students who were strong readers and writers that could assist with reading and writing support for first-year students.

Peer mentors. Ten graduate and undergraduate students participated in the SAFE pilot project. The five undergraduate peer mentors were all current engineering students in their $2^{\text {nd }}, 3^{\text {rd }}$, or $4^{\text {th }}$ year of studies. They were recruited based on recommendations from the associate dean and an Engineering communications instructors. The three upper-year students attended a planning meeting and administered and marked the assessments. The two second-year peer mentors joined to offer academic support once the SAFE drop-in centre opened. A recent engineering graduate administered and marked the assessments, but was not available to work shifts in the centre.

The five ALDS peer mentors were all graduate students with varied and extensive teaching experience. Four had also completed a graduate-level course in language testing and assessment. Three of them were involved in each phase of the SAFE pilot project while a fourth graduate student assisted with the SAFE administration and marking and the fifth was only available to work shifts in the drop-in centre.

The majority of the peer mentors involved in SAFE met in August to get an overview of the SAFE pilot project (see Figure 2 on page 58). The meeting also served as a brief rater training session. The peer mentors marked several DELNA writing samples using the DELNA developed rubric and discussed their ratings as a group. Upon 
hearing that the department also intended to assess the incoming students' math skills, one of the engineering peer mentors agreed to develop diagnostic math tasks that could be incorporated into the assessment.

\begin{tabular}{|c|c|c|c|c|}
\hline \multicolumn{5}{|c|}{ Self-Assessment for Engineers (SAFE) } \\
\hline Diagnosis & & $\begin{array}{c}\text { Academic } \\
\text { Counselling }\end{array}$ & & Intervention \\
\hline $\begin{array}{l}\text { SAFE } \\
\text { Administration }\end{array}$ & $\begin{array}{l}\quad 2 \\
\text { SAFE Marking } \\
\text { and Individual } \\
\text { Results } \\
\text { Summary } \\
\text { Develonment }\end{array}$ & $\begin{array}{l}\quad 3 \\
\text { SAFE Marker } \\
\text { Meeting }\end{array}$ & $\begin{array}{l}\quad 4 \\
\text { SAFE Drop-In } \\
\text { Centre }\end{array}$ & \begin{tabular}{l}
\multicolumn{1}{c}{5} \\
Resources \& \\
Connections \\
Identified and \\
Carried Out
\end{tabular} \\
\hline $\begin{array}{l}\text { September } 7^{\text {th }} \& \\
\text { September } 14^{\text {th }}- \\
21^{\text {st }} \text { (depends on lab } \\
\text { availability) }\end{array}$ & 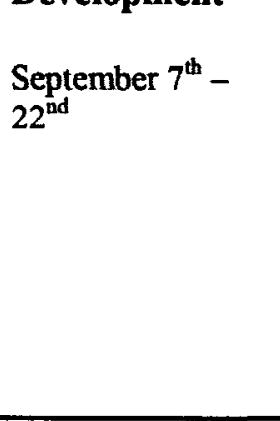 & $\begin{array}{l}\text { Emails sent to } \\
\text { students with } \\
\text { Learning Profile } \\
\text { Information } \\
\text { September } 9^{\text {th }}- \\
22^{\text {nd }} \text {; email } \\
\text { includes invitation } \\
\text { to SAFE Drop-In } \\
\text { Centre }\end{array}$ & $\begin{array}{l}\text { September } 15^{\text {th }}- \\
\text { October } 21^{\text {st }} \\
\text { 6hrs/day, } 2 \\
\text { days/week } \\
\text {-results discussed; } \\
\text {-service person \& } \\
\text { support identified; } \\
\text {-open invitation; } \\
\text {-personal contact; } \\
\text {-connections }\end{array}$ & $\begin{array}{l}\text { Writing Tutorial } \\
\text { Service } \\
\text { Reading Workshop } \\
\text { Math Tutorial } \\
\text { Centre } \\
\text { Learning Support } \\
\text { Services }\end{array}$ \\
\hline
\end{tabular}

Figure 2. Fox's (2011) SAFE Process

Designing the SAFE tasks. As explained in Chapter 3, DELNA consists of a 30minute screening and a two-hour diagnosis. The screening uses vocabulary and reading tasks while the diagnosis uses more in-depth reading, writing, and listening tasks. Time and resource constraints required that the SAFE pilot consist of one 50-minute stage that assessed both language and mathematical knowledge. Although DELNA was designed 
to be applicable to multiple university faculties (see Read, 2008), in this context it had to be adapted to fit the specific needs of the Faculty of Engineering.

To assess students' vocabulary and reading knowledge, the DELNA online screening tasks were chosen. Since DELNA writing tasks use graphs, they can also be used to assess a student's mathematical vocabulary and graph interpretation skills. Two different tasks were used in the pilot booklets: half of the booklets included a DELNA writing task with a graph on a general academic topic while the other half included a similar writing task using an engineering-based graph. The graph was drawn by the associate dean of engineering and was considered typical of a graph a first-year engineering student might encounter in their course materials. Although the graphs were different, both tasks required students to respond in the same manner. The five math tasks included basic questions on fractions, algebra, geometry and calculus. These were developed by an engineering peer mentor and then reviewed and accepted by the associate dean.

Administering and marking SAFE. On academic orientation day, September $7^{\text {th }}$, students were welcomed in the computer labs by the peer mentors and heard a brief overview of SAFE (see Appendix A). The first page of their SAFE booklet also offered a short description of SAFE and outlined the benefits of participating in the assessment. After filling in their name, student number, and email address, students completed an eleven-item background questionnaire. The booklet then provided examples of the vocabulary and reading tasks taken from the DELNA website and listed the time limits for each section of the assessment. Students began by logging into the DELNA website 
for the vocabulary and reading tasks. After completing the vocabulary practice task, students had 7 minutes to answer the 27 items. Next, the students completed the reading practice task and then had 10 minutes to go through the 73 lines of text. Students returned to their paper booklets for the writing task and math tasks.

Once all of the groups had completed the assessment, the peer mentors met to begin marking the tasks. As the vocabulary and reading tasks were marked instantly online, only the writing and math tasks had to be reviewed. The writing tasks were assessed by the ALDS peer mentors. No rubric was used since it was felt that the DELNA rubric was too detailed and it would be too time consuming to use it for over 500 writing samples. Instead, the mentors reviewed each text for clarity of ideas, organization, grammar, and content. Each sample was assigned a score of high $(\mathrm{H})$, medium (M), or low (L). An $\mathrm{H}$ indicated that the student was unlikely to need extensive writing support and would be able to adjust to the demands of engineering writing whereas an $M$ indicated that the student may benefit from some writing support. An L was assigned for students whose writing indicated they were possibly in serious need of writing support and may not succeed on academic written tasks without an intervention. Regardless of whether the students had completed the general DELNA writing task or the engineering specific task, students' writing samples were assessed in the same manner.

The math tasks were corrected by the engineering peer mentors. Students received a mark out of 4 (if they had not previously studied calculus) or 5 (if they had previously taken calculus). Major errors in fractions, quadratic equations, trigonometry, and calculus resulted in lower scores while other errors, such as failing to completely reduce fractions, were considered more minor. All potential issues, whether considered 
major or minor, were mentioned in the emails sent to each student. Although the engineering peer mentors did not assess the writing tasks, they did read them to determine if the students needed support in graph interpretation and math vocabulary. Specifically, they verified that students were able to appropriately use terms like $x / y$ axis, histogram, exponential, linear, etc..., and to correctly identify maximum/minimum values as well as general trends without over generalizing the relationships in the graphs. After the group marking session, the SAFE booklets were divided among markers and taken home.

On September $13^{\text {th }}$, the markers met again to compile the SAFE results and send individual emails to each of the students. The emails aimed to inform students of their results while acknowledging that SAFE was simply a brief snapshot of what a student's abilities may be. The email included the student's vocabulary score out of 27 and their reading score out of 73 . Although the writing tasks were first assessed using high, medium, or low, it was felt that the results would be clearer to students if they received a score out of 5 . A score of 0 to 2 corresponded to an $L$ on the writing task, a 2.5 to 3.5 to an $\mathrm{M}$, and a 4 to 5 to an $\mathrm{H}$. The math score was reported out of 4 or 5 and included a brief list of the math skills that a student may need to review. The email included a reminder that the results were for the students' personal use and students were also strongly encouraged to visit the SAFE Drop-In Centre to discuss their results (see Appendix B). The mean, mode, and median of each diagnostic task for the whole group were included at the end of the email giving students the opportunity to compare their results with the rest of their cohort. This email was not, however, the first email the students would have received regarding their assessment results. Since the vocabulary 
and reading tasks are online, they are immediately scored and an email with the results for those two sections is generated and sent automatically to the student.

While effort was made to contact each student who had completed the assessment, some students provided incorrect email addresses. If an email message was bounced back to a peer mentor, the student's name and student number were recorded on a separate list. The list was then given to the engineering department for them to try to contact the students about their SAFE results. During planning meetings, engineering had discussed the possibility of assigning lab time so that students who had not attended EngFrosh could take the self-assessment on their own time. Unfortunately, scheduling did not permit this to happen.

SAFE cohort demographics. 517 students attending EngFrosh completed the self-assessment. However, once data analysis began, several non-engineering students were identified and removed from the database. Several others did not complete one or more sections of their assessment and thus did not provide a complete profile for analysis. Removing these cases from the database left 489 cases to be analyzed. Even with piloting SAFE on only the students who attended EngFrosh and removing 28 cases, this sample still represents over half of the approximately 850 first-year engineering students.

Table 1 below shows that the students who took the self-assessment were mostly male $(n=396,81.1 \%)$, between the ages of $17-19(n=449,92 \%)$ and identified themselves as Canadian (n-419, 85.9\%) (Fox, 2011). There were 92 (18.9\%) female students, 39 
(8\%) students aged 20 or older, and 69 (14.1\%) international students. 283 (58.2\%) of students indicated that they had lived in Canada all their lives. Even though there were groups of students who indicated that they had lived in Canada for periods of time varying from 6 months to more than 10 years, the next largest group were those that had been in Canada for less than 6 months ( $n=68,14 \%) .334(68.6 \%)$ of 487 students reported that English was their first language. In spite of this majority of native English speakers, this was an incredibly multi-lingual group. 32 other languages were identified as first languages, the most common of which were Arabic (34\%), French (19\%), Chinese (17\%), and Urdu (12\%) (Fox, 2011).

Table 1

Demographic information from SAFE participants (Fox, 2011)

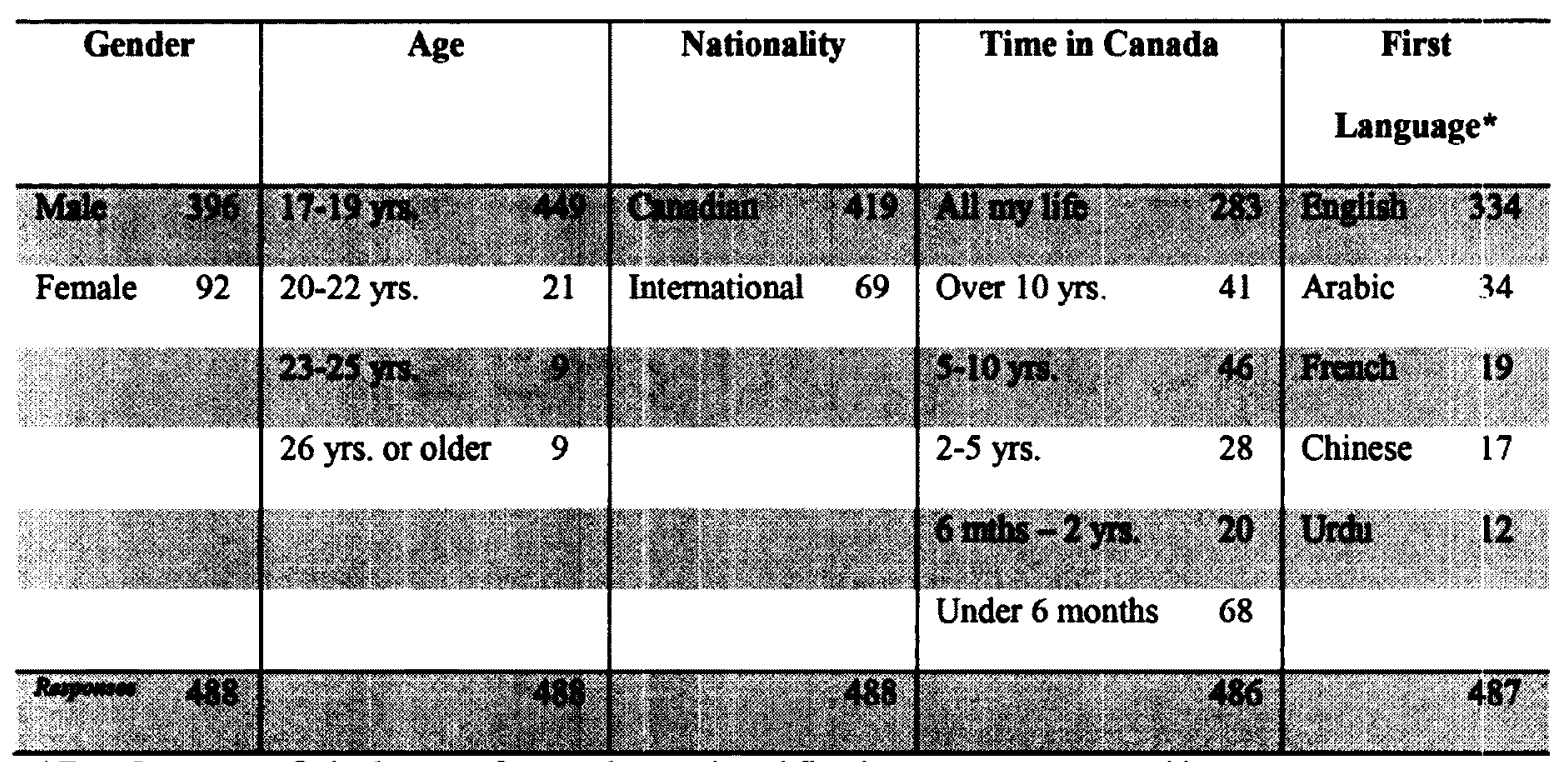

*First Language: Only the most frequently mentioned first languages are reported here.

Moreover, $5(1 \%)$ of students reported that they had more than one first language. $66(13.5 \%)$ of students reported speaking more than two other languages, $15(3.1 \%)$ three 
other languages, and $5(1 \%) 4$ or more other languages. Even though only 334 students reported English was their first language and 69 identified themselves as international students, $457(93.6 \%)$ students indicated that they had completed their high school studies in English (see Table 2 below) (Fox, 2011).

\section{Table 2}

SAFE participants and other variables that contribute to academic success (Fox, 2011)

\begin{tabular}{|c|c|c|c|c|}
\hline & High School in English & First in Family & $\begin{array}{c}\text { Contact with } \\
\text { Engineers }\end{array}$ & $\begin{array}{c}\text { Engineering Work } \\
\text { Experience }\end{array}$ \\
\hline No & 31 & 336 & & 173 \\
\hline
\end{tabular}

Warburton, Bugarin, and Nuñez (2001) and Fike and Fike (2008) have identified students who are the first in their immediate family to pursue post-secondary education as students who may underperform and thus may benefit from support (see also Walker et al., 2009 for discussion on first-generation students' approaches to university learning). $150(30.9 \%)$ of the SAFE participants indicated that they are the first members of their family to attend university. Exposure to and familiarity with engineering also contributes to success in engineering programs (see Artemeva \& Fox, 2010; Pierrakos et al., 2009). $313(64.4 \%)$ students reported having a family member or close friend who was an engineer and $131(26.8 \%)$ reported having previously worked in an engineering situation (Fox, 2011).

Setting risk thresholds. Table 3 (see below) provides an overview of the scores for each individual SAFE task for the 489 students who completed all sections of the 
assessment (Fox, 2011). The vocabulary, writing, and math tasks all have normal distribution of scores. The vocabulary task has a mean score of 24.43 and a standard deviation of 2.17 , the writing task has a mean score of 3.07 and a standard deviation of 1.25 , and the math task has a mean score of 3.87 and a standard deviation of .91 . The reading task, however, did not produce a normal distribution. While it has a mean score of 46.95 and median score of 47 , the mode is 72 (the whole task was 73 points) and the standard deviation is 17.26. These scores seem to support other findings (see Elder \& von Randow, 2008) that cloze elide tasks effectively separate linguistically strong and weak test takers. Combining the scores for the vocabulary and reading tasks (for a total score out of 100) produces a mean score of 71.38 , a median score of 71 , a mode score of 98 and a standard deviation of 18.36 (Fox, 2011).

Table 3

Score for individual SAFE tasks from 489 cases (Fox, 2011)

\begin{tabular}{|l|c|c|c|c|}
\hline & Mean & Median & Mode & Standard Deviation \\
\hline Vocabulary (V) & 24.43 & 25.00 & 24 & 2.173 \\
\hline Reading (R) & 46.95 & 47.00 & 72 & 17.264 \\
\hline VR Total & 71.38 & 71.00 & 98 & 17.264 \\
\hline Writing & 3.0736 & 3.0000 & 3.0 & 1.25080 \\
\hline Math & 3.8681 & 4.0000 & 4.00 & .91113 \\
\hline
\end{tabular}

Based on the assessment results for this group, thresholds needed to be set for each skill area so that the Engineering department could identify students who were 
potentially at risk and use this information to inform curriculum innovations for 2014 . To determine the risk thresholds for the SAFE participants, the standard deviation was subtracted from the mean for each skill area (see Table 4 below).

Table 4

Risk thresholds for the 489 SAFE participants in each skill area (Fox, 2011)

\begin{tabular}{|l|c|c|}
\hline & At-Risk Threshold & Students Below Threshold \\
\hline Vocabulary & $<22$ & $42(8 \%)$ \\
\hline Reading & $<29$ & $82(16 \%)$ \\
\hline Linguistic Total & $<53$ & $90(18 \%)$ \\
\hline Writing & $<1.82$ & $69(14 \%)$ \\
\hline Math & $<2.89$ & $32(6 \%)$ \\
\hline
\end{tabular}

Students who scored below these thresholds may potentially be at risk of being unable to engage appropriately academically in university work. $42(8 \%)$ students scored below 22 on the vocabulary task and $82(16 \%)$ scored below 29 on the reading task; 90 (18\%) students scored below the overall linguistic threshold of $53.69(14 \%)$ students fell below the writing threshold of 1.82 and $32(6 \%)$ students fell below the mathematics threshold of 2.89 (Fox, 2011). (Given that the thresholds were calculated by subtracting the standard deviations from the mean scores, it is important to note that the thresholds set are specific to this cohort of students.)

Performing below the threshold on a single task may not indicate that a student will encounter difficulties in their studies. To further distinguish potentially linguistically 
at-risk students among the SAFE participants, we cross referenced students' total linguistic scores and writing scores. 27 students fell below the thresholds for both linguistic and writing ability (see Table 5 below). The math scores were cross referenced with the writing scores to obtain a more refined math profile -20 students had problems with both the math task and the graphic interpretation in the writing task. Of these 20 students, 7 indicated in their SAFE booklets that they had not previously studied calculus (see Foor et al., 2007 for commentary on the importance of calculus for the retention of engineering students). Further analysis revealed that 13 students fell below the thresholds of all the diagnostic tasks (Fox, 2011).

Table 5

Potentially at-risk SAFE participants (Fox, 2011)

\begin{tabular}{|l|l|}
\hline Students at risk linguistically & 27 \\
\hline Students at risk mathematically & 20 \\
\hline Students at risk both linguistically \& mathematically & 13 \\
\hline
\end{tabular}

Information on how students met the university's language proficiency requirements was available for 24 of the 27 students who demonstrated language weakness on the assessment (see Table 6 on page 68). $9(37.4 \%)$ reported English as their first language, 7 (29\%) had attended a minimum of 3 years of English high school in Canada, $3(8 \%)$ had taken TOEFL or IELTS, and $4(6 \%)$ were enrolled in the university's credit ESL program (Fox, 2011). 
Table 6

Background on meeting language proficiency requirements for 24 SAFE participants (Fox, 2011)

\begin{tabular}{|l|c|}
\hline Indicated English as a first language & 9 out of $24(37.5 \%)$ \\
\hline Met language residency requirements & 7 out of $24(29 \%)$ \\
\hline Took a language proficiency test & 4 out of $24(16.7 \%)$ \\
\hline Enrolled in credit ESL program & 4 out of $24(16.7 \%)$ \\
\hline
\end{tabular}

From diagnosis to intervention. The SAFE Drop-In Centre was open on Tuesdays and Wednesdays from September $20^{\text {th }}$ to October $19^{\text {th }}, 2011$ from $1 \mathrm{pm}$ to $7 \mathrm{pm}$. At the centre, students could meet with an engineering peer mentor to discuss their math results and get course-specific advice. Students spoke with the ALDS peer mentors about their results in vocabulary, reading, and writing. The shifts were designed so that at least one engineering peer mentor and one ALDS peer mentor were in the centre for each shift. Students were asked to sign in when they arrived. Information about the MTC, WTS, LSS, Engineering faculty advisors, reading in Engineering, and ESL conversation classes was available in the centre (see Appendix $\mathrm{C}$ for examples of information sheets). Posters advertising the centre were posted around the engineering buildings and professors made announcements about the centre in the first-year engineering classes (see Appendix D).

Read (2008) reported $30-40 \%$ of students who were flagged by the DELNA screening returned to complete the full DELNA diagnosis. However, uptake had only reached those levels several years into the project - participation was initially quite low. 10 SAFE participants officially signed in at the drop-in centre (see Table 7 on page 70 for 
student profiles). Only one of the students who scored below the language thresholds set signed in at the centre (Case 5). Since they had provided their names when they signed in, these 10 students also received a follow-up email near the end of the semester. Approximately 10 other students stopped by the centre but did not sign in either because they had not participated in SAFE but were seeking information on support services or because they did not want a record of their visit. Low attendance and unwillingness to sign in suggest that marketing SAFE will be a key issue for the engineering department in the future. One student's response to his SAFE results demonstrates the gap between his results and his beliefs about his own skills:

I realize that my reading/writing skills seem to be a little off but unfortunately the instructions were not well heard or clear so $\mathrm{i}$ had waisted about 10 minutes causing me to rush through the reading a writing material. Hopefully providing you feedback on this exercise will help future students to not be inaccurately graded. I do understand that this does not affect my overall grades at [university] but will definitely waist some individuals times in trying to assist those who are perceived as needing help. 
Table 7

Profiles of students who officially signed in at the SAFE Drop-In Centre

\begin{tabular}{|c|c|c|c|c|}
\hline Case & Demographic Profile & $\begin{array}{l}\text { Other Factors that } \\
\text { Contribute to } \\
\text { Academic Success }\end{array}$ & SAFE Results & $\begin{array}{l}\text { SAFE } \\
\text { Consultation }\end{array}$ \\
\hline Case I & $\begin{array}{l}17-19 \text { yr. old male } \\
\text { Canadian who has } \\
\text { lived in Canada for } \\
\text { more than } 10 \text { years } \\
\text { First language is } \\
\text { English } \\
\text { Completed high school } \\
\text { in English }\end{array}$ & $\begin{array}{l}\text { Not the first member of } \\
\text { his family to attend } \\
\text { university } \\
\text { No family members or } \\
\text { close friends who are } \\
\text { engineers } \\
\text { No previous engineering } \\
\text { work experience }\end{array}$ & $\begin{array}{l}\text { Vocabulary - 27 } \\
\text { Reading - } 69 \\
\text { Writing - } 3 \\
\text { Math -4 } \\
\text { Did not take } \\
\text { calculus }\end{array}$ & $\begin{array}{l}\text { Provided with } \\
\text { information on the } \\
\text { Writing Tutorial } \\
\text { Service } \\
\text { Explained the role } \\
\text { of teaching } \\
\text { assistants } \\
\text { Strongly } \\
\text { encouraged to visit } \\
\text { the Math Tutorial } \\
\text { Centre }\end{array}$ \\
\hline Case 2 & $\begin{array}{l}17-19 \text { yr old male } \\
\text { An international visa } \\
\text { student } \\
\text { First language is } \\
\text { English } \\
\text { Completed high school } \\
\text { in English }\end{array}$ & $\begin{array}{l}\text { Not the first member of } \\
\text { his family to attend } \\
\text { university } \\
\text { No family members or } \\
\text { close friends who are } \\
\text { engineers } \\
\text { No previous engineering } \\
\text { work experience }\end{array}$ & $\begin{array}{l}\text { Vocabulary }-24 \\
\text { Reading - 35 } \\
\text { Writing - } 0 \\
\text { Math -4 }\end{array}$ & $\begin{array}{l}\text { Was upset with } \\
\text { receiving a } 0 \text { on the } \\
\text { writing section } \\
\text { Provided with } \\
\text { information on the } \\
\text { Writing Tutorial } \\
\text { Service } \\
\text { Directed to reading } \\
\text { help }\end{array}$ \\
\hline Case 3 & $\begin{array}{l}\text { Over } 45 \text { yr old male } \\
\text { Canadian who has } \\
\text { lived in Canada for } \\
\text { more than } 10 \text { years } \\
\text { First language is } \\
\text { Spanish } \\
\text { Did not complete high } \\
\text { school in English }\end{array}$ & $\begin{array}{l}\text { Not the first member of } \\
\text { his family to attend } \\
\text { university } \\
\text { Has family members or } \\
\text { close friends who are } \\
\text { engineers } \\
\text { Has previous engineering } \\
\text { work experience }\end{array}$ & $\begin{array}{l}\text { Vocabulary }-27 \\
\text { Reading }-22 \\
\text { Writing }-3 \\
\text { Math }-4.5\end{array}$ & $\begin{array}{l}\text { Came in to discuss } \\
\text { his reading results } \\
\text { Had problems } \\
\text { understanding the } \\
\text { instructions for the } \\
\text { reading task } \\
\text { Commented that } \\
\text { his reading was } \\
\text { improving every } \\
\text { day }\end{array}$ \\
\hline Case 4 & $\begin{array}{l}17-19 \text { yr old male } \\
\text { Canadian who has } \\
\text { lived in Canada all his } \\
\text { life } \\
\text { First language is } \\
\text { Cantonese } \\
\text { Also speaks Mandarin } \\
\text { Completed high school } \\
\text { in English }\end{array}$ & $\begin{array}{l}\text { Is the first member of his } \\
\text { family to attend } \\
\text { university } \\
\text { Has family members or } \\
\text { close friends who are } \\
\text { engineers } \\
\text { No previous engineering } \\
\text { work experience }\end{array}$ & $\begin{array}{l}\text { Vocabulary - } 26 \\
\text { Reading - 41 } \\
\text { Writing - } 1 \\
\text { Math -5 }\end{array}$ & $\begin{array}{l}\text { Came in to find out } \\
\text { which mistakes he } \\
\text { made in the writing } \\
\text { section } \\
\text { Was not interested } \\
\text { in seeking help or } \\
\text { improving his } \\
\text { writing skills }\end{array}$ \\
\hline Case 5 & $\begin{array}{l}\text { 20-22 yr old male } \\
\text { Canadian who has } \\
\text { lived in Canada } 1-2 \text { yrs } \\
\text { First language is } \\
\text { Chinese } \\
\text { Speaks both Cantonese } \\
\text { and Mandarin } \\
\text { Did not complete high } \\
\text { school in English } \\
\end{array}$ & $\begin{array}{l}\text { Not the first member of } \\
\text { his family to attend } \\
\text { university } \\
\text { No family members or } \\
\text { close friends who are } \\
\text { engineers } \\
\text { No previous engineering } \\
\text { work experience }\end{array}$ & $\begin{array}{l}\text { Vocabulary - } 23 \\
\text { Reading - } 18 \\
\text { Writing - } 1 \\
\text { Math }-4\end{array}$ & $\begin{array}{l}\text { Registered in } \\
\text { ESLA and is } \\
\text { receiving the } \\
\text { linguistic support } \\
\text { he needs }\end{array}$ \\
\hline
\end{tabular}




\begin{tabular}{|c|c|c|c|c|}
\hline Case 6 & $\begin{array}{l}20-22 \text { yr old male An } \\
\text { international visa } \\
\text { student who has lived } \\
\text { in Canada less than } 6 \\
\text { months } \\
\text { First language is } \\
\text { Malay } \\
\text { Completed high school } \\
\text { in English }\end{array}$ & $\begin{array}{l}\text { Is the first member of his } \\
\text { family to attend } \\
\text { university } \\
\text { Has family members or } \\
\text { close friends who are } \\
\text { engineers } \\
\text { No previous engineering } \\
\text { work experience }\end{array}$ & $\begin{array}{l}\text { Vocabulary-19 } \\
\text { Reading }-17 \\
\text { Writing - } 2 \\
\text { Math }-4 \\
\text { Did not take } \\
\text { calculus }\end{array}$ & $\begin{array}{l}\text { Provided with } \\
\text { information on the } \\
\text { Writing Tutorial } \\
\text { Service } \\
\text { Directed to } \\
\text { Learning Support } \\
\text { Services } \\
\text { Strongly } \\
\text { encouraged to visit } \\
\text { the Math Tutorial } \\
\text { Centre }\end{array}$ \\
\hline Case 7 & $\begin{array}{l}17-19 \text { yr old male } \\
\text { Canadian who has } \\
\text { lived in Canada all his } \\
\text { life } \\
\text { First language is } \\
\text { English } \\
\text { Speaks Vietnamese } \\
\text { and French } \\
\text { Completed high school } \\
\text { in English }\end{array}$ & $\begin{array}{l}\text { Not the first member of } \\
\text { his family to attend } \\
\text { university } \\
\text { Has family members or } \\
\text { close friends who are } \\
\text { engineers } \\
\text { Has previous engineering } \\
\text { work experience }\end{array}$ & $\begin{array}{l}\text { Vocabulary }-26 \\
\text { Reading }-63 \\
\text { Writing }-5 \\
\text { Math }-4 \\
\text { Had problems with } \\
\text { graphic } \\
\text { interpretation }\end{array}$ & $\begin{array}{l}\text { Came in to the } \\
\text { centre because he } \\
\text { was having } \\
\text { problems } \\
\text { understanding } \\
\text { concepts in his } \\
\text { math course } \\
\text { Advised to attend } \\
\text { math lectures for a } \\
\text { different section }\end{array}$ \\
\hline Case 8 & $\begin{array}{l}17-19 \text { yr old male } \\
\text { Canadian who has } \\
\text { lived in Canada 5-10 } \\
\text { years } \\
\text { First language is } \\
\text { Mandarin } \\
\text { Speaks Spanish and } \\
\text { French } \\
\text { Completed high school } \\
\text { in English }\end{array}$ & $\begin{array}{l}\text { Not the first member of } \\
\text { his family to attend } \\
\text { university } \\
\text { Has family members or } \\
\text { close friends who are } \\
\text { engineers } \\
\text { No previous engineering } \\
\text { work experience }\end{array}$ & $\begin{array}{l}\text { Vocabulary }-27 \\
\text { Reading }-73 \\
\text { Writing }-4 \\
\text { Math }-4\end{array}$ & $\begin{array}{l}\text { Concermed with his } \\
\text { results } \\
\text { Provided with } \\
\text { information on the } \\
\text { Writing Tutorial } \\
\text { Service }\end{array}$ \\
\hline Case 9 & $\begin{array}{l}26-35 \text { yr old male } \\
\text { Canadian who has } \\
\text { lived in Canada all his } \\
\text { life } \\
\text { First language is } \\
\text { Arabic } \\
\text { Also speaks French } \\
\text { Did not complete high } \\
\text { school in English }\end{array}$ & $\begin{array}{l}\text { Is the first member of his } \\
\text { family to attend } \\
\text { university } \\
\text { No family members or } \\
\text { close friends who are } \\
\text { engineers } \\
\text { No previous engineering } \\
\text { work experience }\end{array}$ & $\begin{array}{l}\text { Vocabulary }-25 \\
\text { Reading }-57 \\
\text { Writing }-4 \\
\text { Math }-3.5 \\
\text { Did not take } \\
\text { calculus }\end{array}$ & $\begin{array}{l}\text { Was concerned } \\
\text { with his academic } \\
\text { reading skills and } \\
\text { the time he needs } \\
\text { to complete a } \\
\text { reading } \\
\text { Strongly } \\
\text { encouraged to visit } \\
\text { the Math Tutorial } \\
\text { Centre }\end{array}$ \\
\hline Case 10 & $\begin{array}{l}17-19 \text { yr old female } \\
\text { Canadian who has } \\
\text { lived in Canada } 5-10 \\
\text { years } \\
\text { First language is } \\
\text { Arabic } \\
\text { Completed high school } \\
\text { in English }\end{array}$ & $\begin{array}{l}\text { Is the first member of her } \\
\text { family to attend } \\
\text { university } \\
\text { Has family members or } \\
\text { close friends who are } \\
\text { engineers } \\
\text { No previous engineering } \\
\text { work experience }\end{array}$ & $\begin{array}{l}\text { Vocabulary }-23 \\
\text { Reading }-26 \\
\text { Writing }-3 \\
\text { Math }-4 \\
\text { Had problems with } \\
\text { graphic } \\
\text { interpretation }\end{array}$ & $\begin{array}{l}\text { Came in to go over } \\
\text { results and get help } \\
\text { with a lab report } \\
\text { Had already visited } \\
\text { the Math Tutorial } \\
\text { Centre } \\
\text { Provided with } \\
\text { information on the } \\
\text { Writing Tutorial } \\
\text { Service } \\
\text { Visited the drop-in } \\
\text { centre twice }\end{array}$ \\
\hline
\end{tabular}




\section{Summary}

In order to situate the case within the greater context of SAFE, Chapter 4 has provided a detailed overview the pilot project. From the rationale for implementing a diagnostic assessment to decisions regarding timing, marketing, and support services, this chapter aimed to outline the decision-making process leading up to assessment day. It provided the demographics and SAFE results for the first-year cohort. By outlining the at-risk thresholds and participation in the subsequent feedback, the stage is set for this case study to provide additional insight into the role that diagnostic assessment played in the first-year acculturation of an engineering student.

Chapter 5 will provide an overview of case study research and describe the methods used in this study. It will discuss sampling, participants, data collection methods and instruments, and data analysis. 


\section{Chapter 5: Method}

Chapter 4 introduced the larger context of the SAFE pilot project within which the present case study was situated. Chapter 5 offers an overview of case study research and then outlines the methods used for this thesis. Information on sampling, participant demographics, and data collection is included, as is a description of how the data were analyzed.

\section{Approach}

Although language testing research is often dominated by quantitative research methods, qualitative research is becoming more commonplace in the field of applied linguistics (Lazaraton, 2005; see also Benson, Chik, Gao, Huang, \& Wang, 2009). Research in applied linguistics, especially in second language acquisition, has often involved studying the characteristics, knowledge, growth, and so forth of individuals. Since the 1990s, the body of literature dedicated to case study (see Duff, 2008 for an overview) has been growing. Case study research provides a rich, thick, and holistic description of a bounded system (Creswell, 1998; see also Merriam, 1998; Stake, 1994; 1995; Duff, 2008) where a bounded system is defined as a case that is "bounded by time and place" (Creswell, 1998, p. 61). Merriam (1998) characterizes case studies as being particularistic in that they have a specific focus of a situation, heuristic in that they provide new insight into the situation, and descriptive in that they offer a rich description of information from a multitude of sources. While often difficult to define, a case study can be intrinsic, instrumental, or collective (Stake, 1995, p. 3). An intrinsic case study 
examines a case that we do not exactly choose ourselves. We have a need to learn about a particular case, for example a program that we are required to evaluate. On the other hand, an instrumental case study involves a researcher using a case to gain further understanding of and insight into an issue of interest. If multiple cases, instead of a single case, are used to gain insight into the issue of interest, we have a collective case study (Stake, 1995).

The design of a research study must suit the research questions. While ethnography also uses thick and detailed description, its outcome is a "cultural interpretation of the phenomenon" (Merriam, 2009, p. 2009). It is broader in both scope and scale as ethnographic studies are often longitudinal and involve multiple members of the cultural group in question. Since this study sets out to gain understanding of and insight into the "process" (Merriam, 1998, p. 33) of how the implementation of a diagnostic assessment in a university engineering program contributed to a student's firstyear acculturation, case study methodology is the most suitable (see Figure 3 below).

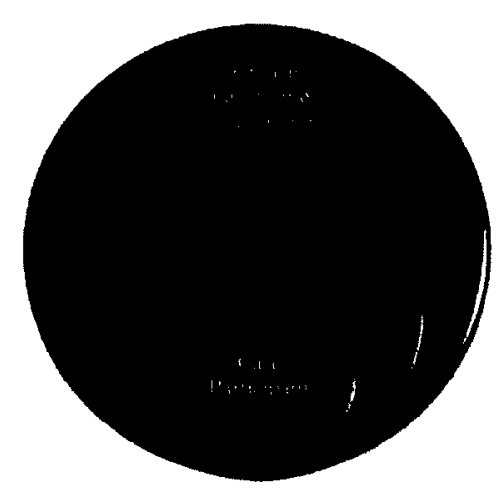

Figure 3. Situating the present case study within the larger phenomenon of first-year student transition and acculturation 
Even though I had the role of participant observer in the project, as an outsider to engineering, I had no control over the events involved. Furthermore, employing a case study methodology permitted me to become closely involved in the SAFE pilot project and to "spread the net for evidence widely" (Bromley as cited in Merriam, 1998, p. 33). Although the first-year acculturation experience is not an unusual case, using diagnostic assessment to help ease students' acculturation into first-year engineering at a Canadian university is distinctive. Therefore, an instrumental case study design will uncover information about this bounded system that might otherwise be missed. The main focus of this study then is to discover knowledge that may potentially inform the use of diagnostic assessment to support students' academic acculturation and lead to future research projects.

\section{Sampling and Recruiting}

I was granted ethics clearance on September $13^{\text {th }}, 2011$ by the Carleton Research Ethics Board and began recruiting participants using a technique referred to as “purposeful sampling" (Patton, 2002, p. 40) (see Appendix E for ethics clearance letter).

Patton explains that purposeful sampling is essential in qualitative research as it allows for the study of "information-rich cases [which] yield insights and in-depth understanding" $(2002$, p. 230$)$ of the phenomena under study. Feedback is a key component of diagnostic testing (see Alderson, 2005, 2007; Alderson \& Huhta, 2005; Fox, 2009; Fox \& Hartwick, 2011; Read, 2008). Given that coming to the SAFE Drop-In Centre to discuss the results of their assessment and taking advantage of the suggested supports was entirely optional, it appeared that trying to recruit the students who chose to 
come to the centre might provide the most insight into SAFE's contributions to their first year experience. (Although completing SAFE was optional, most students assumed that since it was part of their orientation, it was mandatory. In fact, only one student abstained from completing the assessment and only after he confirmed that doing so would not result in any negative consequences.) Information posters describing my study (see Appendix F) were placed in the SAFE Drop-In Centre next to the sign-in sheet and were handed out to each student who visited the centre.

In order to gain a more informed view of the impact of supports offered on campus in addressing a first-year engineering student's diagnosed needs, it was important to not only consider the narrative of my participant's experiences. I also sought to interview individuals with knowledge of the services she visited.

\section{Participants}

SAFE cohort. Read (2008) reported DELNA feedback uptake of approximately $40 \%$. In our planning meetings, we anticipated that around 400 students would complete the assessment, that approximately 100 would subsequently be flagged by SAFE as potentially at-risk, and that around $40 \%$ of those flagged would seek support. As such, in my initial plan for my study, I hoped to have 4-8 participants. However, low turn-out at the drop-in centre only enabled me to recruit one participant. Triangulation of data has been identified as a key aspect in case study research (see Creswell, 1998; Faltis, 1997; Stake, 1994; 1995; Duff, 2008). Although I cannot triangulate the data gained from a single engineering student participant, I can use my own observations and those of the other peer mentors to support or refute the data she provides. I can also compare my 
results to the SAFE Report for Engineering (Fox, 2011). Moreover, I can use "investigator triangulation" (Stake, 1995, p. 113) when coding observation and interview data.

My case study participant (pseudonym Anna) does, however, represent a demographic that is important in DELNA research and is thus what Patton would refer to as an "information-rich case"(2002, p. 40). Further, Foor et al. argue the importance of listening to "these hidden and experientially diverse people one story at a time using research methodologies that are appropriate to the task" $(2007$, p. 104).

Peer Mentors. Ruby and Zoe (both pseudonyms) worked as peer mentors throughout the entire SAFE pilot project. Ruby taught EAP to undergraduate engineering students in Iran for 6 years. She is an ALDS graduate student who had also completed a graduate-level language testing and assessment course. Zoe is an upper year engineering student. She was invited to join the SAFE pilot project by the Faculty of Engineering's associate dean and communications instructors. Ruby and Zoe attended planning meetings, assisted with SAFE's administration and marking, and worked at the drop-in centre. Zoe completed the questionnaire while Ruby opted for an interview.

Academic Support Staff. Meredith (a pseudonym) has a $\mathrm{PhD}$ in mathematics and has teaching experience at several large Canadian universities. She taught math full time for 4 years, including 2 years teaching mathematics courses to undergraduate engineering students. She then worked 5 years as a contract instructor for mathematics at 
two universities, one of which being the same large Canadian university considered in the present case study.

\section{Data Collection}

Data were collected from observations, questionnaires, and interviews. I describe these collection methods in detail in the following sections.

Participant observation. As the researcher, I not only observed the planning and administration of SAFE and the drop-in centre, I was also able to actively participate in the pilot project as a participant observer (see Creswell, 1998; Duff, 2008; Flick, 2009; Merriam, 1998; Patton, 2002). Spradley (as cited in Flick, 2009) describes participant observation as having three stages: descriptive observation happens at the beginning of the study as the researcher becomes familiar with the field and develops research questions; focused observation happens as the researcher's view focuses on areas that are important for addressing those research questions; and finally selective observation which focuses on discovering specific examples and information for the already narrowed research questions.

I attended planning meetings and assisted with SAFE's administration and marking during EngFrosh. I kept detailed notes of what I observed and I spoke with others involved in the process. This knowledge informed my participation as a peer mentor in the SAFE Drop-In Centre. My observations also informed my interviews with my first-year engineering participant Anna. In our initial interview, I would have missed some key questions about her experience taking the self-assessment had I not taken part 
in its administration. This "emic perspective" (Patton, 2002, p. 268; see also Creswell, 1998; Merriam, 1998) created by my role as a participant observer enabled me to gain insight of diagnostic assessment from a first-year student's point of view.

Peer mentor questionnaires. I developed a peer mentor questionnaire with eight questions that were derived from my observations and experiences as a peer mentor administering and marking SAFE and working shifts in the drop-in centre (see Appendix G). The questions were open-ended and aimed to elicit as much information as possible about the experiences and observations of the other peer mentors. Questionnaires and consent forms were sent to the peer mentors via email after the SAFE Drop-In Centre closed in mid-October. I received Zoe's informed consent as per university ethics guidelines when she returned her questionnaire.

Interviews with a SAFE participant. Merriam (1998) identifies three types of interviews: highly structured or standardized, semi-structured, and unstructured or informal. Highly structured interviews involve asking participants a list of prewritten questions in a predetermined order whereas unstructured interviews do not include a set of questions and are more exploratory in nature. Semi-structured interviews include more flexible, open-ended questions. Not all of the questions are written in advance many may arise from a participant's responses. A semi-structured format "allows the researcher to respond to the situation at hand, to the emerging worldview of the respondent, and to new ideas on the topic" (Merriam, 1998, p. 74). 
Interviews with Anna followed a semi-structured format. I received Anna's informed consent at the beginning of our first interview as per university ethics guidelines. Our initial interview was face-to-face and audio-recorded, but subsequent interviews during the semester were carried out via email. Open-ended questions were emailed since Anna was incredibly busy with her first-year course load and may have had difficulty finding time to meet every 2-3 weeks. Instead, she could answer the emailed responses to the questions at her convenience. While the questions I emailed were prewritten, they were often based on her previous responses. In exchange for her participation, Anna could make appointments with me whenever she needed help with her courses or had questions about general university life. Although the appointments had the primary purpose of helping Anna, they also provided me with further observations and opportunities to ask more questions.

Interviews with a Peer Mentor. Ruby opted to participate in an interview rather than complete the peer mentor questionnaire. I received Ruby's informed consent at the beginning of our interview as per university ethics guidelines. Our interview was face-toface and audio-recorded. Although Ruby's interview began with questions taken from the questionnaire, the interview followed a semi-structured format as other questions and comments resulted from Ruby's answers.

Interviews with Academic Support Staff. I interviewed Meredith using a semistructured format. I received Meredith's informed consent at the beginning of our interview as per university ethics guidelines. Our interview was face-to-face and audio- 
recorded. My initial questions were based on Anna's narrative of her visits to the MTC. Subsequent questions arose from Meredith's comments.

\section{Data Analysis}

"Analysis is a matter of giving meaning to first impressions as well as to final compilations" (Stake, 1995, p. 71). Data collection and data analysis in this case study happened simultaneously. Each interview was transcribed using Express Scribe software. I began my analysis with line-by-line coding of Anna's first interviews and emailed responses. Charmaz (2006) explains that line-by-coding allows researchers to take a critical and analytic view of their data. Although Charmaz's (2006) work focuses on grounded theory, using short codes that reflected the action I interpreted from Anna's narrative improved my understanding of her actions and her views (see Appendix $\mathrm{H}$ for an example of my line-by-line coding). The advantage of line-by-line coding is that it allows for both the development of themes and the identification of gaps within the data (Charmaz, 2006). Since I coded each interview or emailed responses soon after collecting them, I was able to identify which data I needed to collect next in order to saturate my themes and fill gaps. This applied not only to data from Anna, but also generated the questions I asked Meredith. Meredith and Ruby's interviews and Zoe's questionnaire were coded through the lens of Anna's experiences. My analysis generated three major themes as representing stepping stones and roadblocks to Anna's success. 


\section{Summary}

This chapter described the case study research methods employed in this study and linked them with the relevant supporting literature (see Creswell, 1998; Merriam, 1998; 2009; Stake, 1994; 1995; Duff, 2008; Flick, 2009; Patton, 2002). The participants were described and the data collection procedures were outlined. Finally, an explanation of the data analysis, which was informed by grounded theory coding methods (see Charmaz, 2006), was provided.

Chapter 6 presents the case study results and discussion in addressing the three research questions which guided the research:

1) How well did the diagnostic tasks work for a first-year engineering student?

2) What role did the diagnostic assessment play in one student's academic acculturation into engineering?

3) How well do the supports offered on campus address the diagnosed needs of a first-year engineering student? 


\section{Chapter 6: Results and Discussion}

While the previous chapter outlined the research methods used in this case study, this chapter provides the results of the three research questions guiding this thesis. The chapter begins by introducing Anna, the subject of this case study on the role of diagnostic assessment in academic acculturation. Then, the results for each research question are provided in the form of Anna's narrative, my observations, and comments from peer mentors and academic support staff. Finally, the results are considered in relation to the theoretical framework and research literature which informed the study (see Chapters 2 and 3).

\section{Anna as a Case of Academic Acculturation}

At 18, Anna is the first member of her immediate family to attend university. She moved to Canada with her family 6 years ago. Anna's spoken and written English reflect that she completed her junior high and high school studies in English. However, her first language is Arabic. Anna is a "covert bilingual" (Taffe \& Pringle, as cited in Fairbairn \& Fox, 2009, p.11) who met the language residency requirements for admission to university (see Fox, 2005).

The first time I met Anna she was sitting in the SAFE Drop-In Centre eagerly asking an engineering peer mentor questions about a lab report that she had to hand in soon. I listened to their conversation and took notes as she shared her frustrations about her core engineering course. When the engineering peer mentor left at the end of her shift, I took the opportunity to discuss Anna's linguistic diagnostic profile with her. 
Anna's self-awareness came across as she openly discussed her beliefs about her weaknesses and asked about various student support services.

Anna later described herself as shy, but her actions never seemed to quite match her description. While always very polite, Anna was never soft-spoken. Further, she never hesitated approaching her professors and teaching assistants to ask questions. One afternoon I ran into her in a common area at the university. She was sitting with a group of 5 friends, laughing and actively participating in their conversation. Although her vibrant personality was sometimes masked by her studious expression, neatly pulled back long dark hair, and glasses, Anna often laughed and joked as she reflected on her experiences as she acculturated into engineering. She also described herself as hardworking and commented that she liked to be around people who were ambitious and motivated. This was made evident through both comments others had made to her and her strong work ethic that she maintained throughout her first year.

Anna viewed university as a place to get an education that will lead to future employment. As a student who enjoyed math and solving problems, she chose environmental engineering as a major that would allow her to combine math and science. While she had no previous engineering work experience, her parents and several members of her extended family were engineers. Anna explained that many members of her cultural community and her high school also study engineering. While attending cultural social events, she began to recognize many people that she had seen in the engineering buildings on campus and vice versa. Very quickly, Anna began to take advantage of this potential resource for help with her assignments: "I don't really know them. But, I see them around and when I recognize them I'll ask if they are in 
engineering and then ask them for help." However, Anna soon recognized that she needed support beyond that which she found from the people around her.

\section{Q1. How well did the diagnostic tasks work for a first-year engineering student? \\ On EngFrosh academic orientation day, Anna reported that she did not feel any apprehension about taking an assessment:}

I didn't feel like I was stressed or anything because I was told it's not for marks, it's just an assessment $[\ldots]$ a lot of other people got scared [...] and I said it doesn't count for anything, it's an assessment, so if you need help they'll give you help.

On the diagnostic tasks, Anna scored $23 / 27$ on vocabulary, but only $26 / 73$ on reading for an overall DELNA score of $49 / 100$. Anna received an $M$, or $3 / 5$, for her writing sample which indicated that she could potentially benefit from writing support (see Chapter 4 for a description of the rating scale). She had the engineering-related graph for the writing task. Despite providing only a very brief writing sample (approximately 100 words), she did attempt to address all 3 questions asked about the graph and to organize the information in a logical way. There were no major errors in terms of grammar and general vocabulary in her paragraph. However, her interpretation of the relationship between variables in the graph was incorrect, poorly explained, and lacked the appropriate mathematical vocabulary. At the bottom of the writing task page, Anna left a note for the markers explaining the difficulties she had with the task: 
I have difficulty writing labs \& understanding graphs. The graph here is not clear to me because I can't picture what is going on.

Anna answered the questions in fractions, algebra, and trigonometry correctly although she did need to further reduce the fractions. She attempted the calculus question, but made an error. She scored a $4 / 5$, but was rated as Low in math by the engineering peer mentors because of her problems with graph interpretation and explanation. These issues were listed after her math score in the email with her SAFE results.

\section{Table 8}

Anna's SAFE results compared with her cohort and the at-risk thresholds

\begin{tabular}{|l|c|c|c|}
\hline & Anna's scores & SAFE Cohort Mean & At-Risk Threshold \\
\hline Vocabulary & 23 & 24.43 & $<22$ \\
\hline Reading & 26 & 46.95 & $<29$ \\
\hline Linguistic Total & 49 & 71.38 & $<53$ \\
\hline Writing & 3 & 3.0736 & $<1.82$ \\
\hline Math & 4 & 3.8681 & $<2.89$ \\
\hline
\end{tabular}

Compared with her cohort, Anna scored below the mean on all of the diagnostic tasks except for math (see Table 8 above; see also Chapter 4 for the SAFE cohort descriptive statistics and thresholds). She also fell below the at-risk threshold for two categories: reading and overall linguistic total. However, since the overall linguistic 
scores were cross-referenced with the writing scores, Anna was not highlighted as a student who potentially needed an immediate language intervention.

Although Anna showed openness to receiving support and acknowledged a need for writing support, she did not come to the SAFE drop-in centre until she had gotten back her first lab report:

After I saw my marks [SAFE results], I was like, what is this, I don't know English [laughs]. I knew after I wrote that lab that coming into university I needed help with writing... that's why I came there [SAFE drop-in centre]... I saw my marks and I was like yeah I should go get help.

\section{Q2. What role did the diagnostic assessment play in one student's academic acculturation into engineering?}

Her first form of assessment at university was Anna's motivation for seeking help during her acculturation to university life. Unhappy with her first grade, a six out of ten on an ECOR 1010 lab report, and confused about what to do for her second lab report, she sought help at the SAFE drop-in centre. Although Anna was initially looking for help with how to complete her second lab report, she discussed her SAFE results with me and learned about the Writing Tutorial Service (WTS). She then spent close to an hour discussing the questions for her second lab report with an engineering peer mentor.

The first time I interviewed Anna she spoke openly about her frustration with her lab reports for ECOR 1010. Introduction to Engineering (ECOR 1010) is a required first year course with four lecture hours and two lab hours per week. The course provides 
students with an overview of society, technology, and the environment and introduces them to methods for graphic design, data management, design analysis, and data reporting. Lab questions are posted before the lab period begins. Students can work individually or in groups and two teaching assistants (one graduate student who is responsible for marking and one undergraduate student who assists with questions during the lab period) are present to field questions.

For her first lab, Anna spent two days trying to find the free downloadable program that was required for the lab. When she couldn't find it herself, she emailed her TA, but did not get a response until 3 days later. Although she had gotten the program from a classmate in the meantime, she was frustrated because she did not understand what she was supposed to do for the lab or what was expected for the written lab report. In an attempt to manoeuver through the support available, since she had problems emailing her first TA, she emailed her next questions to the undergraduate TA. In spite of all the time and effort she invested, she only got 6 out of 10 points on her lab report. Moreover, she received her first lab back the same day she was required to hand in her second lab:

I didn't know what he was looking for in the write up, so I lost marks [...] I had to hand in my second lab today and I did the same mistakes on it because I didn't know, I only got the feedback today [...] so I screw up two labs before I get to fix the things I did wrong. 
Although not shy to ask for help, Anna found it frustrating to ask her ECOR 1010 TA for help because she felt she was being perceived as simply whining for the 'right' answers or for extra marks on her labs instead of trying to develop as an independent learner:

I'm asking, you know, am I doing it the right way, can you make it clarified? [the TA answers] 'I can't tell you the answer.' I'm not asking you the answer, I don't want you to tell me the answer, I want to figure it out myself [...] I just don't wanna like beg for marks.

Anna was often able to recognize if a university process could be made more efficient even though she was still struggling to manage her own time more effectively. After only two lab sessions, she remarked that the labs would possibly be easier to manage if they were posted sooner. That way, she could attempt the entire lab on her own first and then go to the lab with her questions prepared. Anna recognized that lab time was crucial, but she had not yet developed an effective strategy for working on the reports once the lab period ended:

It's hard and you're on your own after those 3 hours.

It was at this stage that Anna appeared at the SAFE Drop-In Centre for help. Communication with her ECOR 1010 TA did not improve over the semester and she was becoming increasingly frustrated with her results: 
I emailed my TA, but I only got a 4 word answer [...] I don't want to do all of this work and only get like $60 \%$ !

Lectures, course materials, and tests for ECOR 1010 also did not meet Anna's expectations of what a university course would be like. In terms of class notes, although the professor posted the lectures prior to class, they were in a format that did not allow students to type in their own comments. When Anna approached her professor about changing the format of his slides, he explained that for copyright reasons, they had to be posted in a format that did not allow students to add content to the files. Although she found it extremely difficult to organize her notes, Anna was unwilling to print the lecture slides and actually handwrite notes. During her second visit to the SAFE Drop-In Centre, an engineering peer mentor twice strongly recommended that Anna refer more to the course textbook for help. Both times, Anna dismissed the suggestion and said she would only read the slides. Anna's SAFE reading score was only 26 out of 73 points and this did fall under the reading at-risk threshold of 29. Anna said that she was a slow reader and did not like to read. I tried to go over the reading for engineering tip sheet with her, but after less than 2 minutes, she turned her attention back to her lab report.

In terms of her ECOR 1010 exams, Anna seriously questioned the material that they were expected to know for the test. She felt that it was unreasonable and unnecessary to memorize data like gas emission percentages, statistical formulas, etc... when they could easily be found in reference materials: 
The things that we have to memories [memorize] don't benefit us at all and won't help us benefit society. [...] Why do I need to memories these kind of data [...] which in real life you won't ever be asked to remember?

Although many of Anna's frustrations came from her introductory engineering course, preparing for all of her midterms was challenging for her. When asked about how she was studying for her midterm exams, she reflected back on how much easier it was to prepare for high school exams. She missed the familiarity not only of the high school exam system, but also the close connections she had with her teachers:

That's the thing, in high school, I knew my teachers, so I knew what to focus on. Here, I don't know, so I'm going in all directions.

When Anna first came to the drop-in centre, I told her about the Writing Tutorial Service (WTS) and how they may be able to help her with her writing. Later, in my first interview with Anna, she explained how she had followed my suggestion of visiting the WTS for writing help with her second ECOR 1010 lab report. Her evaluation of her experience made clear that she was able to differentiate between effective and noneffective feedback on her work:

She helped me see my mistakes [...] it's not like when sometimes somebody helps you and $[\ldots]$ they say it in their own words instead of yours $[\ldots]$ she helped me think about the words I wanna say, you know, or say it in another way. 
Anna had already visited the Math Tutorial Centre (MTC) once before she first visited the SAFE Drop-In Centre. She found it useful. By mid-October her opinion of its effectiveness had changed. At the MTC, TAs are seated at the front of the room and students are expected to approach them with their questions. On Anna's second visit, the centre was quite busy and Anna was unsure of how to ask her question:

I don't really know how it works, so I felt really awkward. I was there and I wanted to ask, but people who came after me got up and asked their questions. [...] I realized I was never gonna get to ask my question so I left. I don't know why I can't write my name and get called when it's my turn. I wouldn't go there and watch them do a question that I don't need. I was there for like 30 minutes.

Developing time management skills also played a role in her unhappiness with her second MTC visit. Consequently, she questioned the value of sitting through other students questions when the students were in different math courses. After that negative experience, Anna only used the MTC as a meeting place for appointments with her linear algebra TA.

When I met with Anna in early November, she appeared tired and told me that she was starting to feel very unhealthy. She also complained that she did not have time to eat properly anymore. She had purchased vitamin D tablets and took her first dose during our meeting to go over her chemistry lab. In an email that same week, she recognized that she needed to use her time more effectively so that her effort matches her results: 
The results I get back are not reflective of the effort that I put in. I seem to be spending more time on labs than other students and I get the same marks. [...] I feel like I over exhaust myself. [...] I need to be faster at finding the solutions for questions I don't understand as well as knowing where to look and how to look properly.

This answer indicates that although Anna had always seemed keen to seek help from as many sources as possible as soon as she ran into trouble, she was still not manoeuvering the various supports as efficiently as she would like. She also acknowledged that she may still have been relying too heavily on others for help instead of beginning to look for the answers herself:

I realize that as I move up in university I will have to do that [find answers herself] more often as well as in real life. I can't always rely on someone to give me the answer.

By the end of November, Anna seemed better able to manage her time and focus her attention appropriately. She was also beginning to use her textbooks. Anna still avoided reading, but began to understand how to use her textbooks effectively. Instead of reading every chapter word for word, she started skimming and would use her books to refer to concepts or ideas that the professor discussed in class but were still unclear. She used her success on her second chemistry midterm to explain: 
I recognized that I don't need to read everything in the book and that way I was able to focus more on the slides and study harder rather than waste time reading (since $[I]$ am a slow reader).

Anna's apprehension about speaking up over what she felt was unfair marking also lessened over the semester. When she received $74 \%$ on a chemistry lab, she took all of her papers and went to her TA to discuss why she had lost points. Anna successfully demonstrated that she had in fact carefully followed the instructions she had been given:

She [the chemistry TA] took off half a point because I described it as fluffy. She wants us to say that there were clumps. I'm like, you can't deduct marks for what I saw. What I saw is what I saw. It's not what I should have seen. It's what I saw. You can't take off marks for that. [...] You were looking for words that don't describe what I saw. How am I supposed to know what you're looking for? [...] It [the mark] got pushed up to an 82 which helped a lot.

Once her final exams were over, Anna reflected on her finals, her first semester of university, and her first semester in engineering. Even though Anna felt she had studied effectively and had prepared as best she could, she questioned the value of learning new material right until the last class. Anna received As in four courses, but only a B-in ECOR 1010. With a GPA of 10.4 , she was able to keep her scholarship. She was happy with her overall results and pleased with her work ethic: 
My [high school] teacher told me that I would do well in uni because I am a hard worker. I never realized it until I saw my friends who did better than me in high school get lower marks than me at uni because they studied last minute.

And, despite her frustrations with her required engineering course, Anna felt she has chosen the right field. Seminars focusing on the different program and career streams for environmental engineering encouraged Anna that she would find future work in the field that she will enjoy. All she felt was left was building more social connections at university:

I am just trying to adjust to the social part of uni since I think I got the studying part figured out by now. [...] I didn't have any social friends or anything until the end of last [the first] semester.

Anna began her second semester satisfied with her university experience and her newfound friends. However, she appeared a bit daunted by her course selection. She registered for mechanics, chemistry, calculus, physics and technical writing. Physics seemed especially challenging and Anna considered dropping it or even retaking it in the summer if she was not happy with her grade. After 3 weeks of class, she had decided to stay in physics, but recognized that she needed to start visiting the physics help centre regularly. When asked if she would consider visiting the MTC again this semester if she needed help, Anna said no and explained that she would be fine just reading the textbook 
and studying on her own. Although she thought physics was a difficult course, Anna was most unhappy with her technical writing course.

Communication Skills for Engineering Students (CCDP 2100) aims to help students develop their written and oral communication competence in engineering. CCDP 2100 focuses primarily on professional written documents such as engineering proposals and reports (for an example of the potential contribution of this professional writing course to an engineer's career, see Artemeva, 2005). Anna explained that the major course project was a group proposal for a system or machine that would benefit people in third world countries. Anna's group designed a water purification system for use in the Philippines and had submitted their statement of intent. Anna knew that her group would eventually submit their proposal to an actual engineering firm and that their proposal could be accepted for real-world use. However, she did not like the class and doubted its usefulness and relevance to her academic study and future career:

[The instructor said] I need to explain that [evaporation] to a non-technical person. [...] Like she wants us to do, kinda crazy, you know, like I don't think my boss is going to be that stupid.

Even though she seemed unclear on the expectations she had to meet, Anna doubted she would have time to visit the WTS again. She also felt that the only reason she needed to meet with the instructor to go over her drafts was because the instructor was so demanding - not because it would help her improve her writing: 
Every week we have an assignment due and every week I have to meet with her and I have to meet with my group. It's so annoying. [...] She [the instructor] meets with 3 of us... like, it's the people who want to, like she really encourages us, because she's really picky. She's like the faster I mark it, the higher your mark will be. If I sit there for 10 minutes trying to read your paper which is like paragraph, you're not getting a good mark. Because she's so picky.

By the end of February, Anna became too busy to participate in further interviews or respond to emailed questions. When she saw me on campus at the beginning of March, she approached me and apologized for not having any extra time. At that point, when she was not doing course work, she was busy applying for summer jobs in the engineering field.

\section{Q3. How well do the supports offered on campus address the diagnosed needs of a}

\section{first-year engineering student?}

Sometimes simply finding the location of the support service or office a student is looking for can be challenging. Anna herself experienced this frustration while looking for some services on campus:

You go through like 4 or 5 people to get to where you need to go to ask the question [...] I got like so mad, like what the hell is going on on campus. Nobody knows anything! 
Anna's motivation certainly pushed her to keep looking for the help she needed. She visited the SAFE drop-in centre once she realized that she needed help. Anna stayed in the centre not only to discuss her results, but also to ask questions about her ECOR 1010 lab report. Then, when she had her negative experience at the MTC, she immediately turned to the SAFE centre's peer mentors again for help and advice. Because the centre was run as a drop-in centre and there were always engineering peer mentors available, Anna was able to get the help she needed when she needed it the most. Further, participating in my study gave her access to another support that she could contact throughout the year.

Ruby and Zoe did not meet with Anna when she came to the drop-in centre, but they did work with several other students. Their experiences suggest that students who came that seemed motivated to improve and possibly agreed with their diagnoses were most open to discussing their options. Zoe commented that some students only wanted to see their mistakes and not discuss any support options. Ruby had a student leave before she could encourage him to consider the different ways he could improve his academic skills:

He told me he just wanted to know how many mistakes he made or what his grade was like. I was going to explain more to him [...] he stopped me $[\ldots]$ and he left the centre.

Even though Anna did not experience any anxiety when taking the assessment, she agreed with her results, and she thought she needed help with her writing, she still 
waited to come to the drop-in centre. Ruby suggested that many first-year students may go through a similar experience:

They are flooded actually by the amount of information they receive. [...] they don't want to do something extra, they're already overloaded by assignments.

Anna followed through on most of the advice that she received from the peer mentors. I introduced her to the WTS and the tutor referral service. Although she eventually decided against getting a tutor, she did visit the WTS with one of her lab reports. Overall, Anna was pleased with the help she got from the WTS even though the TA was not familiar with science writing. However, she only visited the WTS once in the first semester and her full schedule in the second semester prevented her from visiting again with her CCDP 2100 assignments.

It is unclear if Anna's experience at the Math Tutorial Centre is truly representative of the majority of visits to the centre. As Meredith explained, the difficulty Anna had asking her question may have been due to management style and TA training:

There are several different ways to run a help centre. [...] A TA who is used to one-on-one tutoring may not know what to do when suddenly there are 15 students in the room waiting for help. 
In terms of which math courses were given priority at the MTC, Meredith wondered if it all came down to funding:

Math is a service department. So, if the departments they are serving, such as the business department, are giving funding for the help centre, that will determine which courses are given priority and how the help is delivered.

\section{Linking Anna's Experiences to Theory}

Contrary to Read and Alderson's ideas that diagnostic testing is low stakes, Fox argues that once an intervention takes place based on a test's scores, it is no longer low stakes. The success of the intervention is what will lower the stakes involved with a diagnostic assessment (J. D. Fox, personal communication, October 13, 2011). Davies and Elder (2005) posited that students would benefit from their DELNA diagnosis. For this study, the benefit to Anna will be discussed below in regards to the suitability of the diagnostic tasks, the role SAFE played in her academic acculturation, and her experiences with various campus support services. I will also consider how meaningful the information from SAFE is now that Anna has completed her first year of university study.

The accuracy of Anna's SAFE diagnosis. Alderson $(2005 ; 2007)$ posited that diagnostic tests should be low or no-stakes. Subsequently, they "involve little anxiety or other affective barriers to optimum performance" (Alderson, 2005, p.11). Since DELNA is intended to be taken after university admission has been granted, $\operatorname{Read}(2008)$ also 
argues that it is low-stakes. These concepts seemed to hold true for Anna as she reportedly felt no anxiety while taking the assessment. Although she struggled with the reading and writing sections and heard other students expressing concern when they left the room, Anna was confident that she would receive help if her assessment indicated that she needed it. She seized her first opportunity, or kairotic moment, to interact with her discipline (Artemeva, 2005).

Davies and Elder (2005) hypothesized that the DELNA writing tasks were representative of post-secondary language demands and thus would be accepted by different disciplines (see also Read, 2008). However, because the graphs are based on social trends, Fox (personal communication, June 20, 2011) chose instead to try a graph typical of first-year Engineering course materials. Both graphs tasks could be used to assess a student's graph interpretation skills and mathematical vocabulary, but the engineering-specific task required students to explain and discuss the relationship between two variables that are common in engineering. This potentially went further to identify students' difficulties with graph interpretation and math-based writing than a graph of a common social trend.

Discipline specificity has been identified as important in student support initiatives (Peach, 2005; Bernold et al., 2007, Tinto, 2002a; 2002b; Nelson et al, 2012). Modifying the graph task, along with including questions on fractions, algebra, geometry and calculus, permitted Anna to complete an assessment that was specific to her discipline. Since Anna had the engineering-specific graph, it is possible that this helped to highlight her own difficulties with graph interpretation which she herself recognized in the note that she wrote on her SAFE booklet. Still, even though Anna indicated that she 
could not picture the relationship shown in the graph, she attempted to organize and clearly explain her ideas for the SAFE writing task. Her brief writing sample addressed all 3 questions asked and contained no major grammatical errors or general vocabulary problems. Her response was organized in a logical way despite being poorly explained and lacking appropriate mathematical vocabulary.

The engineering department renamed the DELNA as Self-Assessment for Engineers (SAFE) simply for marketing purposes. So, SAFE was not an actual selfassessment and did not contain "I can" statements like the DIALANG (see Alderson, 2005). However, Anna was still able to use SAFE to self-assess her own writing and graph interpretation abilities. Once her first lab report grade confirmed both her perception of her writing abilities and her SAFE results, she again utilized a kairotic moment and sought help at the drop-in centre (Artemeva, 2005). This increase in selfawareness and autonomy as a result of self-assessment is what Alderson (2005) described "as the heart of the DIALANG philosophy" (p. 118).

Detailed and early feedback is characteristic of diagnostic assessment (see Alderson, 2005; Read, 2008). Diagnostic tests should focus more on weaknesses and producing feedback which test takers can actually put to use (Alderson, 2005). Anna received an email with her SAFE vocabulary and reading results immediately after completing the assessment. Then, a week later she received a second, personal email with her SAFE profile which provided her scores and highlighted her weaknesses in math. There was also an invitation to discuss her results at the drop-in centre. The opportunity for a face-to-face meeting to discuss the diagnosis was found to be more effective in ensuring that students take advantage of the support services available to 
them (Bright \& von Randow as cited in Read, 2008). Once at the drop-in centre, peer mentors were able to review each of Anna's assessment tasks with her and make feasible support suggestions based on her specific needs. Additionally, Anna took advantage of her visit to ask questions about the services and her lab report (Artemeva, 2005).

As suggested by Elder and von Randow (2008), Anna's vocabulary and reading scores clearly set her apart as a non-native English speaker. Scoring just above the at-risk threshold for vocabulary but well below the at-risk threshold for reading indicated that she may struggle with academic literacy. Although her first semester GPA was high enough to keep her scholarship, Anna's unwillingness to read her ECOR 1010 textbook possibly contributed to her lower grade in that course. She eventually learned how to use her textbooks more efficiently, but she seemed to apply this only to her chemistry course. Despite being given suggestions on reading at the drop-in centre, Anna chose to ignore them and consequently missed a kairotic opportunity (Artemeva, 2005). This appears to have been somewhat to her detriment. It does, however, stay consistent with Read's (2008) argument that DELNA and the subsequently offered supports remain optional to students (see also Alderson, 2005). Ruby and Zoe both reported meeting with students whose only interest was the mistakes they had made on the assessment. They perhaps did not agree with their results and thus were not interested in learning about any support services. When Anna was offered the advice, she did not feel it met with her needs. It may have also mismatched with her BAK (see Woods, 2006). She later learned by herself how to use her textbooks once she realized that doing so would enable her to find answers to her questions more quickly and independently. This increased her autonomy and improved her time management skills (Hussey \& Smith, 2010). 


\section{SAFE's contribution to Anna's academic acculturation. The process of} acculturation considers what students observe, what they decide to take in, and what they understand about their classroom experiences. Anna's academic acculturation into engineering was heavily influenced by:

- her background knowledge;

- her learning to use her time more effectively; and

- her ability to access and manoeuver the supports available to her as a first year engineering student (see Figure 4 on page 109).

These three dynamic elements greatly contributed to or blocked her learning potential and were each in turn influenced by her SAFE experience.

Background knowledge. Anna's cultural capital and her habitus (Bourdieu, $1977 ; 1990)$ greatly contributed to the beginning of her acculturation to post-secondary education. Even though Anna was the first member of her family to attend university, she had several family members, friends and community members who are engineers thus providing her with some "social capital" (Foor et al, 2007) to help her begin to navigate through her program (see also Artemeva, 2005). This capital also helped Anna to identify at least slightly with the engineering profession (Pierakkos et al., 2009). The environmental engineering seminars, similar to the symposiums and professional talks that Scott (2009) reported as part of a successful engineering learning community initiative, helped expand on her cultural capital and reinforced that she had chosen the right field of study (see also Watson et al., 2010). Anna's first semester of study matched 
her expectations of what she thought university would be. She knew that she would have to work hard and would have to become a more autonomous learner. The match between her expectations and her actual experience pushed her to integrate socially and academically (see Braxton et al., 1995; Thomas, 2002; Walker et al., 2009; Pierakkos et al., 2009; Woods, 2006).

From the beginning of the semester, Anna worked hard to engage with her studies and with her peers (see Tinto, 2009, 2002b; Nora, 2004; Mayo et al., 2004; Scanlon et al., 2007; Lawrence, 2005). Anna sought out support services both pre-emptively and as soon as she realized she did in fact need help. She attended all of her lectures and labs. When she realized that the first friends she made at university did not have a work ethic similar to her own, she began spending all of her time in the library and reported that she did not really have any social friends in engineering until the end of her first semester. Anna felt that the friends she made in engineering were more in tune with her own academic habits and goals. In other words, Anna was seeking a social network that shared a habitus, or BAK, similar to her own (Bourdieu, 1990; Woods, 2006).

Scanlon et al. (2007) reported that relying on learning experience from high school often made the transition to post-secondary education more difficult for students. Anna also often struggled to readjust her learning habits. She reported missing the familiarity of high school, both her close relationships with her teachers and her knowledge of the academic expectations she had to meet. This was particularly true once her midterms began as Anna reported feeling quite unsure about how to prepare for the exams and what material to cover. Her sense of loss soon began to diminish as Anna 
exhibited and developed many of the dynamic success practices outlined by Lawrence (2005).

Her socio-cultural competencies developed as she sought assistance with her work, began discussing her marks with her teaching assistants, and refused interview requests when she did not have time to meet. She also slowly reconstructed her social network. Anna struggled with unclear expectations in her first term as her critical practice, of both self and discourse, developed. She often felt she was guessing at how to format and write her ECOR 1010 labs. When she asked her ECOR 1010 TA for help, she felt she was being perceived as whining for answers and marks. She expressed her frustration to her chemistry TA when she lost marks simply for using different vocabulary than the TA was looking for in a lab report. Anna could differentiate between effective and ineffective feedback on her work. She also noted when a university practice could be run more efficiently. Lastly, Anna began to notice and reflect on her approach to her university course work. She disliked reading, scored low on her SAFE reading tasks, but ignored suggestions from peer mentors about reading in engineering. However, in her third month of study Anna adapted her reading practices to study more effectively for her chemistry course as her reflective competency increased.

Anna's academic success in spite of her low reading, vocabulary and writing SAFE results seem to align with Graham's (1987) idea of a minimum English proficiency level a student needs to be successful. Once a student has reached this proficiency, their motivation or their ability in math, etc... can have a greater influence on their chances of academic success. Anna was an incredibly motivated student. She visited the MTC early in the semester. She came to the SAFE Drop-In Centre twice and she agreed to 
participate in this study. She followed up on most of the suggestions that her peer mentors gave her. And, even when she struggled, Anna still attended every lecture and studied every day on her own in the library. Despite her problems interpreting a graph and writing about it, her results on the diagnostic math tasks and her first term grades in linear algebra and calculus demonstrate her mathematical competence. Although she still needs writing support and reading practice, Anna clearly has sufficient English proficiency to do well in her courses, build social connections and seek help when she needs it (see also Cheng \& Fox, 2008; Evans \& Morrison, 2011).

Using time effectively. Anna's BAK led her to focus on her work and get help instead of procrastinating about doing her assignments (Woods, 2006; Pychyl et al., 2000). Although she did not procrastinate, learning to use her time effectively did play a role in Anna's academic acculturation through both being able to study and answer questions on her own more efficiently and creating/seizing kairotic moments when she needed to (Artemeva, 2005).

In some cases, having enough time to go for help is a deciding factor in whether engineering students seek help or not (Bernold et al., 2007; see also Davies \& Elder, 2005). In the first term, because Anna did not have courses or labs Wednesday afternoons, she could visit the SAFE drop-in centre. However, Anna's schedule did not match with the management style used at the MTC. With lectures every morning and labs most afternoons, she did not have time to listen to math questions that were not relevant and could not spend time waiting for her turn if the centre was busy. Even though Anna greatly appreciated the help she received from the WTS, she doubted she 
would have time for subsequent appointments in the second term. Anna felt she had too much to do already with her 5 courses and group meetings with her CCDP 2100 instructor to take any of her proposal drafts to the WTS.

Learning to use time effectively also played a role in Anna's reading at university. She described herself as a slow reader who avoided using her course textbooks and yet she dismissed reading advice from the peer mentors. Eventually though she had to turn to her chemistry textbook for help. Knowing that she did not have time to read the whole chapter, she chose to skim only sections explaining concepts from her lectures that were still unclear. This resulted not only in improved academic reading skills, but also in an increase in learner autonomy, more efficient study practices, and a developing sense of reflective competency (Lawrence, 2005; Hussey \& Smith, 2010).

At the beginning of the year, Anna often spent several days trying to find the answers to her questions. She became increasingly frustrated with this, especially in regards to emailed responses from her TAs, but several times she acknowledged that she needed to be faster at finding the answers on her own. This, of course, related back to both her background knowledge and her ability to effectively manoeuvre the supports available to her.

Manoeuvering through support. As her BAK was characterized by the motivation to succeed, Anna constantly searched for avenues of effective support (Woods, 2006). Anna worked hard to engage in her classes and with her professors and teaching assistants. She was not usually shy to ask for help and she visited the support 
services offered to her when she needed them. However, her efforts were not always successful.

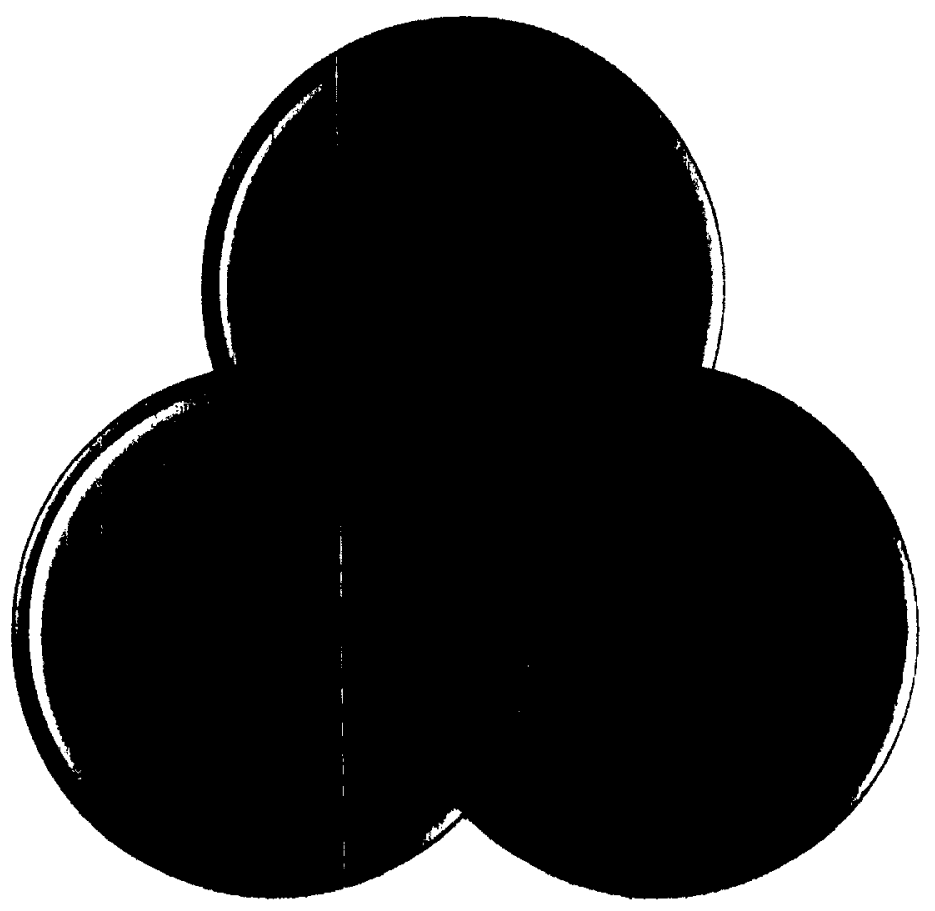

Figure 4. Elements contributing to and/or blocking Anna's learning potential during her academic acculturation

Pierakkos et al. (2009) found that building an engineering social network contributed to students' decisions to stay in engineering (see also Tsang et al., 2009). In her first weeks of engineering, Anna frequently looked for members of her cultural community and students from her high school that might be able to help her. When she needed help, she would often ask around until she found an upper year student who could explain concepts or review her work. This got her the help she needed and it increased her social network in engineering. By the beginning of her second semester, Anna reported having a group of fellow engineering students as friends. 
Even Anna's unsuccessful attempts to manoeuvre through the supports available were an indication of her developing dynamic success practices (see Lawrence, 2005). Anna tried on numerous occasions to seek help and feedback from her ECOR 1010 head TA. However, in lab periods she sometimes felt as though she was being perceived as whining. She often received emailed replies several days after emailing questions. So, in an effort to get help, she went to the TA assistant instead. Although she effectively manoeuvered through her options, the assistant TA was not involved in marking, and thus was not always able to provide effective help. Communicating effectively with her TAs was a skill that Anna developed throughout her first term. Despite often being unsuccessful with her ECOR $1010 \mathrm{TA}$, she still approached her chemistry TA when she felt she had been unfairly docked marks. After several weeks of lectures in which she had problems keeping her notes organized, Anna approached the professor to request receiving the lecture slides in a different format. The professor declined, but nonetheless Anna was still able to convey to him the problem she was having with the course.

Ruby reported that first-year students may feel overwhelmed by the amount of information they receive at the beginning of the semester and the amount of work they have to do. Further, Read (2008) contends that a diagnosis and any offered support should not be punitive. Anna chose when to come to the SAFE drop-in centre. She did not come as soon as she got her diagnosis, but rather when she received a low mark on her first lab report. She knew then that she needed help right away and referred back to her email for the location of the drop-in centre. Her first experience at the centre was positive enough that she chose to return as soon as she did not get the help she was looking for at the MTC. Anna's motivation to succeed pushed her to move on from an 
unhelpful support experience and seek another option, thus creating kairotic moments whenever possible (Artemeva, 2005; see also Woods, 2006).

Addressing Anna's SAFE diagnosis. The SAFE Drop-In Centre was opened so that students could have the face-to-face meeting to discuss their results that Read (2008) highlighted as key for a successful intervention. Often the battle for first-year students is actually locating the support offices and other services on campus. As a Learning Support Services staff member explained during a TA training session:

We don't want our students bounced around campus to get the help they need. Students come to us who have already been to three different places and you can see it. This is their last stop - they won't go anywhere else.

Anna did sometimes have problems finding the services she was looking for, but that was not the case with the SAFE Drop-In Centre. Anna said that once she decided to come to the centre, she referred to the email that she had received with her SAFE results. She also remembered a professor mentioning the centre at least once in class. Moreover, the centre was located in her faculty's building. Although Anna certainly had classes in multiple buildings on campus, having the SAFE Drop-In Centre in the engineering building further emphasized SAFE as a discipline-specific support initiative and potentially increased her sense of connection with her faculty. It also contributed to Anna's familiarity with the engineering building. 
Since Anna's beliefs about her reading and writing skills seemed to match with her SAFE results, she was ready to find help once she got back an unsatisfactory grade. Thus, when she came to the centre, Anna was very open to discussing her weaknesses and learning about the support options that were available to her. She felt the advice and help she received at the centre was so valuable that she visited the centre twice. When the MTC failed to meet her needs, she returned to the drop-in centre for help with her lab report. While only open two days a week, the centre was open from $1 \mathrm{pm}$ to $7 \mathrm{pm}$ and was thus available to students after their labs had ended. Further, the centre remained open for 5 weeks providing the opportunity for students to seek help once they began to receive feedback on course work and marks on labs and midterm exams.

The Writing Tutorial Service (WTS) was another positive support experience for Anna. She appreciated the help she received with her lab report and felt it improved her overall writing on that assignment. Unfortunately though, there are still no engineering TAs working in the WTS. Even if Anna had time in the second semester to take one of her CCDP 2100 assignments to the WTS, the TAs that were would likely have been unable to offer the discourse savvy needed for an engineering proposal or report. Anna was skeptical that her CCDP course would help with her writing. She did not feel that small group meetings with her instructor to go over her drafts could potentially lead to a better-written piece aimed at the appropriate audience. Hearing that information again in a one-on-one appointment with an upper year engineering student may have enabled Anna to better understand engineering discourse and improve her writing skills.

During the planning stages, the WTS coordinator requested engineering TAs for the centre. The associate dean sent out emails to engineering graduate students and 
supervisors, but unfortunately, no one was willing to devote part of their TA hours to working in the WTS. Writing in engineering is greatly undervalued, especially when compared to graduate research projects (Galloway, 2008).

The Math Tutorial Centre (MTC) lost Anna as a client. As a service department, they need to meet the needs of their clients. This may, as Meredith suggested, all come down to management styles and TA training. Meredith suggested that a sign-in sheet is certainly a simple way to make sure everyone's time is used more efficiently and would still allow TAs to serve multiple students at once who need help with the same concepts. Anna herself said that a sign-in sheet would be a more valuable use of her time than waiting for the right moment to dash up to a TA when multiple students were waiting.

The Relevance of Anna's Diagnosis. Six months after participating in SAFE, Anna was half way through her second semester of university study. She had built social connections, learned to successfully manoeuvre various supports, and made friends within her discipline. Equally as important, she was successful academically. Anna received As in first year chemistry, calculus, linear algebra, and computer programming. Her successes came not just from the match between her perceptions about what university would be like and her actual experiences, but also her math abilities, motivation, and determination to succeed.

Despite only scoring B- in her core engineering course, she scored an overall GPA of 10.4 and kept her scholarship. Her lower score in ECOR 1010 may be attributed not only to her weaknesses in academic reading and writing, but also her initial 
difficulties with time management and speaking with her TA. Anna also felt a disconnect between her expectations about her field and the course content.

Anna's SAFE results identified her as a student who may potentially benefit from some support in writing - she was not identified as potentially at risk. So, what relevance then does her diagnosis have if she appears to have successfully acculturated into postsecondary study in spite of her weaknesses in academic reading and writing? Even motivated, able, and successful students benefit from the information and support they receive from a diagnostic assessment. Anna will need to focus on her reading and writing abilities if she wants to continue to be successful in engineering. As she moves up in her program, she will need to write more lab reports and project proposals. Developing her writing skills is also essential for her future employment opportunities (see Artemeva, 2005; Galloway, 2008). Anna started university suspecting that she would need help with writing. This was confirmed by her lab report results. SAFE gave her further confirmation and somewhere to turn when she was ready to get help.

Her diagnosis also highlights the need for the Faculty to gather more extensive demographic information on their applicants. Without the SAFE questionnaire, Anna would never have been identified as a non-native English speaker since she completed high school in Canada. Furthermore, her need for writing support and her negative views of her engineering communications course strengthen the argument for discipline-specific writing support at the WTS.

It is entirely possible that Anna still would have been successful in her first year had she not taken SAFE. She is, after all, a motivated, persistent, and hard-working student. However, SAFE equipped her with the tools she needed to make her 
acculturation process smoother, less stressful, and possibly even more successful. The stakes involved with SAFE were lowered for Anna as the intervention she received contributed to her success.

\section{Summary}

Chapter 6 has introduced Anna as a case of academic acculturation informed by diagnostic assessment. Anna's SAFE experience and results, her successful and unsuccessful attempts to manoeuvre through the supports on campus, and comments from SAFE peer mentors and academic support staff were described. Then, the chapter discussed how well the diagnostic tasks matched with Anna's needs, the role SAFE played in her successful acculturation into engineering, and her experiences with various student support services. Finally, the implications of Anna's diagnosis were discussed in relation to her academic and social success.

The next chapter concludes this case study with a consideration of key findings, the limitations of my research design, potential future research directions, and a personal reflection on this research. 


\section{Chapter 7: Conclusion}

DELNA represented a recognition by the university that it shares with students a joint responsibility to address academic language needs (Read, 2008, p. 182).

Cheng and Fox (2008) defined academic acculturation as "the dynamic adaptation processes of linguistically and culturally diverse students engaging with the academic study cultures of Canadian English-medium universities" (p. 309). The following statistics emphasize the importance of assisting students in those processes:

- more than 180,000 international students were studying in Canadian secondary schools in 2008 (Long, 2012);

- by 2016, one fourth of the Canadian population will be youth either born in Canada to immigrant families or born outside the country (Rieti, 2012);

- international students now make up just over $10 \%$ of the undergraduate student body in Canada (AUCC, 2011);

- in the 2011-2012 academic year, the large Canadian university in this study reported 3,147 full-time undergraduate students, or $15 \%$ of the student body. whose native language was not English (OIRP, 2012b);

- $220(24.9 \%)$ of the 883 students who registered in first year engineering at the large Canadian university in this study in the Fall of 2011 were international students (OIRP, 2012e; 2012d); and

- the 489 students who took SAFE represented 32 different first languages, but only 69 international students. 
Chapter 7 concludes the present case study on the potential role of diagnostic assessment in academic acculturation with a summary of the study and the limitations of my research design. It presents the main findings in response to the research questions guiding this thesis. These findings will be viewed in relation to suggestions for the future implementation of SAFE, potential future research directions, and reflections on my own learning from this research.

\section{Summary of the Study}

This study set out to examine academic acculturation into university through the lens of diagnostic assessment. It considered literature on the first-year experience and the role that language proficiency may play in a successful academic acculturation. Further, campus-wide, embedded support initiatives which gave students the tools they needed to transition to university life and acculturate into their respective disciplines were introduced. The diagnostic testing literature focused on the benefits of diagnosing academic literacy skills for teachers and students alike. In particular, the university-wide support initiative DELNA was explained and identified as a useful tool in assisting potentially linguistically at-risk students. To explore the potential benefits of such an assessment in a Canadian context, I participated in a student support initiative in the Faculty of Engineering at a large Canadian, English-medium university. My involvement with planning meetings, SAFE's administration and marking, and the SAFE Drop-In Centre led me to meet Anna, a student whose acculturation process greatly benefited from her diagnosis. From observations, face-to-face interviews, and emailed questions, I was able to track Anna during her first 6 months of university study. 


\section{Limitations}

Before I can summarize my findings, it is important to consider how the limitations of my research design may influence their interpretation. Being a participant observer provided me with an emic, or insider, perspective. Being a researcher and using an assessment that was designed in another context also provided me with a somewhat etic, or outsider, perspective (Merriam, 2009, p. 29). For my thesis project, I attended planning meetings, administered and marked SAFE, and worked shifts in the SAFE Drop-In Centre. Although this gave me insider knowledge, it also meant that I was analyzing these experiences through the lens of a researcher and may have been perceived by engineering students as being in a position of power. DELNA was designed and implemented in Australia and New Zealand to assess students from all disciplines. The vocabulary and reading tasks and half of the writing tasks were developed off-site more than a decade before the present study was conducted. However, DELNA was modified to suit the particular needs of the Faculty of Engineering and had been piloted at least once by a smaller group of engineering students prior to the beginning of my study.

Perhaps the greatest limitation to my study is that even though I spread "the net for evidence widely" (Bromley as cited in Merriam, 1998, p. 33), I had a single participant. However, despite being only one of the 489 students who completed SAFE and only one of the 10 students who came to the drop-in centre, Anna is an "informationrich case[s] [which] yield insights and in-depth understanding" (Patton, 2002, p. 230) of diagnostic assessment in the academic acculturation process. In an attempt to add rigor to my data, I collected data from Anna for as long as possible. While we remained in contact for 6 months, by March she was too busy to continue with interviews. My 
findings are thus limited in that I cannot provide a fully comprehensive view of her first year experience. Moreover, I was not able to track Anna as she progressed through her engineering communications course which put her weakest skill, her writing, to the test. As a result of these limitations, it is not possible to make generalizations from my findings.

My findings can, however, provide insight into the role of diagnostic assessment in a Canadian context and may potentially inform other contexts. Anna knew that although I was involved with the SAFE project, I was a student and was not a member of the Faculty of Engineering. That Anna seemed to view me somewhat as an equal when she shared her experiences with me was evident in her candidness and relaxed demeanour.

\section{Summary of the Main Findings}

Suitability of the diagnostic tasks. Anna's experiences and academic success support the validity of the DELNA screening tasks (see Read, 2008; Elder \& von Randow, 2008; Davies \& Elder, 2005). Although her reading mark was also low, she had begun to adapt reading strategies that were appropriate to her discipline. As the engineering-specific writing task and the math tasks were designed for this pilot project, their validity has yet to be determined. Those tasks did, however, seem to work well for Anna. She did not struggle mathematically, but had problems with writing. She was not at-risk, but was still clearly in need of at least some writing support. Moreover, Anna did not experience any anxiety while completing SAFE. She immediately recognized its potential benefit and turned to the drop-in centre once she sought help. 
Read posited that "it may be counterproductive to make it [language support] obligatory for students to participate in a support programme when they have no wish to be set apart from their peers and are reluctant to acknowledge that they have language needs" (2008, p. 181). My study seems to suggest that if a student is to benefit from support they need to be predisposed to receive it. In other words, the agenda of the support service and the student's own agenda must match to a degree in order for the student to benefit (Cheng \& Fox, 2008). Anna's BAK enabled her to create kairotic moments by choosing when and how often to seek help from the peer mentors (Woods, 2006; Artemeva, 2005). She also chose which of the suggestions to implement. This enabled Anna to further develop her learner autonomy as she progressively recognized the gaps in her own learning and ultimately decided herself how to address them.

\section{Contribution of diagnostic feedback to Anna's academic acculturation.}

Anna's first year experience matched her expectations of university life. Her SAFE diagnosis contributed to this by confirming her expectations of the areas of academic literacy with which she would need help. Visiting the drop-in centre gave Anna a venue to share her sense of loss of her high school connections with teachers and recognize gaps in her cultural capital. Peer mentors provided her with suggestions on how to prepare for midterm exams, how to find answers on her own, and who to contact when she needed help with her course work. This entire process afforded Anna opportunities to build her cultural capital and benefit from kairotic moments (see Artemeva, 2005; Bourdieu, 1977; 1990; Tsang et al., 2009; Watson et al., 2010). 
Effectiveness of support services. The SAFE Drop-In Centre helped to increase Anna's knowledge of the various support services available to her on campus and its schedule matched with Anna's availability. Nevertheless, the problems that can arise from a mismatch of agendas were also highlighted by her experience. She followed through on advice given to her by peer mentors to visit the MTC and the WTS. Even though both centres are obviously there to assist students, their managerial styles may be in conflict with implementing an institution-wide initiative that offers discipline-specific support. The MTC does not give priority to any engineering math courses nor are any of the TAs from the Faculty of Engineering. They, along with Learning Support Services,

were also unwilling to participate in the SAFE pilot project beyond the services that they already offered to students. While the WTS helped Anna with a lab report, there are no engineering TAs at the WTS. Consequently, the WTS is unable to offer assistance with discipline-specific discourse savvy that would be crucial for engineering communications. This works to further emphasize the current undervaluing of writing that may be present in the Faculty of Engineering.

\section{SAFE Recommendations}

Read (2008) reported that students now hear about DELNA when they receive their university acceptance. And, although most incoming students are now required to participate in the DELNA screening, they still receive positively worded promotional literature about the assessment. It is important to take into consideration the fact that the students who participated in EngFrosh had no advance notice that they would be completing an assessment. Although the EngFrosh website listed an academic 
orientation as part of the week's activities, it did not mention SAFE. The Faculty of Engineering was concerned about marketing the diagnostic assessment to the students, but it needs to go further. In order for SAFE to be "accepted as just another part of the experience of entering the university" (Read, 2008, p. 186), and thus embedded (see Tinto, 2009; Hussey \& Smith, 2010) in the engineering department's practices, it may be beneficial for students to receive information about SAFE well in advance of completing the assessment.

Read's (2008) work and the results from this study suggest that using a support service should remain optional. However, the students who did come to the centre were not required to follow through on the advice they received. So, although actually using the support services is likely a decision best left to the students themselves, all first-year students identified as potentially at-risk may greatly benefit from being required to visit the drop-in centre at least once to discuss their SAFE results. This will provide them with the opportunity to connect with upper year students and thus potentially take advantage of their own kairotic moments and build their cultural capital (Artemeva, 2005; Bourdieu, 1977; Tsang et al., 2009; Watson et al., 2010).

Several changes to the marking and reporting stages of SAFE are needed if the entire first year cohort will complete the hour-long assessment. While peer mentors did receive basic rater training, there were still difficulties and inconsistencies reported during the marking and emailing sessions. No rubric was followed as the original DELNA rubric was considered too detailed for marking 500 writing samples in such a short period of time. Further rater training, a marking rubric, and more group-marking 
sessions may be needed in order for the marking of SAFE to run smoothly once it is fully implemented.

Peer mentors suggested doing more to advertise the SAFE Drop-In Centre especially once the centre had been opened for a couple of weeks. As Ruby pointed out, first-year students may be overwhelmed with information. As such, their personal SAFE email may have soon been forgotten or deleted. Posters were put up in the engineering buildings and professors made at least one in-class announcement. However, larger and more inviting posters in addition to class visits from SAFE peer mentors may increase turn out for the face-to-face meetings.

Fox holds that "the timing of interventions and support may be a critical factor in language development and successful academic performance" (2005, p. 109; see also Kift, 2008; Wilson \& Lizzio, 2008; Tinto, 2009). In the future, it may be beneficial to students to have the SAFE Drop-In Centre opened for a longer period of time and for more hours per week. Keeping the centre open for 5 weeks ensured that students would still have somewhere to turn for help if they started receiving unsatisfactory grades on their assignments. However, many students likely also need academic support and advice as they near the end of their first semester. Just as Nelson et al. (2012) found, reaching out to struggling students near the end of the semester may provide them with the assistance they need to persist with their studies.

Diagnosing students' weaknesses will not necessarily benefit the student population if the appropriate support programs are not in place (see Elder et al., n.d.). If graduate TAs are not available to offer some office hours in the WTS, upper year engineering students could be recruited. Not only will this provide discipline-specific 
writing support to struggling engineering writers, it will put a stronger focus on writing and help upper year students engage even more within their discipline.

\section{Future Research Projects}

Designing a discipline-specific writing task perhaps worked to more effectively market a writing assessment to engineering students (Galloway, 2008). However, after marking the SAFE tasks, several peer mentors wondered if the engineering-specific writing task was, in fact, much more difficult than the original DELNA writing task. Even though both tasks required writers to interpret and write about a graph, there was concern that the engineering-specific writing task was more cognitively demanding. If this was the case, this may have had an effect on the students' writing and thus their results. Validation studies of the new, discipline-specific task (and possibly also the math tasks) are needed.

All native English speakers, regardless of their motivation or background, would succeed in post-secondary education if being proficient in English were the only requirement for success (Fox, 2004). And yet this is not the case. As Anna's experience has shown, countless other factors contribute in varying degrees to academic success. Although great potential exists for DELNA in assisting students as they acculturate, it is currently limited to only measuring academic literacy skills. Perhaps including short scenarios or "I can/know" statements about how and when to seek support might be a way to raise students' awareness about seeking support and inform faculty and administrators of potential gaps in students' cultural capital. However, student BAK, persistence, motivation, cultural capital, and ability to manoeuver support are hard to 
measure constructs. More research is needed to examine if DELNA can in fact be used to assess other constructs that contribute to student success.

\section{Personal Reflection}

A recent report on international student recruitment options at the large Canadian university in this study stated that the university needs to aggressively increase international enrolments "to a level that offsets declines in domestic enrolments and/or replaced revenues lost from provincial funding cuts" (Ricketts, 2011, p. 2). The report also recognized that support services, ESL training, and foundation programs for international students need to be built up and/or created.

While I certainly agree that support services for international students need to become more of a priority in post-secondary education, it is imperative that universities recognize that covert bilinguals and students who meet the language residency admissions requirements also need support (see Fox, 2005). In other words, Anna and her needs, and those of countless others, must be addressed, rather than ignored, by their institutions. To continue to ignore the need to identify and support a potentially large portion of the student body seems both unethical and unprofitable given the university's current financial situation and recruitment processes. Spending increasingly large amounts of money on recruiting students both domestically and internationally seems unwise if money and effort are not spent on supporting and thus retaining those students.

Vested interests will do little to support institution-wide student support initiatives. The climate of post-secondary education in Canada has changed. More flexible admissions policies and cuts in federal funding mean that the student body is 
changing and universities must now run on business models. However, businesses are only successful if they are meeting the needs of their clients. My research taught me that successful university-wide initiatives are possible. SAFE planning meetings involved people from many different backgrounds who recognized a need for support and were trying to adapt to address that need. While I still feel there is a need for some generic student support services, such as workshops on how to write exams or take lecture notes, I am now much more aware of the substantial benefit of offering individualized and discipline-specific support to students.

Finally, I reflect on my own experience at university and wonder how I would have reacted to a diagnostic assessment and support initiative such as SAFE. How would knowing more about my academic literacy skills have helped me? As a strong reader, I am confident that I would have scored extremely well on the vocabulary and reading screening sections. Although I was a good writer, I may have been highlighted as potentially needing some writing support. But, what would I have done with my diagnosis? I would have read my email, compared my results with that of my cohort, and then not visited the SAFE Drop-In Centre.

Two months later, after barely passing several assignments and midterms, I would have certainly been too intimidated to speak with my professors or TAs. I would have thought I just needed to spend more time studying. Eventually I may have remembered my SAFE email or seen a poster and wondered if stopping by would be helpful. Having a peer mentor visit my classes to talk about the drop-in centre would have probably convinced me to go to the centre. But, I would have certainly walked by the door several times to discretely see who was in the room before deciding to enter or not. At the 
beginning of my first year, had seeking feedback on my SAFE results been required, I may have gotten the help I needed so much sooner.

Meeting with a friendly, upper year student in my program would have been intimidating at first, but I would have soon recognized the value of having such a resource. And, like Anna, I would have certainly returned to the centre when I needed more help. Such meetings would not have solved all of my problems, but they would have contributed greatly to how I manoeuvered through my own acculturation process during my first year experience. 


\section{References}

Alderson, J. C. (2005). Diagnosing foreign language proficiency: The interface between learning and assessment. New York, NY: Continuum.

Alderson, J. C. (2007). The challenge of (diagnostic) testing: Do we know what we are measuring? In J. Fox, M. Wesche, D. Bayliss, L. Cheng, C. E. Turner, \& C. Doe (Eds.) Language Testing Reconsidered (pp. 28-39). Ottawa, ON: University of Ottawa Press.

Alderson, J. C., \& Huhta, A. (2005). The development of a suite of computer-based diagnostic tests based on the Common European Framework. Language Testing, 22(3), 301-320.

Allen, J., Robbins, S. B., Casillas, A., \& Oh, I. S. (2008). Third-year college retention and transfer: Effects of academic performance, motivation, and social connectedness. Research in Higher Education, 49(7), 647-664.

Anson, C. M., Bernold, L. E., Crossland, C., Spurlin, J., McDermott, M. A., \& Weiss, S. (2003). Empowerment to learn in engineering: Preparation for an urgently-needed paradigm shift. Global Journal of Engineering Education, 7(2), 145-155.

Artemeva, N. (2005). A time to speak, a time to act: A rhetorical genre analysis of a novice engineer's calculated risk taking. Journal of Business and Technical Communication, 19(4), 389-421.

Artemeva, N., \& Fox, J. (2010). Awareness versus production: Probing students' antecedent genre knowledge. Journal of Business and Technical Communication, 24(4), 476-515. 
Association of Universities and Colleges of Canada. (2011). Trends in higher education volume 1: Enrolment. Ottawa, ON: The Association of Universities and Colleges of Canada. Retrieved from: http://www.aucc.ca/wpcontent/uploads/2011/05/ trends-2011-vol1-enrolment-e.pdf

Astin, A. W., \& Lee, J. J. (2003). How risky are one-shot cross-sectional assessments of undergraduate students? Research in Higher Education, 44(6), 657-672.

Astin, A. W. (1975). Preventing students from dropping out. San Francisco, CA: Jossey Bass.

Astin, A. W. (1993). What matters in college: Four critical years revisited. San Francisco, CA: Jossey Bass.

Astin, A. W. (1993). Engineering outcomes. ASEE Prism, 3(1), 27-30.

Bachman, L.F. (1990). Fundamental considerations in language testing. Oxford, UK: Oxford University Press.

Bachman, L. F., \& Palmer, A. S. (1996). Language testing in practice: Designing and developing useful language tests. Oxford, UK: Oxford University Press.

Barton, B., \& Neville-Barton, P. (2004). Undergraduate mathematics learning in English by speakers of other language. Paper presented at the $10^{\text {th }}$ International Congress on Mathematics Education. Copenhagen, Norway.

Beglar, D., \& Hunt, A. (1999). Revising and validating the 2000 word level and university word level vocabulary tests. Language Testing, 16(2), 131-162.

Benson, P., Chik, A., Gao, X., Huang, J., \& Wang, W. (2009). Qualitative research in language teaching and learning journals, 1997-2006. The Modern Language Journal, 93(1), 79-90. 
Bernold, L. E., Spurlin, J. E., \& Anson, C. M. (2007). Understanding out students: A longitudinal study of success and failure in engineering with implication for increased retention. Journal of Engineering Education, 96(3), 263-274.

Bourdieu, P. (1977). Cultural reproduction and social reproduction. In J. Karabel \& A. H. Halsey (Eds.), Power and ideology in education (487-511). New York, NY: Oxford University Press.

Bourdieu, P. (1990). In other words: Essays towards a reflexive sociology. Cambridge, UK: Polity Press.

Braxton, J. M., Vesper, N., \& Hossler, D. (1995). Expectations for college and student persistence. Research in Higher Education, 36(5), 595-611.

Brown, J. D. (1996). Testing in language programs. Upper Saddle River, NJ: Prentice Hall Regents.

Cassidy, S. (2007). Assessing 'inexperienced' students' ability to self-assess: Exploring links with learning style and academic personal control. Assessment \& Evaluation in Higher Education, 32(3), 313-330.

Chapman, D. W., \& Pascarella, E. T. (1983). Predictors of academic and social integration of college students. Research in Higher Education, 19(3), 295-322.

Charmaz, K. (2006). Constructing grounded theory: A practical guide through qualitative analysis. Thousand Oaks, CA: SAGE Publications Inc.

Cheng, L., \& Fox, J. (2008). Towards a better understanding of academic acculturation: Second language students in Canadian universities. The Canadian Modern Language Review, 65(2), 307-333. 
Council of Europe. (n.d.). Common European Framework of Reference for Languages:

Teaching, Learning, and Assessment (CEFR). General Format. Retrieved from: http://www.coe.int/t/dg4/linguistic/CADRE_EN.asp

Creswell, J. W. (1998). Qualitative inquiry and research design: Choosing among five traditions. Thousand Oaks, CA: Sage Publications, Inc.

Davies, A. \& Elder, C. (2005). Validity and validation in language testing. In E. Hinkel (Ed.), Handbook of research in second language teaching and learning (pp. 795813). Mahwah, NJ: Lawrence Erlbaum Associates, Inc.

di Gennaro, K. (2009). Investigating differences in the writing performance of international and generation 1.5 students. Language Testing, 26(4), 533-559.

Dooey, P. (2010). Students' perspectives on an EAP pathway program. Journal of English for Academic Purposes, 9(3), 184-197.

Duff, P. A. (2008). Case study research in applied linguistics. New York, NY: Lawrence Erlbaum Associates.

Elder, C., Bright, C., \& Bennett, S. (2007). The role of language proficiency in academic success: Perspectives from a New Zealand university. Melbourne Papers in Language Testing, 12(1), 24-58. Retrieved from http://trc.unimelb.edu.au/mplt/index.html

Elder, C., Erlam, R., \& von Randow, J. (n.d.). Enhancing chances of academic success among first year undergraduates from diverse language backgrounds. Retrieved from: www.fyhe.com.au/past_papers/papers02/ErlamPaper.doc

Elder, C., \& von Randow, J. (2008). Exploring the utility of a web-based English language screening tool. Language Assessment Quarterly, 5(3), 173-194. 
Evans, S., \& Morrison, B. (2011). Meeting the challenges of English-medium higher education: The first-year experience in Hong Kong. English for Specific Purposes, 30(3), 198-208.

Fairbairn, S. B., \& Fox, J. (2009). Inclusive achievement testing for linguistically and culturally diverse test takers: Essential considerations for test developers and decision makers. Educational Measurement: Issues and Practice, 28(1), 10-24.

Faltis, C. (1997). Case study methods in researching language and education. In N. H. Hornberger \& D. Corson (Eds.), Encyclopedia of language and education volume 8: Research methods in language and education (pp. 145-152). Dordrecht, The Netherlands: Kluwer Academic Publishers.

Fike, D. S., \& Fike, R. (2008). Predictors of first-year student retention in the community college. Community College Review, 36(2), 68-88.

Flick, U. (2009). An introduction to qualitative research edition 4. London, UK: Sage.

Foor, C. E., Walden, S. E., \& Trytten, D. A. (2007). "I wish that I belonged more in the whole engineering group:" Achieving individual diversity. Journal of Engineering Education, 96(2), 103-115.

Fox, J. (2004). Test decisions over time: Tracking validity. Language Testing, 21(4), 437465.

Fox, J. (2005). Rethinking second language admission requirements: Problems with language-residency criteria and the need for language assessment and support. Language Assessment Quarterly, 2(2), 85-115. 
Fox, J. (2008). Alternative assessment. In E. Shohamy \& N. H. Hornberger (Eds.) Encyclopedia of Language and Education, $2^{\text {nd }}$ Edition, Volume 7: Language Testing and Asssessment (pp. 97-108).

Fox, J. (2009). Moderating top-down policy impact and supporting EAP curricular renewal: Exploring the potential of diagnostic assessment. Journal of English for Academic Purposes, 8, 26-42.

Fox, J. (2011). SAFE Report for Engineering. (Unpublished report). Ottawa, ON: J. D. Fox.

Fox, J., \& Hartwick, P. (2011). Taking a diagnostic turn: Reinventing the portfolio in EAP classrooms. In D. Tsagari \& I. Csepes (Eds.), Classroom-based language assessment (pp.47-62). Frankfurt am Main: Peter Lang.

Galloway, P. D. (2008). The $21^{\text {st }}$ century engineer: A proposal for engineering reform. Renton, VA: American Society of Civil Engineers.

Graham, J. G. (1987). English language proficiency and the prediction of academic success. TESOL Quarterly, 2I(3), 505-521.

Hughes, A. (1989). Testing for language teachers. Cambridge, UK: Cambridge University Press.

Hughes, A. (2003). Testing for language teachers second edition. Cambridge, UK: Cambridge University Press.

Hussey, T., \& Smith, P. (2010). Transitions in higher education. Innovations in Education and Teaching International, 47(2), 155-164. 
Kemppainen, A., \& Hein, G. (2008). Enhancing student learning through self-assessment. $38^{\text {th }}$ ASEE/IEEE Frontiers in Education Conference. Saratoga Springs, NY: IEEE.

Kift, S. (2008). The next, great first year challenge: Sustaining, coordinating and embedding coherent institution-wide approaches to enact the FYE as "everybody's business". Keynote address at the $11^{\text {th }}$ International Pacific Rim First Year in Higher Education Conference, Hobart. Retrieved from http://www.fyhe.com.au/past_papers/papers08/FYHE2008/content/pdfs/Keynote \%20-\%20Kift.pdf

Kinneavy, J. L. (2002). Kairos in classical and modern rhetorical theory. In P. Sipiora \& J. S. Baumlin (Eds.), Rhetoric and kairos (pp. 58-76). Albany, NY: State University of New York.

Koizumi, R., Sakai, H., Ido, T., Ota, H., Hayama, M., Sato, M., \& Nemoto, A. (2011). Development and validation of a diagnostic grammar test for Japanese learners of English. Language Assessment Quarterly, 8(1), 53-72.

Krause, K. L. (2006). On being strategic about the first year. Keynote presentation at the Queensland University of Technology First Year Forum October 2006. Retrieved from http://www3.griffith.edu.au/03/ltn/docs/GIHE-First-Year-Experience.pdf

Krause, K. L., \& Coates, H. (2008). Students' engagement in first-year university. Assessment \& Evaluation in Higher Education, 33(5), 493-505. 
Lawrence, J. (2005). Re-conceptualising attrition and retention: integrating theoretical, research and student perspectives. Studies in Learning, Evaluation, Innovation and Development, 2(3), 16-33. Retrieved from http://sleid.cqu.edu.au/viewissue.php?id=8

Lazaraton, A. (2005). Quantitative research methods. In E. Hinkel (Ed.), Handbook of research in second language teaching and learning (pp. 209-220). Mahwah, NJ: Erlbaum.

Lew, M. D. N., Alwis, W. A. M., \& Schmidt, H. G. (2010). Accuracy of students' selfassessment and their beliefs about its utility. Assessment \& Evaluation in Higher Education, 35(2), 135-156.

Long, J. (2012, January 4). Foreign students boost Ottawa economy. CBC. Retrieved from http://www.cbc.ca/news/canada/ottawa/story/2012/01/03/ottawainternational-students-money.html

Mayo, D. T., Helms, M. M., \& Codjoe, H. M. (2004). Reasons to remain in college: A comparison of high school and college students. The International Journal of Educational Management, 18(6), 360-367.

Merriam, S. B. (1998). Qualitative research and case study applications in education. San Francisco, CA: Jossey-Bass Publishers.

Merriam, S. B. (2009). Qualitative research: A guide to design and implementation. San Francisco, CA: Jossey-Bass Publishers.

Meyers, K. L., Silliman, S. E., Gedde, N. L., \& Ohland, M. W. (2010). A comparison of engineering students' reflections on their first-year experiences. Journal of Engineering Education, 99(2), 169-178. 
Nelson, K. J., Duncan, M., \& Clarke, J. (2009). Student success: The identification and support of first year university students at risk of attrition. Studies in Learning, Evaluation, Innovation, and Development, 6(1), 1-15.

Nelson, K. J., Quinn, C., Marrington, A., \& Clarke, J. A. (2012). Good practice for enhancing the engagement and success of commencing students. Higher Education, 63(1), 83-96.

Neville-Barton, P., \& Barton, B. (2005). The relationship between English language and mathematics learning for non-native speakers. Wellington, NZ: Teaching and Learning Research Initiative. Retrieved from http://www.tlrl.org/nz/pdfs/13909.pdf

Nist, S. L., Holschuh, J. L., \& Sharman, S. J. (1995). Making the grade in undergraduate biology courses: Factors that distinguish high and low achievers. Paper presented at the American Educational Research Association annual meeting. San Francisco, CA. Retrieved from: http://eric.ed.gov/PDFS/ED390934.pdf

Nora, A. (2004). The role of habitus and cultural capital in choosing a college, transitioning from high school to higher education, and persisting in college among minority and nonminority students. Journal of Hispanic Higher Education, 3(2), 180-208.

Office of Institutional Research and Planning. (2012a). First year undergraduate students in degree programs (summary). Ottawa, ON: OIRP. Retrieved from http://oirp.carleton.ca/retention/tables/fyret12-degsum20042011-nft.pdf 
Office of Institutional Research and Planning. (2012b). Native language of full-time and part-time undergraduate, special and graduate students by sex 2011-12. Ottawa, ON: OIRP. Retrieved from http://oirp.carleton.ca/databook/2011/students/tables/table-SD3-1-aft.pdf Office of Institutional Research and Planning. (2012c). Mean admission averages by degree program of all students applying directly from Canadian high schools who registered in first year at Carleton. Ottawa, ON: OIRP. Retrieved from http://oirp.carleton.ca/pi-2011/tables/hs-grades-update.pdf Office of Institutional Research and Planning. (2012d). Admissions to First Year by Degree and Major - 2011. Ottawa, ON: OIRP. Retrieved from http://oirp.carleton.ca/databook/2011/students/tables/table-AD1-3.pdf Office of Institutional Research and Planning. (2012e). Carleton undergraduate degree programs: International student applications and registrations. Ottawa, $\mathrm{ON}$ : OIRP. Retrieved from http://oirp.carleton.ca/pi-2011/tables/applreg-internat.pdf O'Loughlin, K. (2011). The interpretation and use of proficiency test scores in university selection: How valid and ethical are they? Language Assessment Quarterly, 8(2), $146-160$.

Patton, M. Q. (2002). Qualitative research \& evaluation methods $3^{\text {rd }}$ edition. Thousand Oaks, CA: Sage Publications, Inc.

Peach, D. (2005). Ensuring student success - the role of support services in improving the quality of the student learning experience. Studies in Learning, Evaluation, Innovation and Development, 2(3), 1-15. Retrieved from http://sleid.cqu.edu.au/viewissue.php?id=8 
Pierrakos, O., Beam, T. K., Constantz, J., Johri, A., \& Anderson, R. (2009). On the development of a professional identity: Engineering persisters vs. engineering switchers. $39^{\text {th }}$ ASEE/IEEE Frontiers in Education Conference. San Antonio, TX: IEEE.

Poulos, A., \& Mahony, M. J. (2007). Effectiveness of feedback: The students' perspective. Assessment \& Evaluation in Higher Education, 33(2), 143-154.

Pychyl, T., Morin, R. W., \& Salmon, B. R. (2000). Procrastination and the planning fallacy: An examination of the study habits of university students. In J. R. Ferrari \& T. A. Pychyl (Eds.), Procrastination: Current issues and new directions (pp. 239-254). Journal of Social Behavior and Personality, 15(5), 239-254.

Queensland University of Technology. (2009). Articulating a transition pedagogy. Queensland University of Technology: Australian Learning and Teaching Council. Retrieved from http://www.fyecd2009.qut.edu.au/resources/ RES_KiftTransitonPedagogySixPrinciples.pdf

Railton, D., \& Watson, P. (2005). Teaching autonomy: Reading groups and the development of autonomous learning practices. Active Learning in Higher Education, 6(3), 182-193.

Read, J. (2008). Identifying academic language needs through diagnostic assessment. Journal of English for Academic Purposes, 7, 180-190. doi:

10.1016/j.jeap.2008.02.001 
Ricketts, P. (2011). Provost's responses to the recommendations of the working group international recruitment. Ottawa, ON: Peter Ricketts. Retrieved from http://wwwl carleton.ca/ provost/ccms/wp-content/ccms-files/PROVOSTSRESPONSES-TO-THE-RECOMMENDATIONS-OF-THE-WORING-GROUPON-INTERNATIONAL-RECRUITMENT.pdf

Rieti, J. (2012, February 15). Children of immigrants challenged at school, home. $C B C$. Retrieved from: http://www.cbc.ca/news/canada/story/2012/02/15/f-audio-photosimmigrant-canadian-children.html

Sadler, D. R. (1989). Formative assessment and the design of instructional systems. Instructional Science, 18, 119-144. Retrieved from: http://www.springerlink.com/content/x71185036h 762m45/fulltext.pdf

Scanlon, L., Rowling, L., \& Weber, Z. (2007). 'You don't have like an identity ... you are just lost in a crowd': Forming a student identity in the first-year transition to university. Journal of Youth Studies, 10(2), 223-241.

Scott, M. A. (2009). Work in progress - comparative and quantitative analysis of writing apprehension in first-year engineering student cohorts at New Mexico State University. $39^{\text {th }}$ ASEE/IEEE Frontiers in Education Conference. San Antonio, TX: IEEE.

Stake, R. E. (1994). Case studies. In N. K. Denzin \& Y. S. Lincoln (Eds.), Handbook of qualitative research (pp. 236-247). Thousand Oaks, CA: SAGE Publications, Inc.

Stake, R. E. (1995). The art of case study research. Thousand Oaks, CA: SAGE Publications, Inc. 
Stern, S. (2001). Learning assistance centers: Helping students through. ERIC Digest, ERIC Identifier ED455901. Retrieved from http://www.ericdigests.org/2002$2 /$ centers.htm

Taras, M. (2001). The use of tutor feedback and student self-assessment in summative assessment tasks: Towards transparency for students and for tutors. Assessment \& Evaluation in Higher Education, 26(6), 605-614.

Taylor, J.A. (2008). Assessment in first year university: A model to manage transition. Journal of University Teaching \& Learning Practice, 5(1), 19-33.

Thomas, L. (2002). Student retention in higher education: The role of institutional habitus. Journal of Educational Policy, 17(4), 423-442.

Thompson, G., Pilgrim, A., \& Oliver, K. (2005). Self-assessment and reflective learning for first-year university geography students: A simple guide or simply misguided? Journal of Geography in Higher Education, 29(3), 403-420.

Tinto, V. (1975). Dropout from higher education: A theoretical synthesis of recent research. Review of Educational Research, 45(1), 89-125.

Tinto, V. (2002a). Taking student retention seriously: Rethinking the first year of college. Presented at the annual meeting of the American Association of Collegiate Registrars and Admissions Officers. Minneapolis, Minnesota.

Tinto, V. (2002b). Promoting student retention: Lessons learned from the United States. Presented at the $11^{\text {th }}$ Annual Conference of the European Access Network. Prato, Italy. 
Tinto, V. (2009). Taking student retention seriously: Rethinking the first year of university. Keynote speech delivered at the ALTC FYE Curriculum Design Symposium. Brisbane, Australia.

Tsang, E., Halderson, C., \& Kallen, K. (2007). Work in progress - Western Michigan University's effort to increase retention of first-time, first-year engineering and applied sciences students. $37^{\text {th }}$ ASEE/IEEE Frontiers in Education Conference. Milwaukee, WI: IEEE.

Tsang, E., Darrah, L., Engelmann, P., Halderson, C., \& Butt, D. (2009). Work in progress - academic and student affairs collaboration to enhance student success in engineering and applied sciences. $39^{\text {th }}$ ASEE/IEEE Frontiers in Education Conference. San Antonio, TX: IEEE.

University of Auckland. (2011). DELNA (Diagnostic English Language Needs Assessment): Handbook for candidates at the University of Auckland. Retrieved from http://www.delna.auckland.ac.nz/webdav/site/delna/shared/delna/ documents/delna-handbook.pdf

Wait, I. W., \& Gressel, J. W. (2009). Relationship between TOEFL score and academic success for international engineering students. Journal of Engineering Education, 98(4), 389-398.

Walker, S., Brownlee, J., Lennox, S., Exley, B., Howells, K., \& Cocker, F. (2009). Understanding first year university students: Personal epistemology and learning. Teaching Education, 20(3), 243-256. 
Warburton, E. C., Bugarin, R., \& Nuñez, A. M. (2001). Bridging the gap: Academic preparation and postsecondary success of first-generation students. Washington, DC: U.S. Department of Education. Retrieved from http://nces.ed.gov/pubs2001/2001153.pdf

Watson, H., Pierrakos, O., \& Newbold, T. (2010). Research to practice: Using research findings to inform the first-year engineering experience. $40^{\text {th }}$ ASEE/IEEE Frontiers in Education Conference. Washington, DC: IEEE.

Wilson, K., \& Lizzio, A. (2008). A 'just in time intervention' to support the academic efficacy of at-risk first-year students. Paper presented FYE Pacific Rim Conference. 2009.

Wintre, M. G., Bowers, C., Gordner, N., \& Lange, L. (2006). Re-evaluating the university attrition statistic: A longitudinal follow-up study. Journal of Adolescent Research, 21(2), 111-132.

Woods, D. (1996). Teacher cognition in language teaching: beliefs, decision-making, and classroom practice. Cambridge, UK: Cambridge University Press.

Woods, D. (2006). Who does what in the 'management of language learning'? In S. Gieve \& I. Miller (Eds.), Understanding the language classroom (pp. 88-114). New York, NY: Palgrave MacMillan. Retrieved from http://www.scribd.com/doc/52048277/Understanding-the-Language-Classroom Xue, G., \& Nation, I. S. P. (1984). A university word list. Language Learning and Communication, 3(2), 215-229. 
Appendix A SAFE Invigilator's Script

Appendices

September 2011/SAFE

\section{INVIGILATOR'S SCRIPT}

$\mathrm{Hi}$, my name is I'm a year (e.g. $\left.4^{\text {th }}\right)$ Engineering student in (Discipline). The next hour is all about playing it safe - getting information and making the right connections as a Carleton engineering student. SAFE stands for self-assessment for engineering. It's a self-assessment strategy run by students for students. It'll give you information about your language and mathematics readiness for success in engineering.

SAFE is personal and confidential. Results are sent to you - and you alone- by connect email. You'll get your SAFE results by email in about a week. Once you have your SAFE results, you can drop in at the SAFE centre, located in this building. We know how critical the first few weeks of your first year are. SAFE is a way of assuring a good start. Once of the most important investments you can make to ensure a successful term is the time you spend at the beginning of year with me or with another engineering student at the Centre. The Centre will be open from the $15^{\text {th }}$ of September to the $21^{\text {st }}$ of October. You'll meet me and other engineering students there who know the ropes and can talk with you one-on-one about your SAFE results, your courses, and concerns. We can also connect you with other people on campus who may be useful to you. There will be more information about the SAFE Centre in the email we send you.

Now, look at the SAFE booklet at your lab/computer station. Do all of you have a pen to write with? Please fill in your name, student number, and email contact - at Carleton.connect - on the cover of the SAFE booklet. We will send your results to this email address. When you finish reading and filling in the information on page 1 , go on to page 2, and complete the questionnaire. While we are logging you on to the SAFE site, read over pages 3 and 4 , so you know what to expect. We have only about 5 minutes for this step, so read quickly as far as page 4 . We'll let you know when we are ready to begin the SAFE.

[Check that the students are filling in the booklet information completely and clearly, help to log them into the site. Time this so that no more than 10 minutes is spent for the intro and $\log$ in.] [When you are ready say]: begin Part 1.

[When Part 1 Screening is finished, tell the students]: Ok, now look at your booklet again. Turn to page 6 . This is part 2 of SAFE. Follow the instructions and write your response on pages 7 and 8 . We have allowed 20 minutes for this part of SAFE. If you finish early, go on to part 3 . We will announce when the 20 minutes is up. We have allowed 10 minutes for part 3 . Please remain in your seats, even if you finish early. When you're finished, we'll take you to the next orientation activity. Just raise your hand if you have questions. 
Appendix $B$ SAFE Results Email

Subject: YOUR SAFE RESULTS and the SAFE CENTRE at ME4346

Hi

The SAFE Centre - Room ME 4346 -- is open from September 20-October 19 (Tuesdays and Wednesdays) from 1 to 7 p.m. Last week you participated in SAFE (Self-Assessment for Engineering). This e-mail is a summary of all of your results. Of course, this is just a limited snapshot of what you did during one hour last week, but it provides some useful information for you to consider. There are $3^{\text {rd }}$ and $4^{\text {th }}$ year students in the SAFE Centre who will go over your results with you one-on-one. They will also identify resources and people who will help you succeed in your first year at Carleton. The more information you have, the more likely you are to achieve your goals. Here is your personal result summary:

[Reference: Booklet

Vocabulary: $\_/ 27$

Reading: $\_73$

Writing: 15

Mathematics: $1 / 5$ [issues:

Remember, these results are confidential and are only sent to you for your personal

information. [You can compare your own results with those of other students in the first year of Carleton engineering by looking at the information below] ${ }^{*}$. You can calculate your own percentage in relation to other students in the first-year program, but for details you need to come and see us. Just drop in at the SAFE Centre September 20-October 19 (Tuesdays and Wednesdays) anytime from 1 to 7 p.m.

We hope you will take advantage of the SAFE Centre to discuss your results, meet with an upper-year student who knows the ropes, and get a jump on a successful academic year!

Your SAFE TEAM

*How did first year engineering students perform as a group:

Vocabulary: Average Score: 24; Mode (most common score): 24; Median (the score where 50\% are higher and $50 \%$ are lower): 25.

Reading: Average Score: 46.8; Mode (most common score): 72; Median (the score where 50\% are higher and $50 \%$ are lower): 47

Writing: If you received 3 or less, you may need additional support. If you received $\mathbf{4}$ or more, you may have the writing skills you need to develop effective engineering writing in future.

Come to see us to find out more.

Mathematics: If you received 3 or less, you may need additional support. If you received 4 or more, you may have the mathematics skills that you need for engineering. Come and see us to find out more. 
Appendix $C$ Support Services Information Sheets

If you need help with:

\begin{tabular}{|c|c|}
\hline Developing your writing skills & $\begin{array}{l}\text { Writing Tutorial Service } \\
4^{\text {th }} \text { Floor MacOdrum Library } \\
\text { Fall } 2011 \text { Tutoring Hours } \\
\text { Monday/Wednesday/Fridays 9am - 4:30pm } \\
\text { Tuesday/Thursdays 9am - 7:30pm } \\
\text { To schedule an appointment, students can: } \\
\text { (1) call } 613-520-2600 \text { ext. 1125, or } \\
\text { (2) come in person to the Learning Support Services Desk on } \\
\text { the } 4 \text { th floor of the library, or } \\
\text { (3) go online using MySuccess on Carleton Central. }\end{array}$ \\
\hline $\begin{array}{l}\text { Developing your spoken English } \\
\text { skills }\end{array}$ & $\begin{array}{l}\text { English Conversation Groups } \\
\text { Learning Support Services, } 4^{\text {th }} \text { Floor MacOdrum Library } \\
\text { All students are welcome to drop-in at any of the sessions, } \\
\text { no registration is necessary. These groups are informal and } \\
\text { casual and have no assignments or grades attached to them. } \\
\text { However, regular attendance is encouraged and new visitors } \\
\text { are always welcome. } \\
\text { Fall } 2011 \text { Group Meeting Times } \\
\text { Tuesdays } 10-11 \mathrm{am} \\
\text { Thursdays } 1-2 \mathrm{pm} \\
\text { Fridays } 2: 30-3: 30 \mathrm{pm}\end{array}$ \\
\hline $\begin{array}{l}\text { Developing your mathematical } \\
\text { skills }\end{array}$ & $\begin{array}{l}\text { Math Tutorial Centre } \\
\text { Monday - Thursday } 10 \mathrm{am}-4 \mathrm{pm} \\
\text { Room } 1160 \mathrm{HP} \\
\text { http://wuw.math.carleton.ca/grad/tutorial center.html } \\
\text { Teaching Assistants are seated at the front of the room at } \\
\text { the tables marked "TA DESK". }\end{array}$ \\
\hline Academic Study Skills & $\begin{array}{l}\text { Learning Support Services Study Skills Workshops } \\
\text { Learning Support Services, } 4^{\text {th }} \text { Floor MacOdrum Library } \\
25 \text { minute workshops on topics like: Writing Lab Reports, } \\
\text { Academic Reading, Note-Taking in Lectures, and Success in } \\
\text { Math } \\
\text { To register, use the MySuccess link on Carleton Central }\end{array}$ \\
\hline A specific class & $\begin{array}{l}\text { 1) Get in touch with your professor and/or teaching } \\
\text { assistant; OR } \\
\text { 2) Tutor Referral Service } \\
\text { Under the MySuccess tab on Carleton Central, you will see } \\
\text { "Tutor Referral Service" link. Submit the form and you will } \\
\text { be matched with potential tutors who you can contact for } \\
\text { your tutoring needs. Please note that filling out the form } \\
\text { does not necessarily mean there is a tutor available. You will } \\
\text { be notified via your Carleton email account of tutor } \\
\text { availability within } 3 \text { to } 5 \text { business days. }\end{array}$ \\
\hline A learning/physical disability & $\begin{array}{l}\text { Paul Menton Centre } \\
\text { http://www1.carleton.ca/pmc/ }\end{array}$ \\
\hline
\end{tabular}




\section{Tips for Reading Success in Engineering}

\section{Make time for reading}

Reality check: reading textbook chapters, scientific articles, etc... takes time. Schedule: time for yourself to do your weekly readings and stick to it.

\section{Learn your reading habits}

Learn what conditions you need to do focused reading and make it happen. You'll be able to use your reading time effectively and get your work done sooner.

\section{Take notes while you read}

Summarizing the key concepts and vocabulary in your own words will help you understand and remember the material better. Note taking will help you find any concepts that you don't quite understand and need to ask more questions about. Plus, you probably won't have time to re-read all the material and take notes once you start studying for your exams. Writing notes while you read the first time will save you time later and give you good study material!

\section{Read BEFORE class}

You will get more out of the lecture if you do the readings ahead of time. Taking notes will be easier because you will already be a bit familiar with the vocabulary and concepts. Not only will the reading make understanding the lecture easier, but the lecture will help you understand what you read.

\section{Use the text to help you read}

Read the title, headings, and subheadings. Check out any graphics. Read the chapter overview and/or a summary first because they will give you the most important points in the reading. When you're finished reading, read carefully through the summary one more time to make sure that you've understood the main concepts. Try the study questions at the end of the reading and ask your prof and/or TA about any problems you have.

\section{Know why you're reading}

Keeping up with all of your reading will be challenging. Talk with your prof and/or TA about how to use your textbook. For each reading, do you need to know just the main points and some relevant examples, or do you need all of the details of a scientific process? Knowing what you're reading for will let you read more efficiently and save you time.

\section{Check your course outline}

Your course outline probably has information on what you should be reading in the textbook and/or which practice problems you should focus on. If your prof has listed specific sections or practice problems, it's for a reason! This is very likely key information that you will need to know for you assignments and exams. 
Appendix D SAFE Drop-In Centre Poster

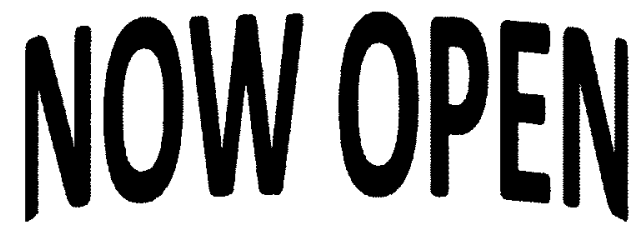

Self-Assessment for Engineers

(SAFE) FALL 2011

Having problems with any assignments?

Don't know what your prof expects?

Worried about how to get everything done?

\section{SAFE Drop-In Centre \\ ME 4346}

Come and make a plan for your academic

success with an engineering peer mentor and discuss your SAFE results!

Tuesdays \& Wednesdays (Sept. 20 $0^{\text {th }}$ Oct. $19^{\text {th }}$ ) from 1pm - 7pm

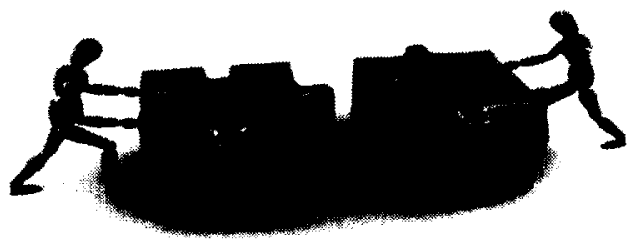


Appendix $E$ Ethics Clearance Form

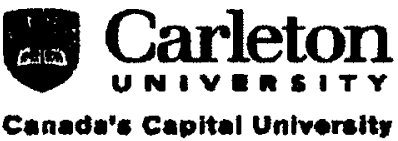

\author{
Carteteon Unlvardty Research Ofines \\ Research Ethics Bosid \\ 5 Fioor Tor Bulldine \\ 1125 Colonel By Ditve \\ Ottawe, ON K1S $5 \mathrm{BS}$ Consda \\ Tel: 613-520-2517 \\ Fax: 613-520-2521 \\ ethicesondenca
}

\title{
Ethics Clearance Form
}

This is to certify that the Carteton University Research Ethics Board has examined the application for ethical clearance. The REB found the research project to meet appropriate ethical standards as outlined in the Tri-Councll Pollcy Statement: Ethical Conduct for Research Involving Humans and, the Carleton University Policles and Procedures for the Ethical Conduct of Research.

\section{$x$ Now edentrence a Renewal of eriginat clearance}

\section{Oripinal date of clearance:}

Date of clearance

Researcher

Status

Supervisor

Funding status

Project number

Title of project

\author{
13 September 2012 \\ Melisan Mcteod \\ M.A. student, School of Um.ulotics and Langunge Studles \\ Protessor Janno Fox, School of Lngulstics and Lenguage studies \\ Non-funded \\ 12-0884 \\ SAFE Euceses: Self-Asesament for Engineers and the uptake of \\ acedemic support sarvices among fint-year engineering students \\ (working titla)
}

Clearance explres: 31 may 2012

All researchere are governed by the following conditions:

Annual status Report! You are required to submit an Annual Stutus Report to either renew clearance or close the fle. Fallure to submit the Annual Status Report will result in the immediate suspension of the project. Funded projects will have accounts suspended untll the report is submitted and approved.

Changen to the profbet: Any changes to the project must be submitted to the Carleton University Research Ethics Board for approval. All changes muat be approved prior to the continuance of the research.

Adverse eventa: Should any particlpant suffer adversely from their participation in the project you are required to report the matter to the Corleton University Research Ethics Bourd. You must submit a written record of the event and Indicate what steps you have taken to resolve the sltuation.

Surpenton or termination ef clearanca: Fallure to conduct the research in accordance with the prindples of the Tri-Councll Policy Statement: Ethical Conduct for Research Involving Humens and the Carteton University Pollctes and Procedures for the Ethical Conduct of Reseanch may result in the suspension or termination of the research project.

Antonlo R. Gualtler, Chair

Carteton University Research Ethics Board 
Appendix $F$ Participant Recruitment Poster

- Carleton

Cenade's cepltal University

\section{Did you participate in SAFE?}

Do you have any concerns about your $1^{\text {st }}$ year in Engineering? How do you feel about your reading, writing, note-taking, and math skills?

\section{Would you like to talk to someone about your experience with SAFE and your goals for academic success? Sharing your experience will put you in contact with a teaching assistant who can offer personalized help when you need it during your first semester in Engineering.}

Participants in this study will receive emails with 5-6 interview questions. You can respond to the questions via email and/or request a one-on-one meeting to discuss your answers or receive general academic input. Responding to the emailed questions will take 5-15 minutes per email. Since meetings will be focused on your needs, the length may vary. Your participation in this study will be kept anonymous. Participating in this study will allow you to have personalized input throughout your first semester of university study. While I will only email you every 2-3 weeks, you may contact me to make appointments when you need help.

If you are interested in participating, please email Melissa McLeod at: mmcleod4@connect.carleton.ca

Researcher: Melissa McLeod, MA Student in Applied Linguistics \& Discourse Studies, Carleton University. mmcleod4@connect.carleton.ca

Supervisor: Dr. Janna Fox, Associate Professor in the School of Linguistics \& Language Studies. Janna Fox@carleton.ca, tel. 613-520-6612.
This project has been reviewed and cleared by the Carleton University Research Ethics Board

613-520-2517 or ethics@carleton.ca 
Appendix $G$ Peer Mentor Questionnaire

\section{Peer Mentor Questionnaire}

1) Did you attend any planning or information sessions for the SAFE project?

$\square$ Yes $\square$ No

2) Are you familiar with the self-assessment tasks used for the SAFE project?

$\square$ Yes $\square$ No

3) What instruction, if any, were you given before offering discussing the learner profiles and academic advice with the SAFE students?

4) How would you describe your experience of interpreting and explaining the information contained in the learner profiles?

5) In your opinion, were the learner profiles easy for the SAFE students to understand?

Please explain your answer. 
6) Based on their learner profiles, did you know which academic support services to recommend to the SAFE students?

7) Overall, how do you feel most students reacted to their individual meetings? Please elaborate.

8) Are there any changes to the learner profiles or the feedback process that you would recommend for the future?

9) Any other comments?

Email is not a secure or confidential form of communication. Interview questions will only be sent to your Carleton email account and you must ensure the responses are sent to: mmcleod4@connect.carleton.ca 
Appendix $H$ Line-by-Line Coding Sample

$$
\text { Mon, Oct. } 3^{\text {rd }}
$$

Ok, so you emailed your TA on Wednesday and he didn't get back to you until Saturday

He didn't get back to me until Saturday and like the thing is there was like this program in waiting for help telecad that we're supposed to um download and it was Monday he's like oh yeah. I was like l asking for hely don't have my laptop with me to download it on it, and he says it's ok you can find it online,

Monday on Monday, Tuesday, Wednesday I spent just looking online trying to find it and I boxing for progam couldn't. so I emailed him he doesn'l answer me, so I was talking to this student and she's like asking for help yeah I downloaded it on my flash and I have my laptop so I was lucky hmm I got it and I getting the progoem downloaded it but my TA regardless of that only emailed me on Saturday saying oh I don't knowgeth ing himer taje where you can get it it's online it's for free you should be able to find it and then like then he send bok do char anom me another email saying oh here's the website or whatever he gave me, but I had it by then, so getting the info didn't even check the website I still emailed him and was like thank you but it's kinda too late I interacting wath have it now I was kind of frustrated and I didn't know what he was looking for and I didn't get feding frutrateds the mark I wanted to I got 6 out of 10 on a lab that I spent I think I deserved at least a 9 or an 8 corng confured minimum, 7, and I got a 6 so I was kinda frustrated and uh like to see the point the way he the feeling confosed lab questions were not clear that I didn't know what I was being asked to do and I was like I stexling help emailed him and $1 \mathrm{had}$ a problem emailing him so 1 emailed the other TA who was not uctually maneaving haygh marking my lab and 1 showed him my calculations and he was like yeah you seem to be on the get ing fuld bav right track when I handed in my lab, no, this is wrong, this is wrong and then I didn't know what foeling confured he was looking for in the write up so I lost marks there too and then um so my lab was like blaming Th Gor low mork poorly marked I guess and I had to hand in my second lab today and I did the same mistakes on recognicing midits it because I didn't know I only got feedback today and I had to hand in today's lab you know, so getting lat facturk

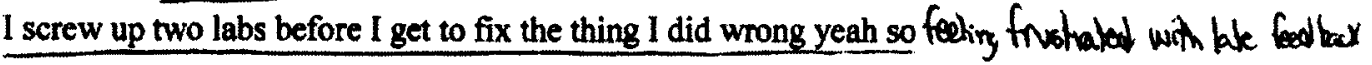

